\title{
ASTRAL - Ambiente de Simulação e Teste de pRogramas paraLelos
}

\author{
Tomás Dias Sant'Ana
}

Orientadora: Profa. Dra. Regina Helena Carlucci Santana

Dissertação apresentada ao Instituto de Ciências Matemáticas e de Computação - ICMC-USP, como parte dos requisitos para obtenção do título de Mestre em Ciências de Computação e Matemática Computacional.

USP - São Carlos

Agosto/2001 


\section{A Comissão Julgadora:}

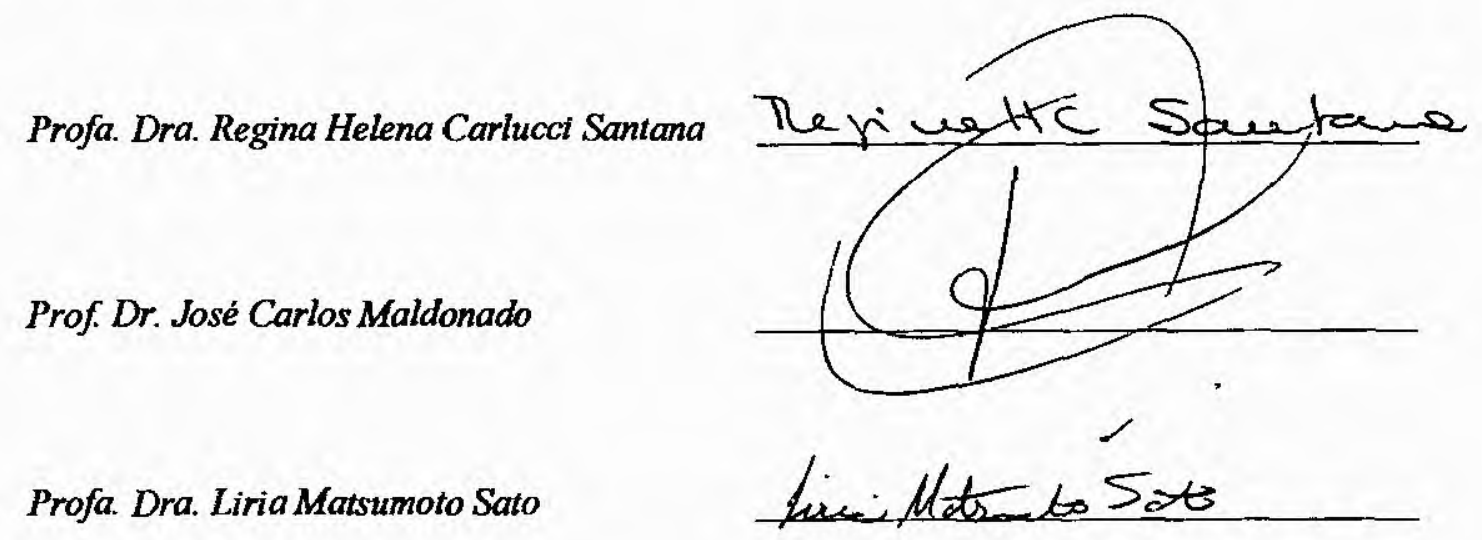


Dedico esta dissertação aos meus pais,

João Santana e Marília, pelo carinho, amor, incentivo e confiança. 
À Nágila, que participou de todas as minhas grandes conquistas. 


\section{Agradecimentos}

À Prof $f^{\text {. Dr }}$. Regina Helena Carlucci Santana, pela orientação, carisma e principalmente pela oportunidade e pelos conhecimentos transmitidos durante todo este tempo que estivemos trabalhando juntos.

Ao Prof. Dr. Marcos José Santana, pelas criticas sempre construtivas, pelos ensinamentos e principalmente pelos divertidos churrascos.

Ao Prof. Dr. José Carlos Maldonado, pelas valiosas dicas no exame de qualificação e pelos jogos de futebol.

Ao amigo Edmilson Marmo Moreira, meu "pai USP", pela oportunidade, confiança, incentivo, simplicidade... Eu sou seu fã...

À minha mãe Marília, pelo carinho, incentivo, confiança e ao meu pai João Santana, pela inteligência, pelos conselhos sempre valiosos e principalmente por ter me inscrito no vestibular para computação em 1995. Eu amo vocês...

À Nágila Ap. Alves Galdino Sant'Ana, pelo apoio, compreensão, confiança e principalmente pelo carinho...

À minha família: Leandro, Adélia, Monique, Letícia, Marilinha, Margarida, Regina, David, e aos mais novos membros: Domingos, Delma, Débora, Felipe, Daniela e Bianca.

Ao amigo Mauro Cesar Bernardes, meu “irmão USP”, pelo apoio sempre constante.

Aos amigos e companheiros: Márcio (pelas constantes dicas sempre muito valiosas e por seu jeito sempre protetor), Arion (pelas noitadas de trabalhos árduas), Omar (pelas brincadeiras), Renato Francês (pelas dicas e pelas músicas), Paulo Sérgio (pelas dicas e principalmente pelo presente de amigo da onça), Ricardo, Stênio (pelos dois anos que estivemos juntos), Werley, Tiago, Luis Fernando, Sarita, Tatiana, Kalinka, Célia, Simone, João Carlos, Mário, Renato Bulcão, e muitos outros, que de uma maneira ou de outra contribuíram para realização deste trabalho.

Aos novos amigos e alunos da Universidade de Alfenas, que me receberam com muito carinho.

À CAPES, pelo apoio financeiro parcial.

E, sobretudo a $D E U S$, por tudo... 


\section{Resumo}

Este trabalho apresenta a especificação e implementação do ASTRAL - Ambiente de Simulação e Teste de pRogramas parALelos. Neste ambiente os programas paralelos são representados através de grafos, que indicam o fluxo de execução da aplicação e as comunicações entre as tarefas que a compõem. A simulação desses grafos permite ao usuário observar e controlar o comportamento do programa, possibilitando a identificação de possíveis erros de comunicação e de problemas relacionados ao desempenho.

A especificação do ASTRAL é independente de plataforma, permitindo sua utilização para simulação de qualquer linguagem e ou biblioteca paralela. Uma instanciação deste ambiente para a plataforma PVM é apresentada.

O ASTRAL faz parte de um ambiente maior que visa a depuração de programas paralelos, responsabilizando-se pela implementação dos grafos necessários e sua simulação. 


\section{Abstract}

This work presents the specification and implementation of ASTRAL - Parallel Program Test and Simulation Environment. This environment allows representing the parallel programs by means of graphs, that indicate the execution flow of the application and the communication between the processes. The simulation of these graphs allows the user to follow and control the program behavior, thus identifying possible communication errors and performance problems.

The specification of ASTRAL is platform independent, allowing its utilization for simulation of any language or parallel library. An environment instantiation for PVM platform is presented.

The ASTRAL is part of a major environment that aims at parallel programs debugging, being responsible for the graphs implementation and simulation. 


\section{Sumário}

Índice de Figuras......................................................................................................................................

Índice de Tabelas..........................................................................................................................

Índice de Listagens.............................................................................................................................................. ii

1. Introdução.................................................................................................................................. 1

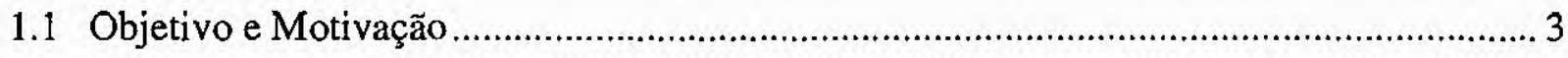

1.2 Organização da Dissertação .......................................................................................... 3

2. Computação Paralela ........................................................................................................... 5

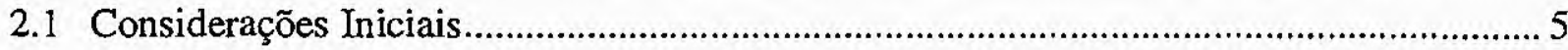

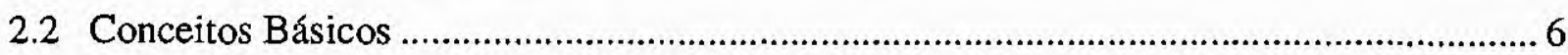

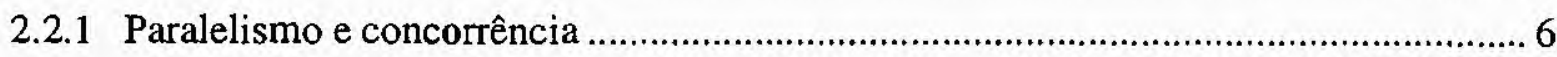

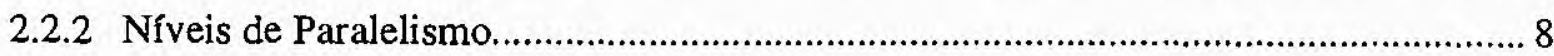

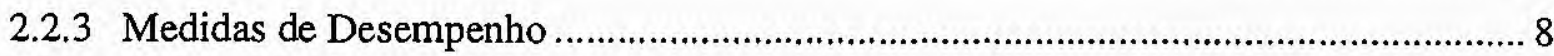

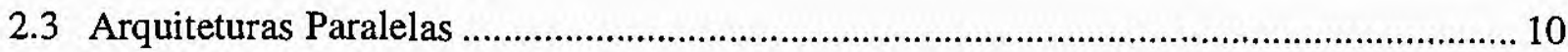

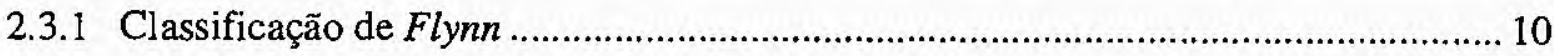

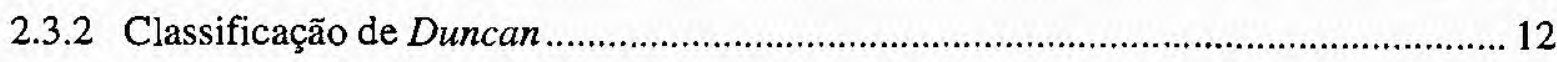

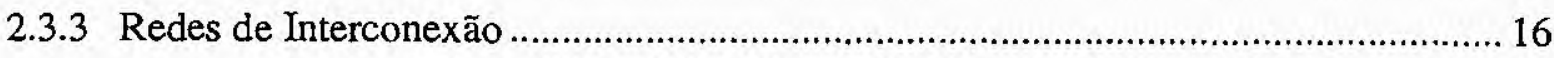

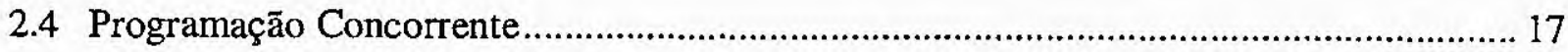

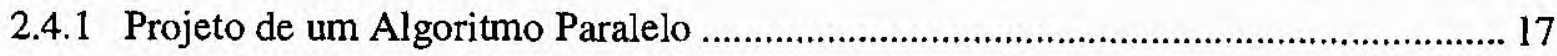

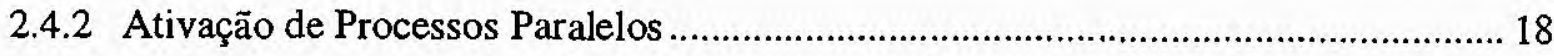

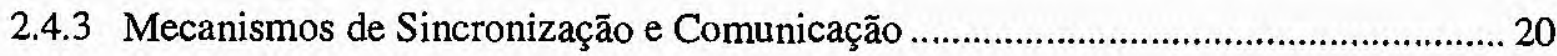

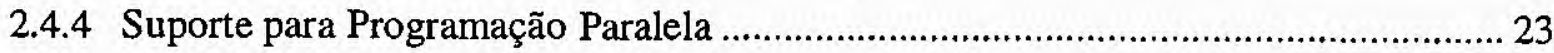

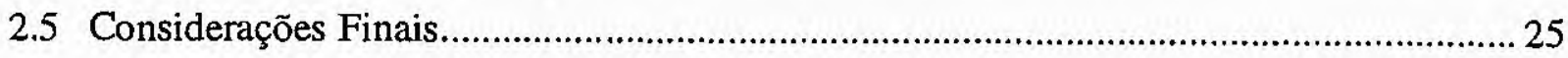

3. Teste e Depuração de Programas Paralelos..........................................................................2 27

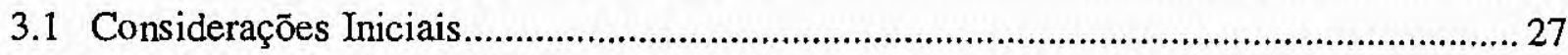

3.2 Dificuldade na Depuração de Programas Paralelos ......................................................... 27

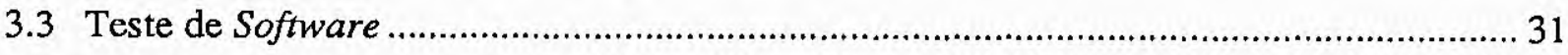

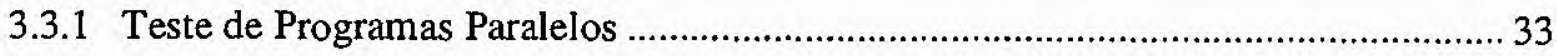

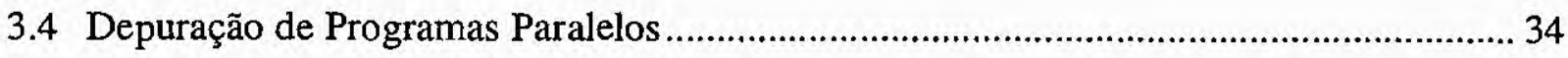

3.4.1 Organização dos Depuradores de Programas Paralelos ............................................... 34 
3.4.1.1 Técnicas de Depuração Tradicional ................................................................. 35

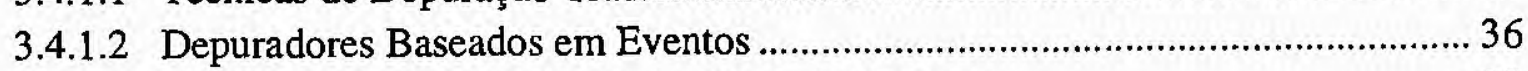

3.4.1.3 Técnicas para Apresentação do Fluxo de Controle............................................ 37

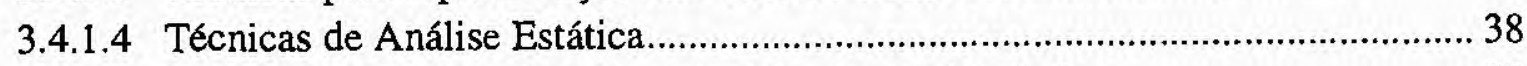

3.4.1.5 Combinando Análise Estática com Depuração Dinâmica ................................ 39

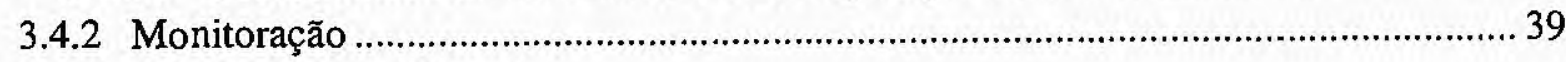

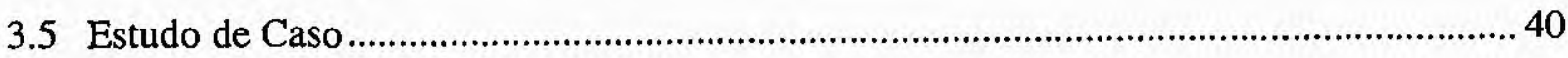

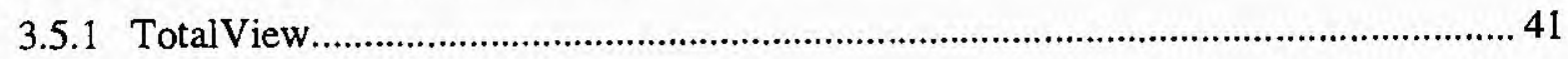

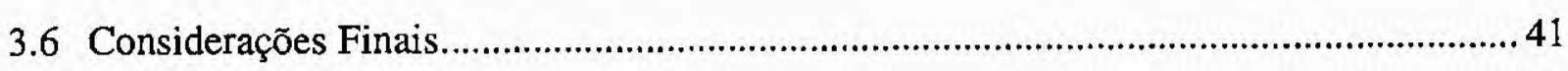

4. Representação de Programas Paralelos ........................................................................ 43

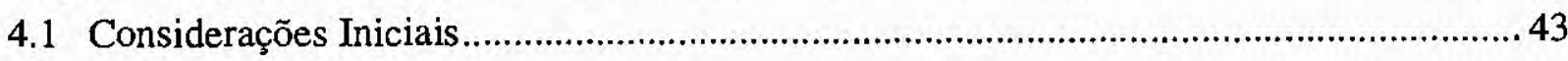

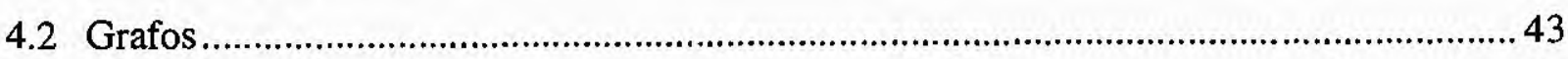

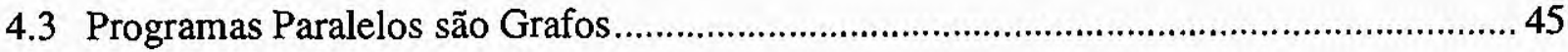

4.3.1 Representação Direta de Paralelismo Implícito ..................................................... 45

4.3.2 Exemplo com Passagem de Mensagem ............................................................. 46

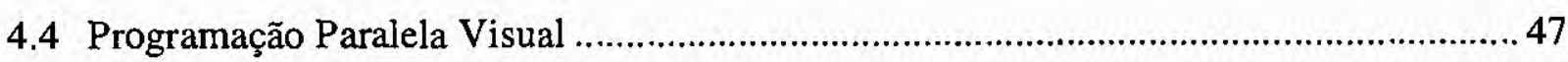

4.5 Depuração em Ambiente de Programação Visual ....................................................... 49

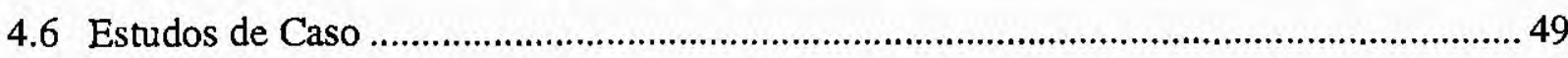

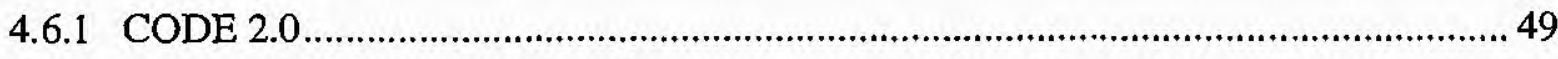

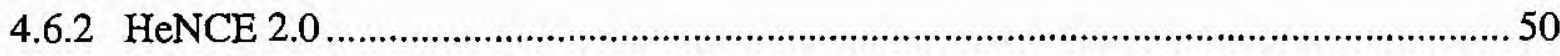

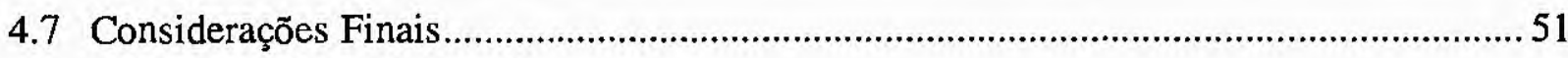

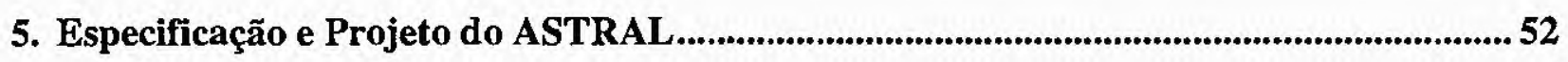

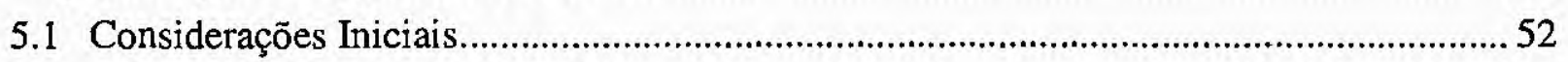

5.2 Ferramenta de Auxílio na Depuração de Programas Paralelos ..................................... 53

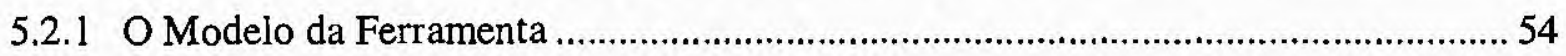

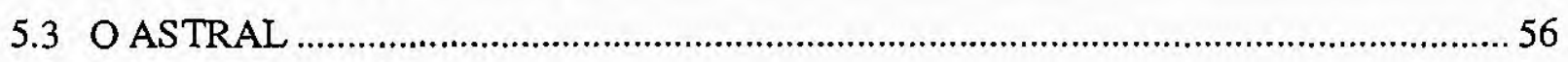

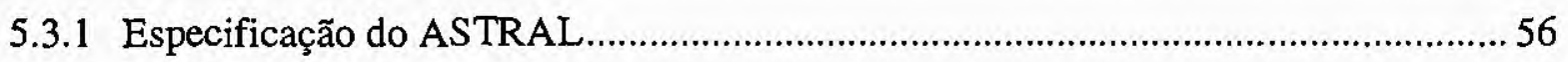

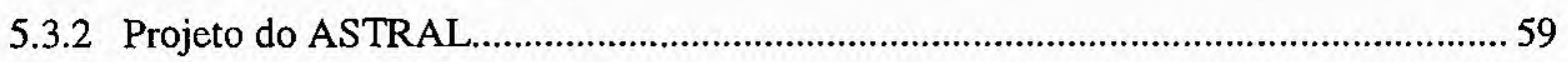

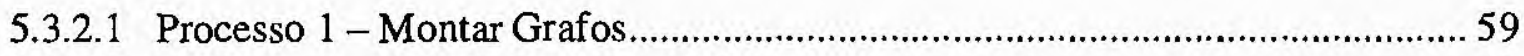

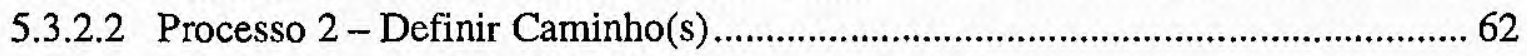

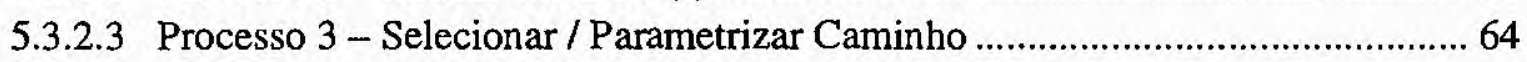

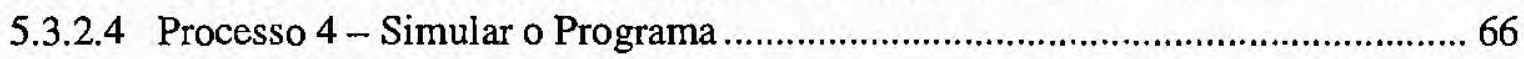

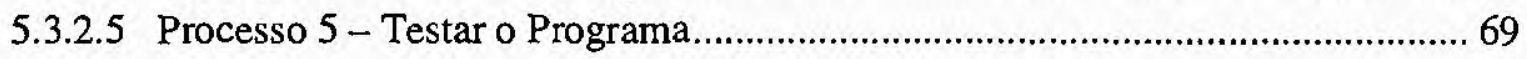

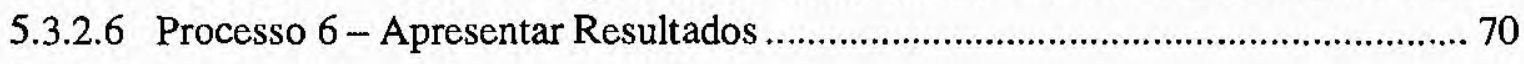

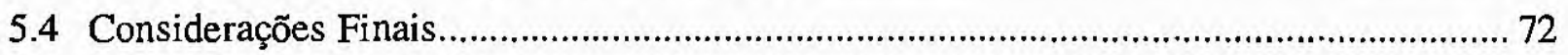




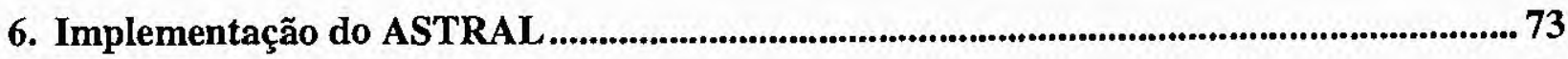

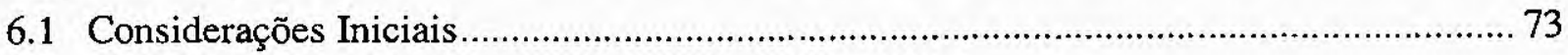

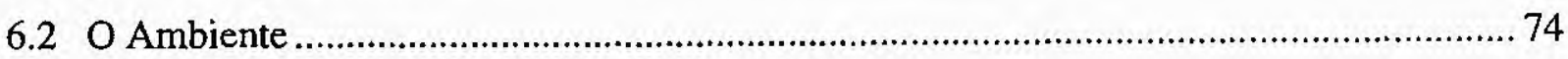

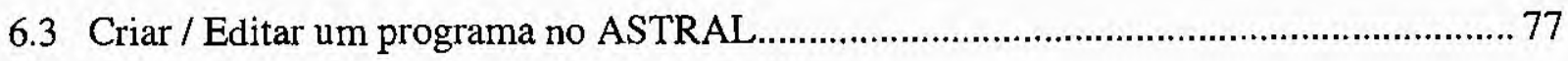

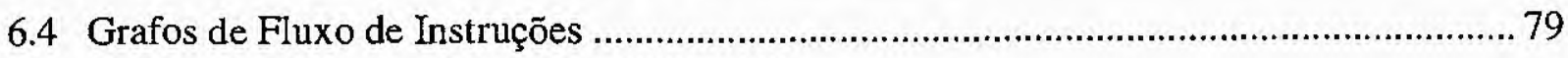

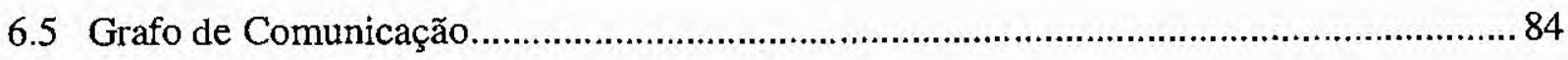

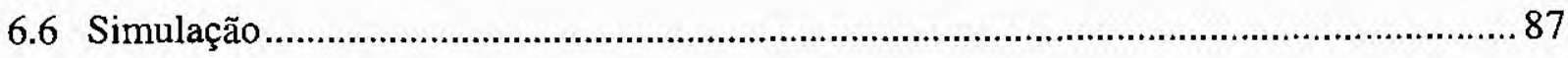

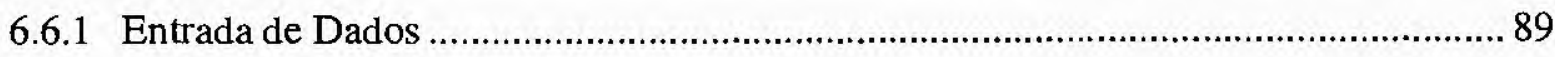

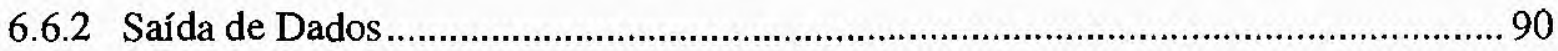

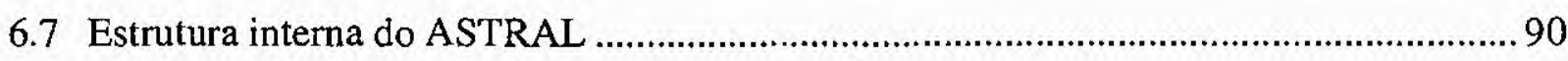

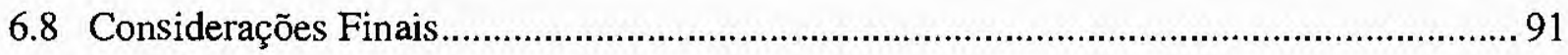

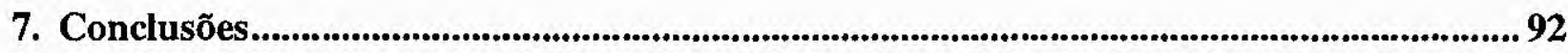

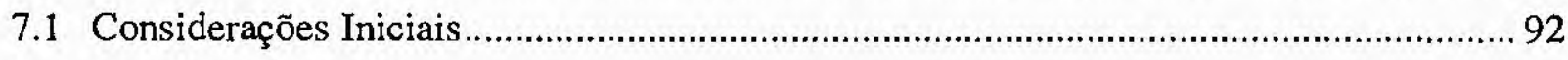

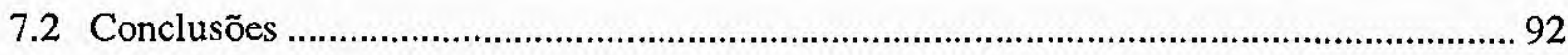

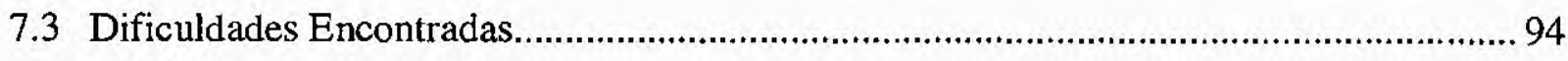

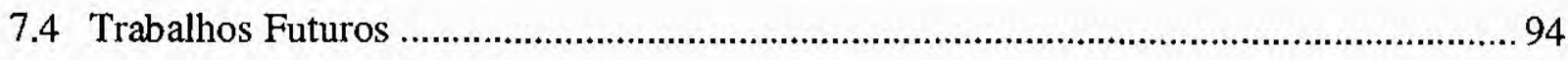

Referências Bibliográficas..................................................................................................................95 


\section{Índice de Figuras}

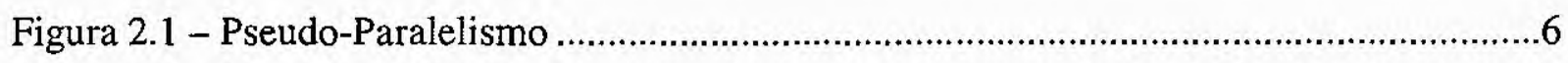

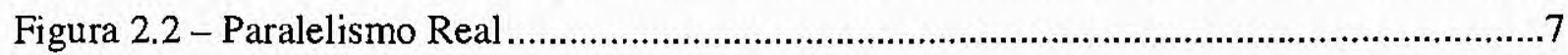

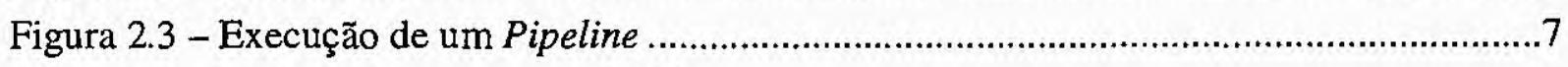

Figura 2.4 - Modelo Computacional SISD..................................................................

Figura 2.5 - Modelo Computacional SIMD …..........................................................11

Figura 2.6 - Modelo Computacional MISD .................................................................. 11

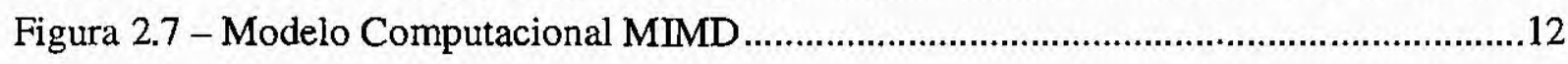

Figura 2.8 - Classificação de Duncan ..............................................................................13

Figura 2.9 - Arquitetura de Memória Compartilhada .....................................................14

Figura 2.10 - Arquitetura de Memória Distribuída ..........................................................15

Figura 2.11 - Exemplo de utilização de Fork/Join ...............................................................19

Figura 2.12 - Exemplo de utilização de Cobegin/Coend .........................................................19

Figura 2.13 - Exemplo da utilização de Doall ................................................................20

Figura 2.14 -Send/Receive. (a) Bloqueante (b) Não-Bloqueante...................................23

Figura 3.1 - Exemplo de um deadlock ........................................................................28

Figura 3.2 - Exemplo de um livelock ..................................................................................29

Figura 4.1 - Estrutura dos algoritmos e a representação através dos Grafos .........................44

Figura 4.2 - Grafo do programa exemplo.......................................................................46

Figura 4.3 - Exemplo de um programa com Passagem de Mensagem ..................................46

Figura 4.4 - Exemplo com Passagem de Mensagem...............................................................47

Figura 4.5 - Grafos mostrando problemas no desempenho................................................48

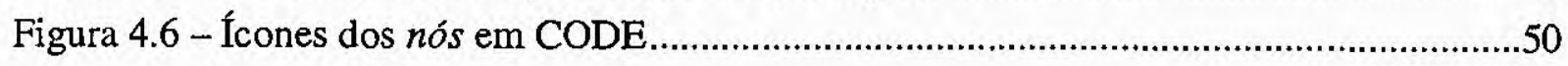

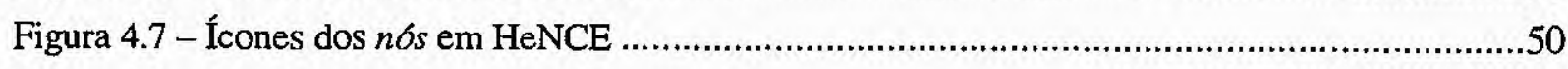

Figura 5.1 - Camadas que definem a Ferramenta .................................................................53

Figura 5.2 - Modelo da Ferramenta de Auxílio na Depuração de Programas Paralelos .....................55

Figura 5.3 - Modelo de projeto do ASTRAL …..................................................................58

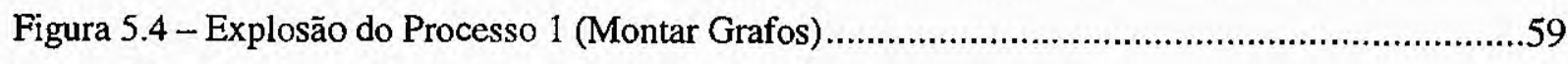

Figura 5.5 - Grafos de Fluxo de Instruções da Listagem 5.1 .................................................61

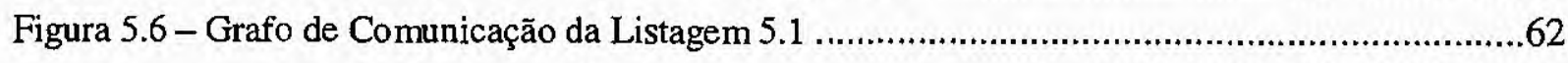

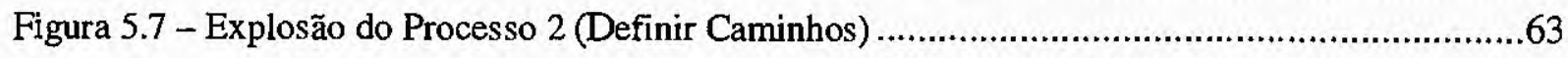

Figura 5.8 - Explosão do Processo 3 (Selecionar / Parametrizar Caminho) ..................................65

Figura 5.9 - Explosão do Processo 4 (Simular o Programa) .....................................................66

Figura 5.10-Grafos de Fluxo de Instruções da Listagem 5.3 ................................................68

Figura 5.11 - Explosão do Processo 5 (Testar o Programa)....................................................... 70

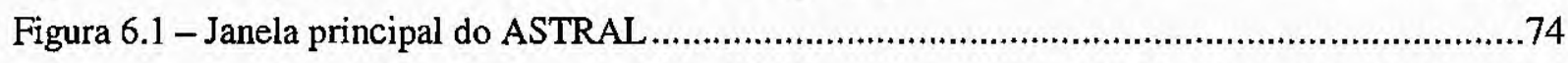

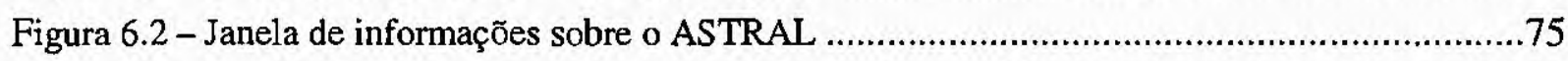


Figura 6.3 - Barra de ferramentas do ASTRAL …............................................................... 75

Figura 6.4 - Menu local dos grafos de fluxo de instruções....................................................76

Figura 6.5 - Arquivo Exemplo1.c sendo editado no ASTRAL ................................................77

Figura 6.6 - Controle de Páginas com uma linha (b) e múltiplas linhas (a)...................................78

Figura 6.7 - Exemplo de um grafo de fluxo de instruções gerado no ASTRAL ...............................8 I

Figura 6.8 - Grafo de fluxo de instruções de Funcao ......................................................................82

Figura 6.9 - Grafo de fluxo de instruções do processo Mestre ...................................................83

Figura 6.10 - Grafo de fluxo de instruções do processo Escravo ..............................................84

Figura 6.11 - Grafo de comunicação gerado no ASTRAL ….................................................... 85

Figura 6.12 - Simulação de um programa no ASTRAL .........................................................87

Figura 6.13 - O processo Mestre aguarda por uma mensagem do Escravo...................................8

Figura 6.14 - O processo Escravo já terminou sua execução....................................................8

Figura 6.15 - Exemplo de uma entrada de dados durante a simulação. ........................................89

Figura 6.16 - Exemplo de uma saída de dados do processo Mestre durante a simulação.................90

\section{Índice de Tabelas}

Tabela 6.1 - Relação dos ícones do ASTRAL

\section{Índice de Listagens}

Listagem 2.1 - Primitivas Down e UP ...........................................................................21

Listagem 4.1 - Programa exemplo para representação de paralelismo ....................................45

Listagem 5.1 - Programa exemplo para geração dos grafos ...............................................60

Listagem 5.2 - Programa exemplo para definição dos caminhos.........................................63

Listagem 5.3 - Programa exemplo para simulação ...........................................................67

Listagem 6.1 - Estrutura de armazenamento do Grafo de Fluxo de Instruções ......................79

Listagem 6.2 - Código fonte do programa Mestre.c .............................................................86

Listagem 6.3 - Código fonte do programa Escravo.c ....................................................86 


\section{Introdução}

Os primeiros computadores digitais, surgidos no início da Segunda Guerra Mundial, eram formados por milhares de válvulas, ocupando áreas enormes, com um funcionamento lento. O ENIAC (Eletronic Numerical Integrator and Computer) foi o primeiro computador digital de propósito geral. Criado, em 1946, para realização de cálculos balísticos, sua estrutura possuía 18 mil válvulas, 10 mil capacitores, 70 mil resistores e pesava 30 toneladas [MAC97].

Desde então, a computação (hardware e software) passou por um processo intenso de evolução. Na década de 50 surgiu o modelo de Von Neumann ${ }^{1}$, que se tornou à base de todo o desenvolvimento. Durante as décadas seguintes, os componentes do modelo de Von Neumann foram aperfeiçoados, e esse ciclo evolutivo permanece até os dias atuais.

Em paralelo à evolução da arquitetura de Von Neumann, novas tecnologias de organização dos computadores, como a computação paralela, as redes de computadores, os mecanismos de pipeline, entre outras, começaram a surgir aproximadamente a partir de 1970. No início da década de 80, o surgimento das tecnologias LSI (Large Scale Integration) e VLSI (Very Large Scale Integration), facilitaram e impulsionaram o projeto de miniaturização e barateamento dos equipamentos.

No final dos anos 80 , as redes de computadores se tornaram mais confiáveis, possibilitando a interligação dos computadores pessoais com estações de trabalho, permitindo também o acesso a outros sistemas de computação, independentemente de estado, país e, até mesmo, fabricante. Nesse contexto, surgiram os sistemas distribuídos, construídos com o intuito de oferecer ao usuário uma imagem de sistema único, apesar da distribuição de seus componentes.

Nos últimos anos o interesse pela computação paralela tem crescido muito, principalmente pela utilização dos sistemas distribuídos para execução de programas paralelos, em substituiçāo às arquiteturas paralelas que são mais caras e menos flexíveis. Do ponto de vista do hardware, esta tendência crescente da computação paralela, é bastante 
atrativa já que "máquinas de alta performance" podem ser construídas combinando grande número de microprocessadores que podem ser comprados a preços relativamente baixos, se comparados às máquinas paralelas [BRO94].

Uma das razões pela qual a computaçāo paralela ainda não se tornou tão popular, quando se previa há alguns anos, é a grande diferença entre a evolução dos hardwares e dos softwares paralelos. O projeto e desenvolvimento das máquinas paralelas evoluíram muito nos últimos anos, de forma a atingir arquiteturas eficientes, de construção não muito complexa e a custo acessível. Por outro lado, o desenvolvimento de software paralelo nāo apresenta uma evolução tão acentuada. As linguagens e ferramentas disponíveis para programação paralela estão ainda muito distantes de oferecer as facilidades presentes nas ferramentas para programação sequiencial.

Desta forma, além da programação paralela ser mais difícil (principalmente devido aos problemas relacionados à comunicação e ao sincronismo), outros fatores dificultam a utilização da programação paralela, tais como técnicas para obter eficiência e portabilidade. Outra lacuna observada nesta área é a existência de poucas ferramentas para a validação (teste e depuraçāo) de programas paralelos, sendo a maioria delas específicas e com uma interface pouco amigável [MOR00].

Nesse sentido, a construçāo de ferramentas que auxiliem o desenvolvimento de programas paralelos, e a pesquisa de novas técnicas para facilitar o teste e a depuração desses programas. formam o ambiente propício e as motivações necessárias de uma linha de pesquisa do Grupo de Sistemas Distribuídos e Programaçāo Concorrente (LASDPC) do Instituto de Ciências Matemáticas e de Computação (ICMC) da Universidade de São Paulo (USP).

A depuração de programas paralelos vem sendo abordada no referido grupo, através do desenvolvimento de uma ferramenta de auxílio na depuração de programas paralelos [MOR00], que visa facilitar a depuração e a aprendizagem da computação paralela, principalmente para usuários iniciantes.

\footnotetext{
${ }^{1} \mathrm{O}$ modelo de Von Neumann é formado basicamente por: processador, memória e dispositivos de Entrada/Saída.
} 


\subsection{Objetivo e Motivação}

O objetivo deste projeto é o desenvolvimento de um ambiente de simulação e teste para programas paralelos que será utilizado na ferramenta mencionada na seção anterior. Dentro desse ambiente os programas paräelos serão representados através de grafos, que indicam o fluxo de controle da aplicação e as comunicações entre as tarefas que a compõem. A simulação desses grafos permite ao usuário observar e controlar o comportamento do programa (através da dependência que existe entre as tarefas) e o desempenho a ser atingido (através da verificação do balanceamento de carga e da quantidade de paralelismo).

Uma motivação adicional para este projeto é facilitar o aprendizado da programação paralela por usuários iniciantes deste assunto. Principalmente devido à dificuldade que um usuário iniciante da programação paralela tem para visualizar o comportamento do programa, que possui tarefas executando em processadores diferentes e em muitos casos (por exemplo, em sistemas distribuídos) fisicamente distantes.

\subsection{Organização da Dissertação}

Visando a motivação e objetivo apresentados anteriormente, a dissertação está dividida da seguinte forma:

- Revisão bibliográfica dos assuntos relacionados ao desenvolvimento da dissertação:

Capítulo 2: apresenta os principais conceitos que envolvem a computação paralela, entre eles: níveis de paralelismo e medidas de desempenho. Nesse capítulo são apresentados, também, a classificação das arquiteturas paralelas, o projeto de algoritmos paralelos, a ativação de processos paralelos e os mecanismos de sincronização e comunicação.

Capítulo 3: intitulado teste e depuração de programas paralelos, apresenta as dificuldades na depuração de programas paralelos; os conceitos de teste de softwáre, de teste e depuração dos programas paralelos; a classificação dos depuradores de programas paralelos; e o estudo de caso de uma ferramenta para depuração de programas paralelos.

Capítulo 4: neste capítulo são discutidos os benefícios que podem ser obtidos com a representação gráfica de programas paralelos e qual a melhor maneira para esta representação. Os principais tópicos apresentados nesse capítulo são: 
representação natural de programas paralelos, programação paralela visual, e depuração em um ambiente de programação paralela visual.

- Projeto e implementação do ASTRAL - Ambiente de Simulação e Teste de pRogramas parALelos:

Capítulo 5: neste capítulo são apresentados a especificação e o projeto do ambiente de simulação e teste de programas paralelos.

Capítulo 6: a implementação do ambiente é apresentada neste capítulo.

- Finalização da dissertação:

Capítulo 7: este capítulo apresenta a conclusão do trabalho, as dificuldades encontradas e os passos a serem seguidos para a continuidade deste trabalho. 


\section{Computação Paralela}

Nesse capítulo são apresentadas algumas características fundamentais da computação paralela, abordando seus tópicos mais relevantes. Os tópicos apresentados são: conceitos básicos da computação paralela, taxonomias para arquiteturas paralelas e finalizando os principais conceitos envolvidos com a programação concorrente.

\subsection{Considerações Iniciais}

Computação paralela (ou processamento paralelo) consiste basicamente em uma coleção de elementos de processamento, que cooperam e comunicam entre si e resolvem um problema mais rapidamente do que se estivessem sendo solucionados seqüencialmente [ALM94].

O principal objetivo do processamento paralelo é a busca por maior desempenho. Durante anos, o desempenho foi sinônimo de aumento no poder de processamento dos computadores. Atualmente, o desempenho pode ser conseguido também através da otimização dos programas, ou da paralelização dos códigos seqüenciais, e com a utilização de sistemas distribuídos ou de máquinas paralelas.

Outros fatores, além da busca por maior desempenho, impulsionam o desenvolvimento da computação paralela [ALM94]. Entre eles:

- Solução mais natural para programas intrinsecamente paralelos.

- Substituição de computadores de altíssimo custo.

- Maior facilidade de implementação de tolerância à falhas.

- Restrições físicas, como a velocidade da luz, podem dificultar futuros aumentos na velocidade em um único processador.

Alguns pontos negativos surgem com a utilização do processamento paralelo. Entre eles:

- Programação mais complexa.

- Necessidade de técnicas de balanceamento de carga para melhor distribuição dos processos nos vários processadores.

- Sobrecargas introduzidas no sincronismo e comunicação entre os processos. 


\subsection{Conceitos Básicos}

Essa seção apresenta alguns conceitos básicos relacionados à computação paralela. São discutidos os seguintes conceitos: paralelismo e concorrência, níveis de paralelismo e medidas de desempento.

\subsubsection{Paralelismo e concorrência}

Na programação seqüencial, os processos são executados um após o outro, enquanto que na programação concorrente os processos são executados concorrentemente. A Concorrência implica em mais de um processo iniciado e ainda não terminado, podendo ocorrer tanto em sistemas com um único processador (pseudoparalelismo), como em sistemas com vários processadores (programação paralela). Dentro desta definição, pode-se abstrair dois tipos de paralelismo:

- Pseudo-Paralelismo: os processos são executados de forma intercalada em um único processador, de maneira que apenas um está ativo a cada instante. A Figura 2.1 exemplifica este tipo de paralelismo, com a execução de três processos $(e 1, e 2$ e $e$ ) em função do tempo.

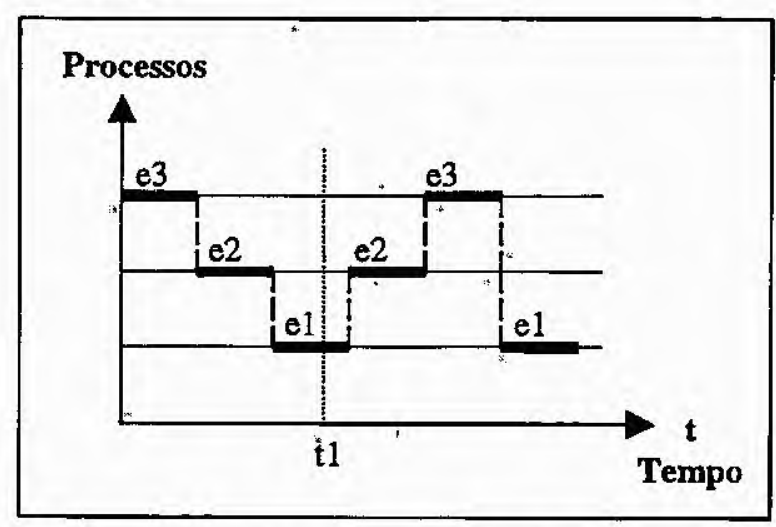

Figura 2.1 - Pseudo-Paralelismo

- Paralelismo Real: vários processos são executados no mesmo intervalo de tempo, ou seja, têm-se vários processadores podendo executar os processos simultaneamente (Figura 2.2). Se existem $p$ processos e $P$ processadores sendo executados concorrentemente, e $p>P$, forma-se uma situação de paralelismo misto. 


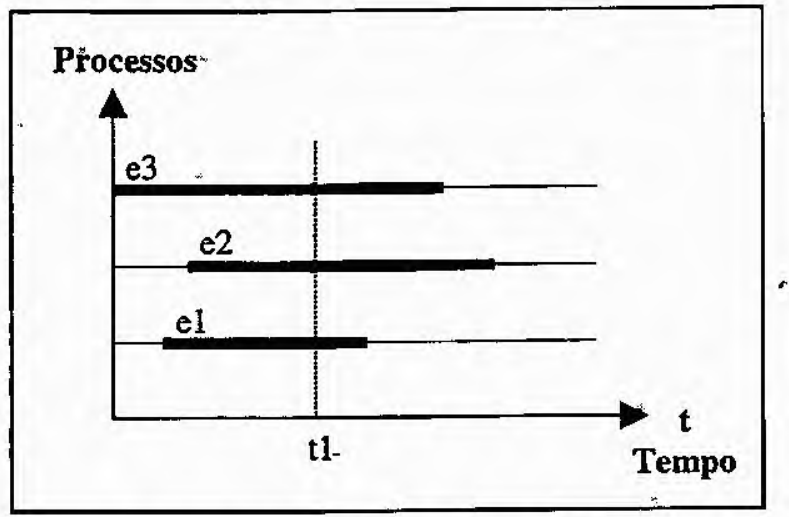

Figura 2.2 - Paralelismo Real

O paralelismo real pode ser dividido em três tipos: paralelismo espacial (paralelismo real), temporal (pipeline) e combinado [SOU96a].

O paralelismo espacial está relacionado à execução simultânea dos processos. O paralelismo temporal, ou pipeline, implica na execução de eventos sobrepostos no tempo. $O$ processo é dividido em vários sub-processos, sendo cada um executado em um estágio especializado de hardware e software operando concorrentemente com os outros estágios do pipeline [HWA93] [NAV89].

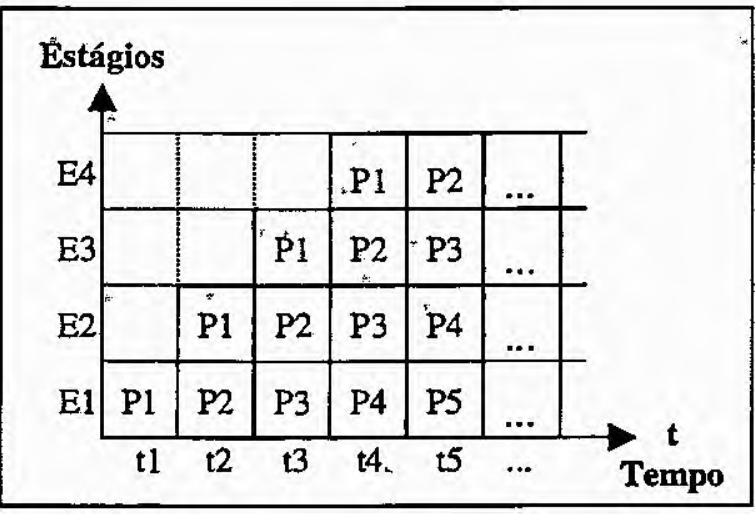

Figura 2.3 - Execução de um Pipeline

A Figura 2.3 demonstra o funcionamento de um pipeline de quatro estágios $(E 1, E 2$, $E 3$ e $E 4)$. Os estágios são organizados seqüencialmente de maneira que o primeiro estágio (El) executa uma parte do processo $P 1$ e, ao terminar, entrega o resultado para o segundo estágio que dará continuidade ao processamento. A cada unidade de tempo, um novo processo é iniciado, denominados $P 1, P 2, P 3 \ldots, P n$. Após quatro unidades de tempo, neste exemplo, o fluxo de processos completos torna-se contínuo, sendo que um processo é executado a cada unidade de tempo (paralelismo de eventos sobrepostos). No paralelismo combinado existem vários estágios de pipeline sendo executados em paralelo. 
Em termos de programação não existem diferenças entre programação concorrente e programação paralela, sendo os dois termos utilizados indistintamente nesta dissertação.

\subsubsection{Níveis de Paralelismo}

Granulosidade (ou nível de paralelismo) pode ser definida como o tamanho das unidades de trabalho submetidas aos processadores. Esta é uma definição muito importante na computação paralela, pois está intimamente ligada ao tipo de plataforma (número de processos/processadores e o tamanho de cada tarefa) à qual se aplica o paralelismo.

Várias definições de granulosidade são encontradas na literatura [ALM94] [HWA93] [NAV89]. Mas, basicamente, a granulosidade é dividia em três níveis:

- Grossa (ou Paralelismo de Alto Nível): relaciona o paralelismo ao nível de programas, e geralmente se aplica a plataformas com poucos processadores grandes e complexos.

- Fina (ou Paralelismo de Baixo Nível): relaciona paralelismo ao nível de instruções ou operações, com um grande número de processadores pequenos e simples.

- Média (ou Paralelismo de Nível Médio): situa-se entre as duas anteriores, com dezenas de processos de tamanho médio.

\subsubsection{Medidas de Desempenho}

Na computação paralela uma característica fundamental é o ganho de desempenho obtido com o paralelismo. Neste contexto, existem várias medidas para analisar o desempenho: tempo de execução, speedup, eficiência e escalabilidade [FOS95].

Tempo de execução é o tempo gasto para que o programa paralelo termine de executar. Compreende os tempos de computação, comunicação e espera:

- Tempo de computação: tempo gasto pelo programa para sua execução propriamente dita.

- Tempo de comunicação: tempo gasto pelo programa para mandar e receber informações. Pode ser do tipo: intraprocessadores (no mesmo processador) e interprocessadores (entre várias tarefas em vários processadores). 
- Tempo de espera (Idle Time): tempo gasto devido à falta de computação ou falta de dados.

O Speedup pode ser definido como o aumento de velocidade observado quando se executa um determinado processo em $p$ processadores em relação à execução deste processo em 1 (um) processador. Obtendo o seguinte:

$$
\text { Speedup }=\frac{\mathrm{T} 1}{\mathrm{~T} p}
$$

Onde: $\mathrm{T} 1$ = tempo de execução em $1(\mathrm{um})$ processador

$\mathrm{T} p=$ tempo de execução em $p$ processadores

O ganho de speedup deveria tender a $p$, porém, três fatores dificultam a obtenção do speedup ideal: sobrecarga de comunicação entre os processadores, partes do código estritamente sequienciais e o nível de paralelismo utilizado (uso de granulosidade inadequada à arquitetura) [ALM94] [QUI87].

A eficiência é a fração de tempo em que os processadores estão fazendo algum trabalho, ou seja, é a relação entre o speedup e o número de processadores.

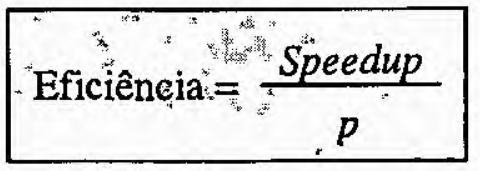

No caso ideal (speedup $=p$ ), a eficiência seria máxima e teria valor $1(100 \%)$. Mas no caso real, speedup $<p$ e eficiência $<1$.

A escalabilidade implica no aumento da capacidade computacional sem afetar a utilização do sistema. Com relação ao speedup, a escalabilidade pode ser:

- Escalabilidade com problema de tamanho fixo: implica em como o tempo de execução e o speedup de um programa variam com o acréscimo do número de processadores para um problema de tamanho fixo.

- Escalabilidade com problema de tamanho variável: implica na capacidade de manter o speedup em valor fixo aumentando o número de processadores e o tamanho do problema. 


\subsection{Arquiteturas Paralelas}

Diversas taxonomias diferentes, para arquiteturas paralelas, foram propostas baseadas em atributos diferentes. Uma classificação ideal, segundo Ben-Dyke [BEN93], deve ser:

- Hierárquica: partindo de !rm nível mis shstrato para níveis mais detalhados.

- Universal: um computador deve ter uma classificação única.

- Extensível: novas máquinas que surjam, devem ser incluídas sem que sejam necessárias modificações na classificação.

- Concisa: os nomes das classes devem ser pequenos para que a classificação seja de uso prático.

- Abrangente: deve incluir todos os tipos de arquiteturas existentes.

A taxonomia mais utilizada pela comunidade computacional é a de Flynn [FLY96] (seção 2.3.1). No entanto esta taxonomia não engloba diversas arquiteturas atuais. A taxonomia de Duncan tenta englobar estas arquiteturas [DUN90] (seção 2.3.2).

\subsubsection{Classificação de Flynn}

A classificação de Flynn divide as arquiteturas em quatro categorias de máquinas, conforme a quantidade de fluxo de instruções e de fluxo de dados. Fluxo de instruções equivale a uma sequiência de instruções executadas (em um processador) sobre o fluxo de dados que as instruções estão relacionadas [DUN90] [FLY96]. As categorias são:

- SISD (Single Instruction Single Data Stream): possui apenas um fluxo de instruções e um fluxo de dados, corresponde ao tradicional modelo de Von Neumann. Um processador executa seqüencialmente um conjunto de instruções sobre um conjunto de dados (Figura 2.4).

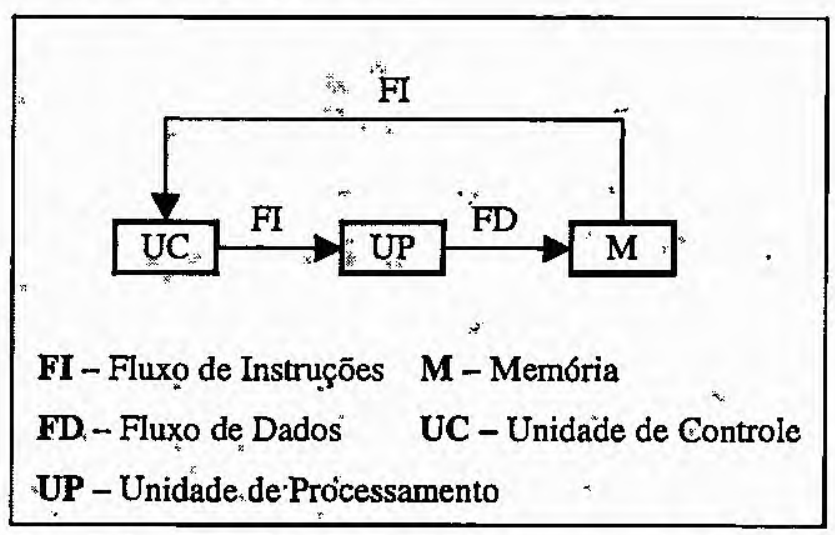

Figura 2.4-Modelo Computacional SISD 
- SIMD (Single Instruction Multiple Data Stream): único fluxo de instrução sobre vários fluxos de dados. Possui vários processadores controlados por uma única unidade de controle, executando simultaneamente a mesma instrução em diversos conjuntos de dados (Figura 2.5). Arquiteturas SIMD são utilizadas, por exemplo, para manipulação de matrizes e processamento de imagens.

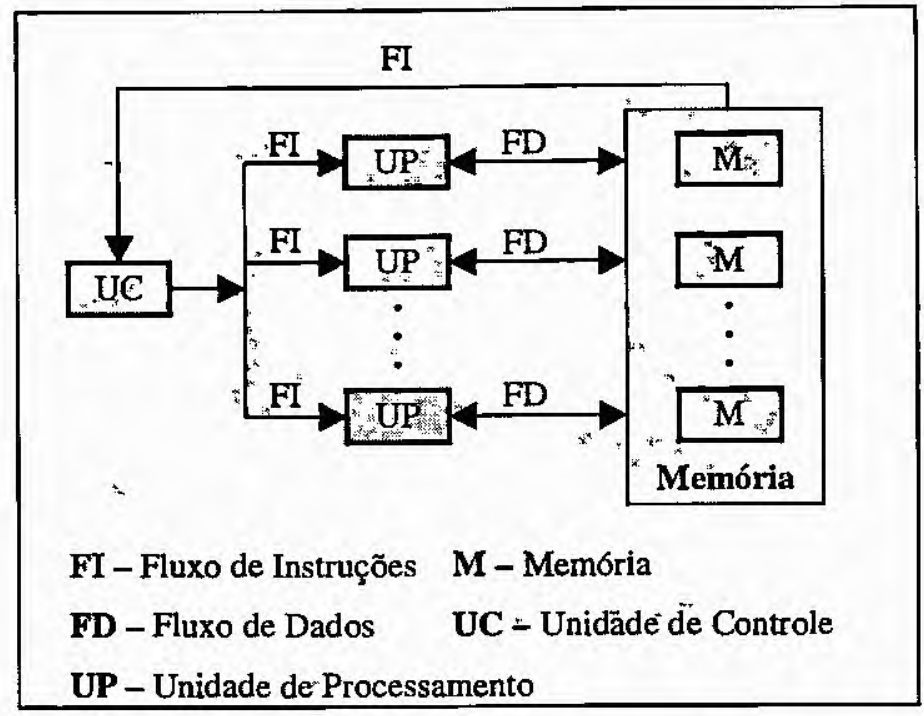

Figura 2.5 - Modelo Computacional SIMD

- MISD (Multiple Instruction Single Data Stream): múltiplos fluxos de instruções para um único fluxo de dado. Envolve múltiplos processadores executando diferentes instruções em um único conjunto de dados (Figura 2.6).

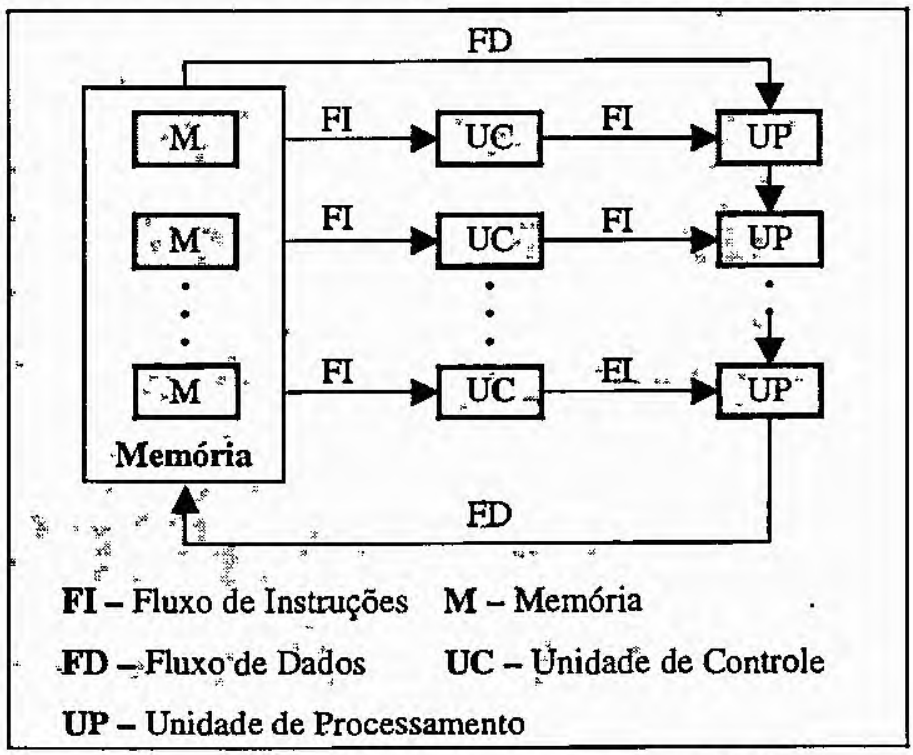

Figura 2.6 - Modelo Computacional MISD

- MIMD (Multiple Instruction Multiple Data Stream): composta por múltiplos fluxos de instruções e múltiplos fluxos de dados. Envolve múltiplos processadores 
executando diferentes instruções em diferentes conjuntos de dados, de maneira independente (Figura 2.7). Essa classe engloba a maioria dos computadores paralelos.

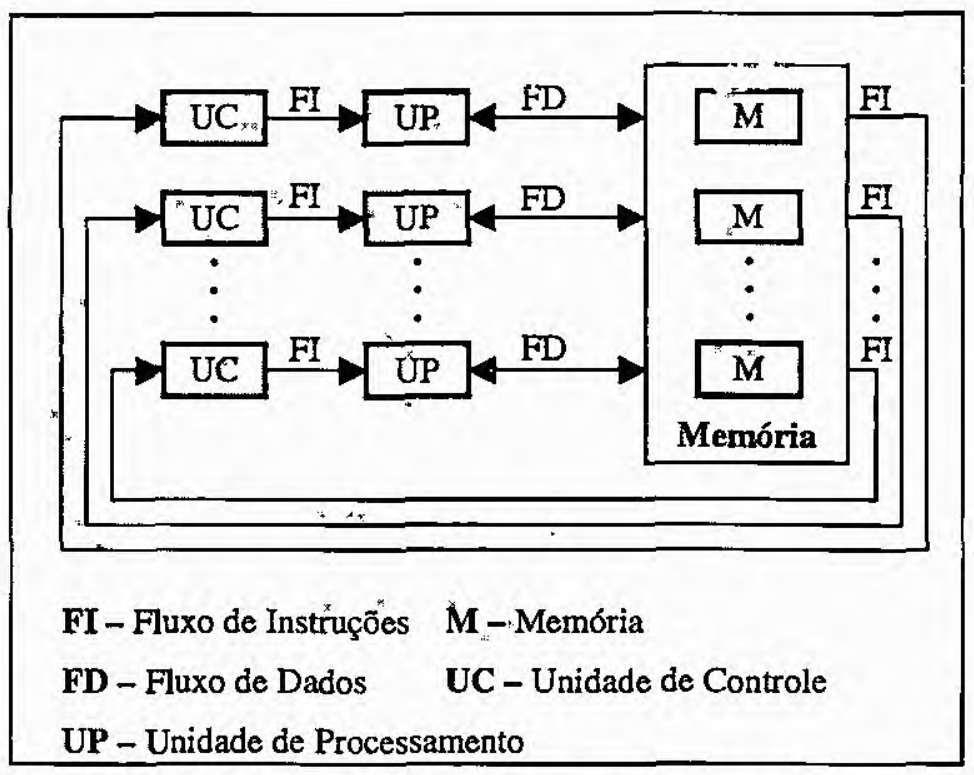

Figura 2.7-Modelo Computacional MIMD

A classificação de Flynn é bastante concisa e utilizada, mas apresenta alguns problemas. Não sendo abrangente e extensível o suficiente para incluir alguns computadores modernos (por exemplo, processadores vetoriais e máquinas de fluxo de dados). Outro ponto negativo é a falta de hierarquia, a classificação MIMD, por exemplo, engloba quase todas as arquiteturas paralelas sem apresentar sub-níveis.

\subsubsection{Classificação de Duncan}

Duncan [DUN90] propôs uma classificação mais completa, permitindo apresentar uma visão geral dos estilos de organização para computadores paralelos da atualidade. Para o desenvolvimento desta classificação três aspectos básicos são considerados [SOU96b]:

- Manter os elementos da classificação de Flynn, devido sua grande utilização.

- Incluir as novas arquiteturas (como as sistólicas e hipercúbicas).

- Excluir arquiteturas que apresentem paralelismo de baixo nível, como por exemplo: pipeline dos estágios de execução de uma instrução e unidades funcionais múltiplas de uma única UCP (Unidade Central de Processamento).

A classificação de Duncan é apresentada na Figura 2.8, e a seguir seus componentes são brevemente discutidos. 


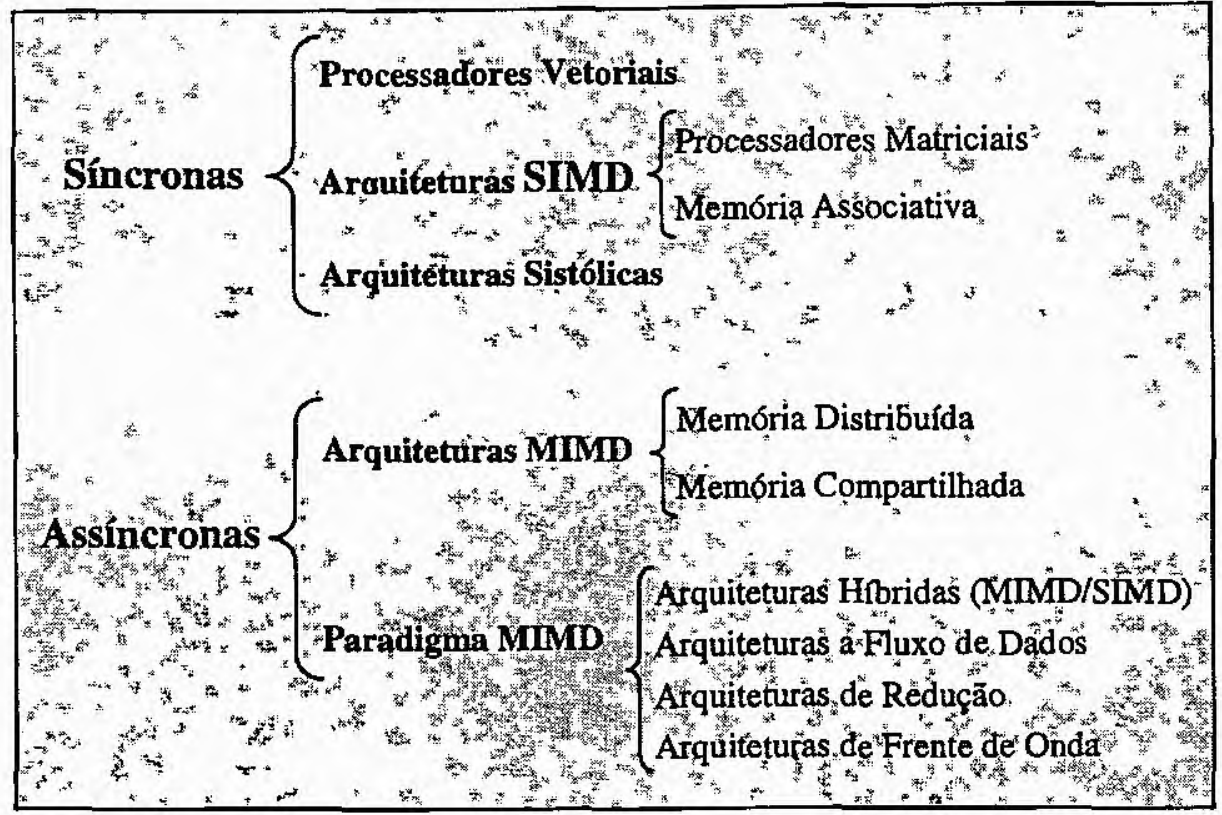

Figura 2.8 - Classificaçāo de Duncan

\section{Arquiteturas Síncronas}

Nas arquiteturas paralelas síncronas as operações concorrentes são coordenadas sincronamente por uma unidade de controle central e por um relógio comum ao sistema. As arquiteturas que compõem esta categoria são:

- Processadores Vetoriais: possuem um hardware específico para a execução de operaçōes em vetores, proporcionando mecanismos eficientes para o suporte de cálculos pesados em matrizes ou vetores. É importante ressaltar que o paralelismo dessas arquiteturas é explorado em nível de compilação e não de programação.

- Arquiteturas SIMD: como já descrito anteriormente, arquiteturas SIMD apresentam múltiplos processadores sob a supervisão de uma unidade central de controle, executando a mesma instrução sincronamente em conjuntos de dados distintos. Podem ser organizadas de duas maneiras:

- Processadores Matriciais: fornecem estruturas para computação sobre matrizes de dados, sendo empregados para fins específicos.

- Memória Associativa: o acesso à memória é feito de acordo com o seu conteúdo, visando o acesso paralelo de acordo com certo padrāo de dados.

- Arquiteturas Sistólicas: caracterizam-se pela presença de vários processadores enfileirados (pipeline), formando uma cadeia na qual apenas os processadores localizados nos limites desta estrutura possuem comunicação com a memória. Seu principal objetivo é fornecer uma estrutura eficiente para a solução de problemas 
que necessitem de computação intensiva, junto a grande quantidade de operações de entrada e saída.

\section{Arquiteturas Assíncronas}

Estas afquiteturas caracterizam-se pelo controle descentralizado de hardware, onde cada unidade de processamento executa diferentes instruções sobre diferentes dados. Os processadores são independentes entre si. Esta classe é formada basicamente pelas arquiteturas MIMD, sejam convencionais ou não [DUN90]:

- Arquiteturas MIMD: enquanto arquiteturas síncronas utilizam algoritmos de granulosidade fina, as arquiteturas MIMD pressupõem algoritmos de granulosidade mais grossa com pouca comunicação entre processos. Além disso, arquiteturas MIMD oferecem grande flexibilidade para construção de algoritmos paralelos. Apesar de independentes, os processos executando nos diversos processadores devem cooperar entre si, tornando necessárias à comunicação e o sincronismo entre esses processos. A implementação dos métodos de comunicação e sincronismo depende da organização de memória, que pode ser compartilhada ou distribuída:

- Arquiteturas de Memória Compartilhada: caracterizam-se pela existência de um única memória, a qual é utilizada por todos os processadores (Figura 2.9). O compartilhamento e sincronismo são feitos pelo acesso simples aos dados na memória, embora sejam necessários critérios adicionais para que acessos concorrentes não resultem em informaçб̃es inconsistentes. As máquinas que implementam esta arquitetura são chamadas de multiprocessadores. Para evitar que a memória se torne um gargalo pode-se implementar mecanismos de cache.

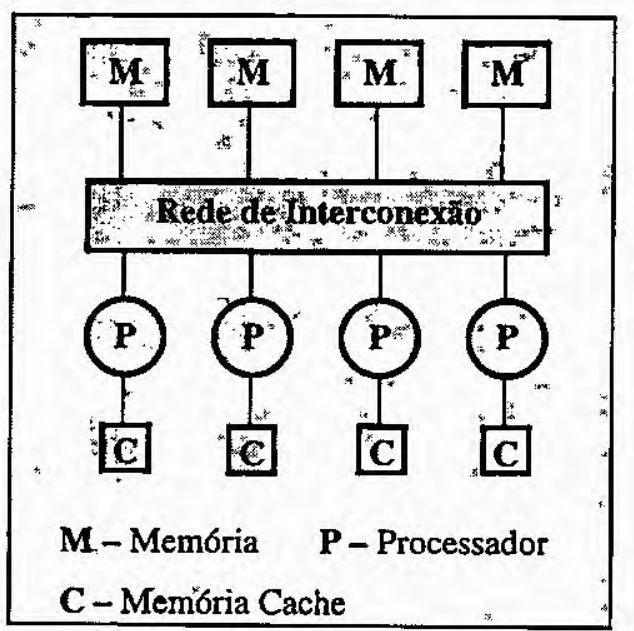

Figura 2.9 - Arquitetura de Memória Compartilhada 
- Arquiteturas de Memória Distribuída: cada processador possui sua própria memória local (Figura 2.10), não tendo acesso à memória dos outros processadores. Em virtude de não haver compartilhamento de memória, a comunicação e o sincronismo são realizados via troca de mensagens, que se trata da transferência explicita de dados entre os processadores. Este tipo de organização é também conhecido como multicomputador.

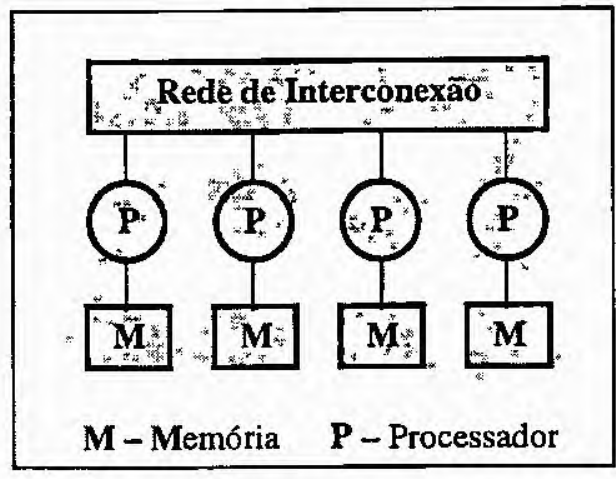

Figura 2.10 - Arquitetura de Memória Distribuída

- Paradigma MIMD: essa classe engloba todas as arquiteturas que não se encaixam em nenhuma das categorias anteriores. Estas arquiteturas apresentam características MIMD, pois são assíncronas e com múltiplos fluxos de instruções e de dados, mas possuem características próprias, dificultando sua classificação como puramente MIMD. Estas arquiteturas são:

- Arquiteturas Híbridas (MIMD/SIMD): também conhecidas por MSIMD, são compostas basicamente por uma arquitetura MIMD, que possui algumas partes controladas por arquiteturas SIMD. Aplicações nas quais podem ser utilizadas são: processamento de imagens e sistemas especialistas.

- Arquiteturas a Fluxo de Dados (dataflow): neste tipo de arquitetura, uma instrução é executada assim que todos os seus operandos estão disponíveis. A sequiência de instruções a ser executada é baseada na dependência de dados, permitindo a concorrência em nível de tarefas, rotinas e instruções.

- Arquiteturas de Redução: também conhecidas como arquiteturas dirigidas à demanda, visto que os processadores só executam os comandos quando as expressões necessitam do seu calculo.

- Arquiteturas de Frente de Onda: combinam as estruturas pipeline sistólicas com a execução assíncrona a fluxo de dados, com o objetivo de conservar as vantagens das arquiteturas sistólicas e eliminar algumas de suas desvantagens. 


\subsubsection{Redes de Interconexão}

Uma rede de interconexão pode ser definida como um conjunto de conexões e chaves, que permitem a comunicação entre processadores e memórias em uma arquitetura paralela. Esse é um aspecto muito importante de uma arquitetura paralela, visto que a comunicação entre processos influencia diretamente o desempenho de um programa paralelo [ALM94].

Redes de interconexão podem ser organizadas em duas categorias de topologias:

- Topologias estáticas: os elementos de processamento estão conectados diretamente entre si. Por isso, o caminho a ser seguido por uma mensagem deve ser determinado explicitamente. Topologias deste tipo não são reconfiguráveis, de maneira que a estrutura de conexão de processadores não pode ser modificada após a sua construção. Apresentam menor custo e maior simplicidade para o seu projeto, e sua utilização tem eficiência no projeto de computadores de propósito específico, com padrões simples e previsíveis de comunicação.

- Topologias dinâmicas: existem chaves de ligação entre os elementos de processamento. As chaves de ligação são responsáveis por rotear à mensagem até o seu destino. As topologias dinâmicas apresentam, em geral, melhor desempenho, são mais caras e mais difícil de se construir. São muito utilizadas em arquiteturas MIMD com memoria compartilhada, em virtude de possibilitarem demora constante para todos os processadores no acesso à memória.

A eficiência da comunicação e a rede empregada são pontos que apresentam grande influência no desempenho de um computador paralelo. $O$ que se espera é uma rede de baixa latência com uma alta taxa de transferência de dados e uma ampla largura de banda de comunicação.

Dentre as arquiteturas apresentadas, o modelo MIMD tem se destacado (principalmente o modelo de memória distribuída), devido à sua flexibilidade e por representar uma boa opção para algoritmos de granulosidade média è grossa. Assim, nas próximas seções serão discutidos alguns tópicos importantes para este tipo de arquitetura. 


\subsection{Programação Concorrente}

Um programa concorrente especifica dois ou mais processos seqüenciais que podem ser executados concorrentemente como processos paralelos. $O$ objetivo da programação consorrente é fornecer ferramentas para a construção de programas, permitindo assim uma melhor utilização dos recursos de hardware disponível.

Em um programa concorrente, além das construções básicas comuns aos programas seqüenciais (atribuições, comandos de decisão, laços), novas construções são necessárias para tratar os aspectos decorrentes da execução paralela dos vários processos. Basicamente existem três fatores essenciais para a execução paralela:

- Definir um conjunto de tarefas a serem executadas paralelamente (Seção 2.4.1).

- Ativar e encerrar a execução dessas tarefas (Seção 2.4.2).

- Coordenar e especificar a interação entre essas tarefas (Seção 2.4.3).

\subsubsection{Projeto de um Algoritmo Paralelo}

Para o desenvolvimento de um algoritmo paralelo, várias abordagens podem ser seguidas. Entre estas abordagens pode-se citar:

- Detectar e explorar algum paralelismo inerente a um algoritmo seqüencial existente: esta abordagem apreșenta speedup limitado e uma baixa flexibilidade, mas é bastante utilizada, visto que não há necessidade de nova análise do algoritmo.

- Criar um algoritmo paralelo novo: permite alcançar um melhor desempenho, pois é possível desenvolver uma solução que explore com muito mais eficiência o paralelismo.

- Adaptar outro algoritmo paralelo que resolva problema similar: esta abordagem apresenta um bom desempenho, e exige menos trabalho do programador em relação à criação de um algoritmo paralelo novo.

Além da abordagem a ser seguida, dois aspectos devem ser considerados quando se projeta um algoritmo paralelo: o custo de comunicação entre os processos e a arquitetura na qual se executará o algoritmo. Pois, dependendo da escolha adotada na concepção do algoritmo pode-se desenvolver um programa pior em eficiência que a versão seqüencial ou outra versão paralela já existente. 
Outro aspecto importante no desenvolvimento de um algoritmo paralelo é definir como os processos serão organizados. Vários tipos de organizações podem ser encontrados na literatura computacional, entre elas pode-se citar:

- Mestre/Escravo (ou Processor Farm): onde o processo mestre coordena o trabalho, ativando e recebendo os resultados dos escravos.

- Pipeline (ou Especialista): os processos possuem especialidades diferentes, executando fases do processo.

- Por Resultado (ou Geométrica): analisa-se o resultado e destina-se uma parte do resultado para cada processo.

- Dividir e Conquistar: o problema é dividido e as partes são resolvidas recursivamente.

\subsubsection{Ativação de Processos Paralelos}

Várias primitivas para a ativação e término de processos concorrentes têm sido propostas, cada uma apresentando características e finalidades distintas [ALM94] [QUI87]. Entre elas pode-se citar:

- Fork/Join: sua função é ativar dois processos em paralelo. O comando fork inicia a execução de um processo (processo filho), concorrentemente ao processo que está sendo executado (processo pai). O comando join é utilizado para sincronização com os filhos gerados. As sintaxes dos comandos fork/join são:

- Fork endereço: executa o processo que está em endereço concorrentemente ao processo atual, que continua normalmente sua execução.

- Join num, end1, end2: decrementa num em uma unidade e depois verifica seu valor. Se o valor de num for igual a zero, desvia a execução para endl. Caso contrário, desvia para end2 (podendo ser um comando quit, que finaliza a execução).

Este tipo de construção é flexível e bastante poderoso, porém, o código gerado é obscuro e sem estruturação. Como pode ser visto na Figura 2.11. 


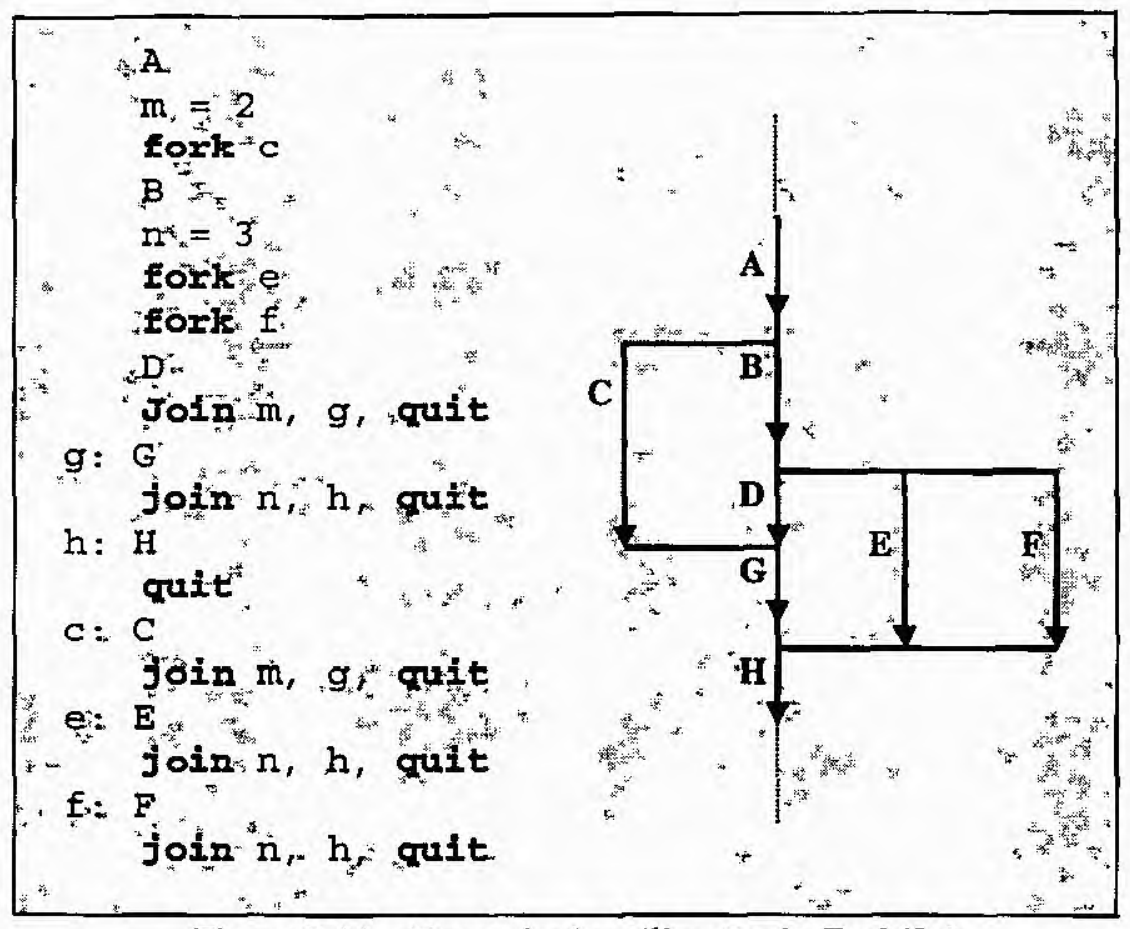

Figura 2.11 - Exemplo de utilização de Fork/Join

- Cobegin/Coend: também chamados de parbegin/parend, oferecem uma maneira estruturada de ativação de um conjunto de instruções que devem ser executadas concorrentemente (Figura 2.12). Este tipo de construção é mais alto nível que a anterior, sendo fácil reconhecer os processos que estāo executando em paralelo. Porém, são menos flexíveis, existindo casos em que não é possível obter a melhor forma para ativação dos processos concorrentes.

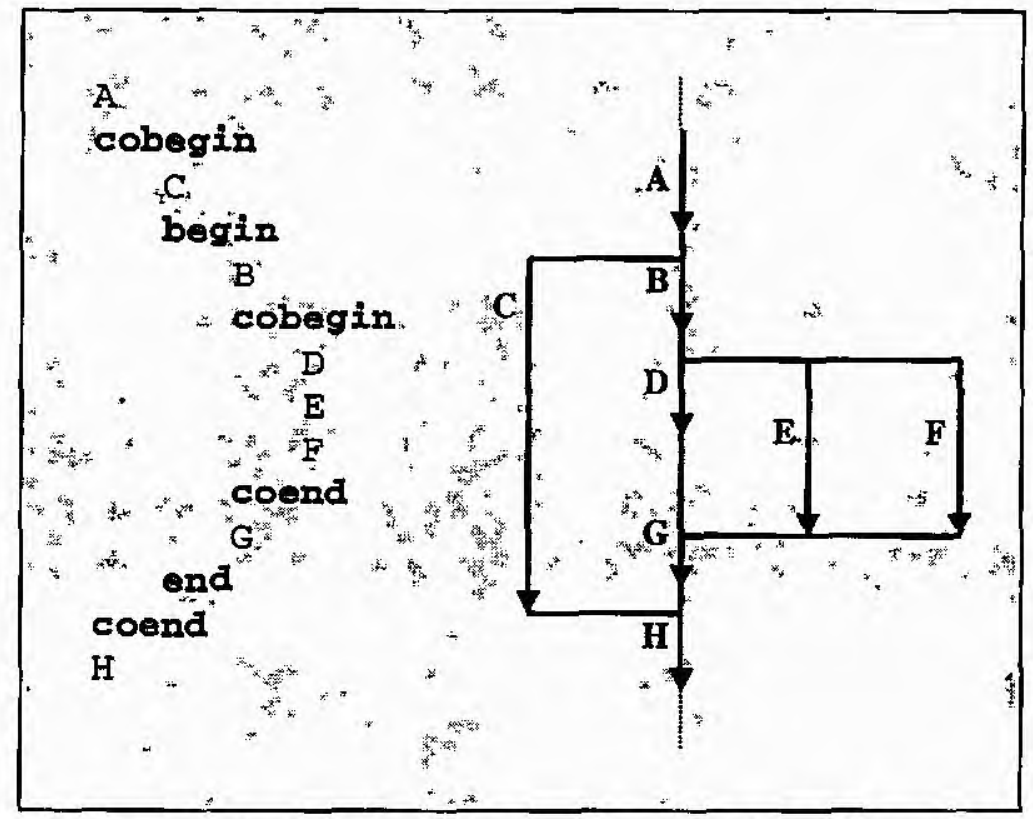

Figura 2.12 - Exemplo de utilização de Cobegin/Coend 
- Doall: executa em paralelo as instâncias de um bloco de comandos dentro de um comando de loop, não podendo haver dependência entre as diversas instâncias do loop. Muito utilizado para operações com matrizes e vetores. A Figura 2.13 mostra a execução de uma estrutura normal e uma estrutura doall.

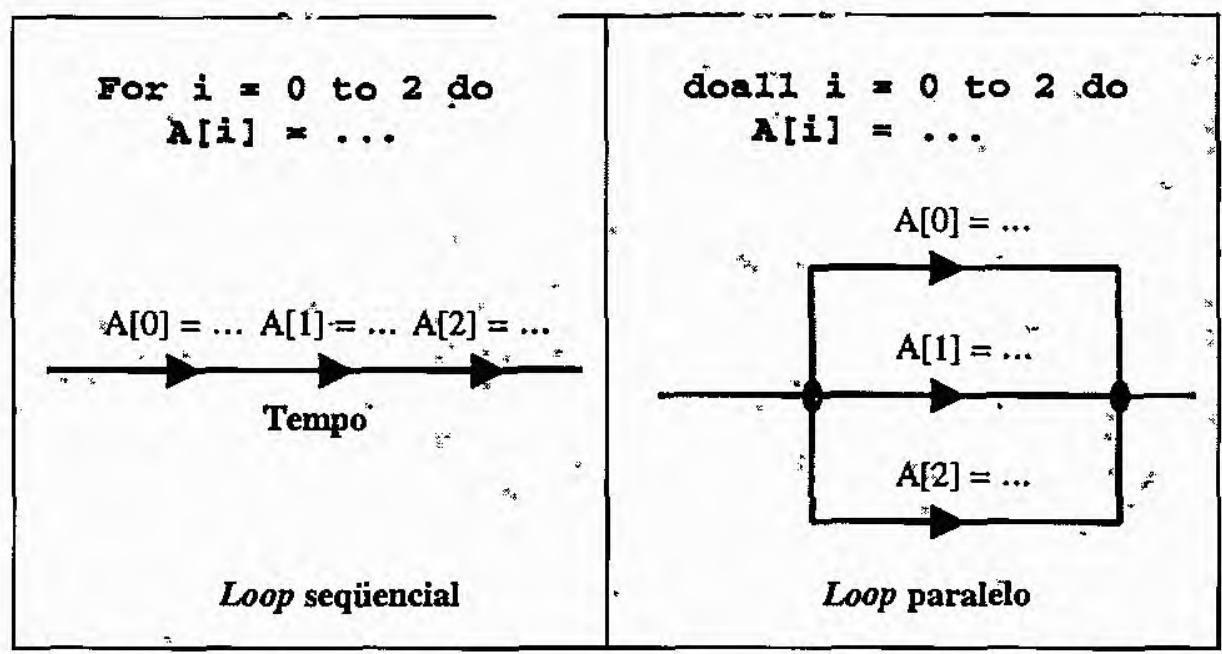

Figura 2.13 - Exemplo da utilização de Doall

\subsubsection{Mecanismos de Sincronização e Comunicação}

A comunicação permite que a execução de um processo influencie na execução do outro. E a sincronização permite a imposição de uma ordem na execução dos processos.

Arquiteturas MIMD são compostas por vários processadores independentes. Como dito anteriormente, os processos executando nos diversos processadores devem cooperar entre si. As técnicas que garantem a comunicação e o acesso a recursos comparti]hados são conhecidas como mecanismos de sincronização.

A área de dados compartilhados é conhecida como região crítica. Os mecanismos de sincronizaçāo devem evitar a concorrência nas regiões críticas, permitindo que somente um processo tenha acesso em um determinado instante. Esta idéia de exclusividade de acesso é denominada exclusão mútua [BEN90] [TAN92].

\section{Comunicação e Sincronismo em Memória Compartilhada}

Comunicação e sincronismo em memória compartilhada são implementados através de variáveis compartilhadas entre os diversos processos concorrentes. Vários métodos podem ser utilizados, entre eles: so]uções de hardware, semáforos e monitores. 
- Soluções de Hardware: as soluções de hardware criam mecanismos para implementação das soluções de software. Existem vários métodos de solução de hardware, entre eles [MAC97]:

- Desabilitação de Instruções: uma solução simples é fazer com que o processo, antes de entrar na região crítica, desabilite as interrupções externas e as reabilite após deixar a região crítica. Esta implementação traz uma série de inconvenientes, o maior deles ocorre quando o processo que desabilitou as interrupções não volta a habilitá-las.

- Instrução Test-and-Set: é uma instrução especial utilizada em muitos processadores, que permite ler uma variável, armazenar seu conteúdo em uma outra área e atribuir um novo valor a essa variável.

- Soluções de Software: as primeiras soluções de software apresentadas tinham a deficiência da espera ocupada (busy wait). Na espera ocupada, o processo que não consegue acessar a região crítica, entra em looping, até que consiga o acesso. Dessa forma, o processo consome tempo do processador desnecessariamente. As soluçōes de software mais recentes e utilizadas são [MAC97]:

- Semáforos: um semáforo é uma variável inteira, não negativa, que só pode ser manipulada pelas instruções atômicas DOWN e UP. Estas primitivas funcionam como protocolos de entrada e saída da região crítica.

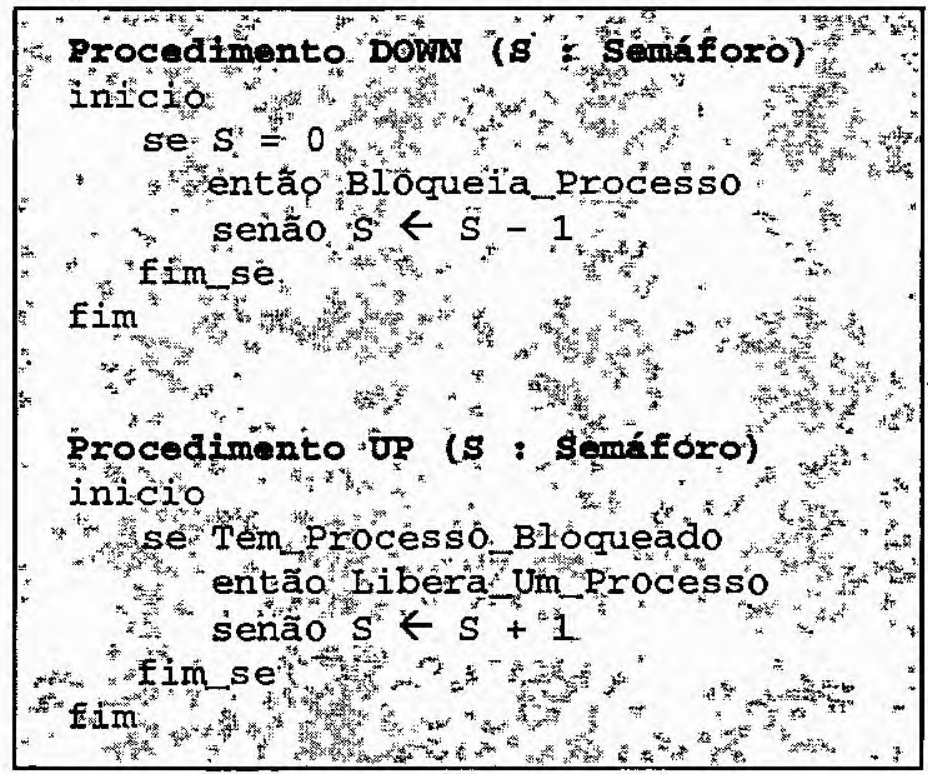

Listagem 2.1 - Primitivas Down e UP

O funcionamento do semáforo é muito simples (Listagem 2.1): para entrar na região crítica, o processo executa uma instrução $D O W N$. Se o semáforo for 
maior que 0 (zero), este é decrementado de 1 , e o processo pode executar a região crítica. Entretanto, se o valor for igual a 0 (zero), o processo ficará em estado de espera. Ao sair da região crítica o processo executa uma instrução UP, incrementando o semáforo em 1 e liberando o acesso ao recurso.

- Monitores: uma desvantagem do uso de semáforos é o fato de serem pouco estruturados, o que pode levar a erros se o programador não tiver muito cuidado. Os monitores apresentam mais alto nível, oferecendo uma maneira mais estruturada para a implementação de exclusão mútua. O monitor é um conjunto de procedimentos, variáveis e estrutura de dados definidos dentro de um módulo. Toda vez que um processo chama um desses procedimentos, o monitor verifica se já existe outro processo executando algum procedimento monitor. Caso exista, o processo aguarda sua vez até que tenha permissão para executar. A implementação da exclusão mútua nos monitores é realizada pelo compilador e não pelo programador, como é o caso dos semáforos.

\section{Comunicação e Sincronismo em Memória Distribuída}

Comunicação e sincronismo em arquiteturas de memória distribuída devem ser implementados através de troca de mensagens, que é realizado pelas primitivas SEND $e$ RECEIVE [ALM94] [QUI87]. A rotina SEND é responsável por enviar uma mensagem para um processo receptor, e a rotina RECEIVE por receber uma mensagem de um processo transmissor. As rotinas podem ser representadas através das sintaxes a seguir:

Send mensagem to processo_destino
Receive mensagem from processo_fonte

Alguns problemas surgem com a comunicação por troca de mensagens, e o principal é a perda de mensagem. Para evitar que uma mensagem se perca, o processo receptor deve enviar ao processo transmissor uma mensagem confirmando o recebimento (acknowledgement - ACK). Caso o transmissor não receba um ACK em um determinado tempo, ele reenvia a mensagem.

Basicamente, existem duas formas de comunicação entre processos através de troca de mensagens [MAC97]: 
- Comunicação síncrona: onde o processo que transmite a mensagem (transmissor) é bloqueado até que receba uma confirmação de recebimento da mensagem pelo processo receptor (Figura 2.14 (a)).

- Comunicação assíncrona: o processo transmissor envia a mensagem (que deve ser armazenada em um buffer) e continua a sua execução (Figura 2.14 (b)).

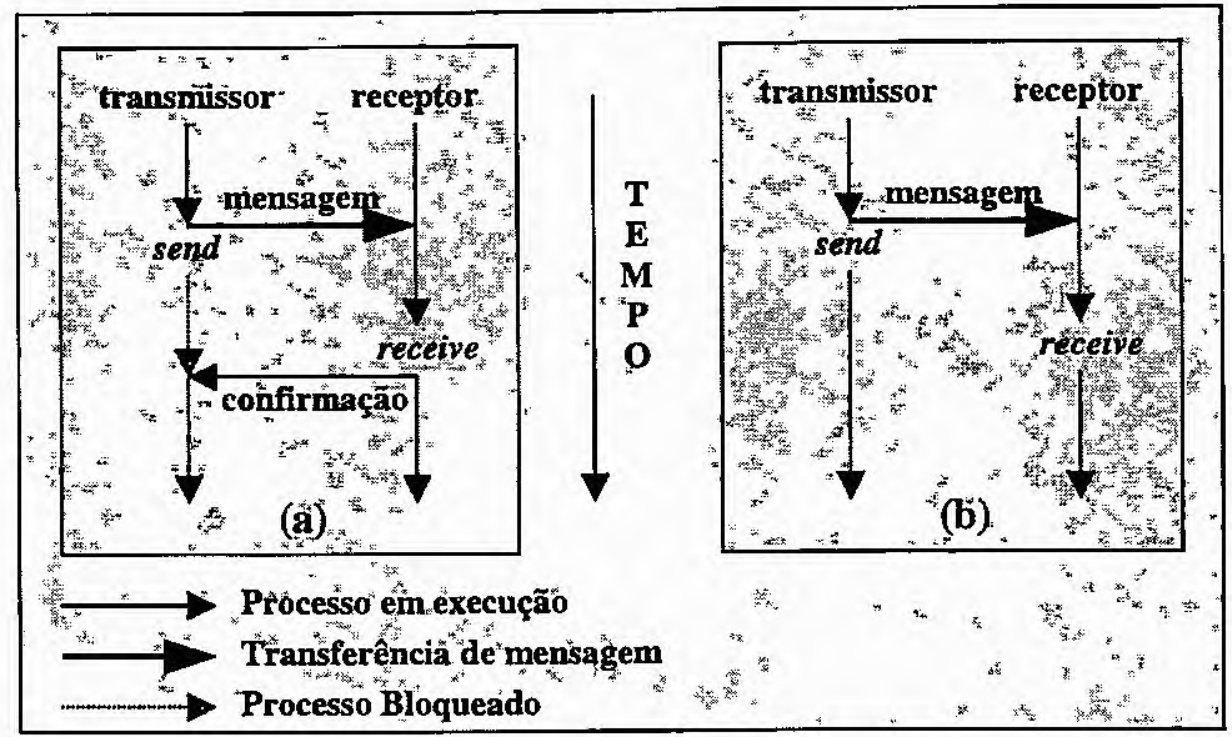

Figura 2.14 - Send/Receive. (a) Bloqueante (b) Não-Bloqueante

\subsubsection{Suporte para Programação Paralela}

Para escolha de uma ferramenta para programação paralela, vários aspectos devem ser levados em consideração. Entre eles: o tipo de aplicação, o tipo de usuário, a arquitetura a ser utilizada, o tempo de trabalho do programador (inclui o tempo de aprendizado da ferramenta) e o desempenho.

Basicamente, existem três tipos de ferramentas para a construção de programas paralelos [ALM94]:

- Ambiente de paralelização automática: existem compiladores paralelizadores responsáveis por gerarem automaticamente versões paralelas de programas não paralelos. Este tipo de ferramenta exige o mínimo de trabalho do usuário, mas o desempenho obtido geralmente é modesto. Além disso, nem sempre esses compiladores são disponíveis, principalmente para sistemas de memória distribuída. Exemplos: MIPRAC, PARTI (Parallel Automated Runtime Toolkit at ICASE) 
- Extensões paralelas de linguagens seriais: são bibliotecas que contêm um conjunto de instruções que complementam linguagens seriais já existentes. Esse ambiente é adequado para paralelização de programas existentes, requerem algum trabalho do programador, mas ainda evitam a necessidade de aprendizagem de uma nova linguagem. Geralmente, o desempenho obtido é superior ao obtido pelos ambientes de paralelização automática. Exemplos: MPI (Message Passing Interface), PVM (Parallel Virtual Machine).

- Linguagens concorrentes: são linguagens criadas especialmente para processamento concorrente, o que implica em tempo de aprendizagem de uma linguagem totalmente nova e reescrita total do código fonte. Essas ferramentas apresentam maior flexibilidade e normalmente um melhor desempenho. Outra vantagem é que existem ferramentas para depuração e detecção de erros. Exemplos: Occam e ADA.

Os ambientes de passagem de mensagem (ou interfaces de passagem de mensagens), que se enquadram nas extensões paralelas de linguagens seriais, foram criadas inicialmente para o desenvolvimento de aplicações paralelas em máquinas com processamento maciçamente paralelo (Massively Parallel Processing - MPP), mas passaram a dar suporte a programação paralela em sistemas distribuídos. Esses ambientes têm sido aperfeiçoados nos últimos anos para serem utilizados por uma grande quantidade de equipamentos diferentes, ganhando com isso popularidade e aceitação, visto que proporcionam o desenvolvimento de aplicações paralelas a um custo relativamente baixo em relação às máquinas paralelas [BEG94].

A utilização da computação paralela em sistemas heterogêneos possui algumas vantagens e desvantagens. As maiores dificuldades encontradas em sistemạs heterogêneos são:

- Diferença de potência computacional: cria obstáculos a um balanceamento de carga eficiente, devido à dificuldade de se estabelecer comparações nos diversos tipos de processadores.

- Formatos de dados diferentes: dados diferentes enviados de um computador para outro devem ser traduzidos para permitir a comunicação. 
- Máquinas de arquiteturas diferentes: muitas vezes é difícil prever todas as características das máquinas, dificultando o programa explorar todo o potencial das máquinas envolvidas no sistema.

Apesar destas dificuldades, a computação paralela sobre sistemas distribuídos oferece grandes vantagens como:

- Custo atrativo: utilização de hardware já existente.

- Alto desempenho: por atribuir cada tarefa para a arquitetura mais apropriada.

- Heterogeneidade natural de certas aplicações: permitindo acesso a bancos de dados diferentes e a processadores especiais para determinadas partes do problema.

- Utilização de produtos conhecidos: programadores podem utilizar editores, compiladores, e periféricos disponíveis para os equipamentos seriais.

- Facilidade de trabalho cooperativo: uso da computação distribuída.

\subsection{Considerações Finais}

A razão de ser da computação paralela é o aumento de desempenho. Para se conseguir um bom desempenho vários fatores devem ser considerados e analisados. Entre eles destacam-se: a arquitetura e a ferramenta para programação paralela.

As arquiteturas SIMD, por apresentarem fluxo único de instruções, oferecem facilidade para programação e depuração de programas paralelos. Além disso, seus elementos de processamento são simples sendo destinados à computação de pequena granulosidade e ao processamento de propósito específico. Por outro lado, arquiteturas MIMD apresentam grande flexibilidade para a execução de algoritmos paralelos e um bom desempenho [ALM94]. Dentro do modelo MIMD com memória distribuída, uma tendência atual é a utilização de sistemas distribuídos como plataformas de programação paralela, que representam uma solução de custo acessível.

Com relação às ferramentas para programação paralela, a escolha deve ser feita de acordo com os objetivos do programador. A paralelização automática oferece desempenho difícil de ser previsto e dependente da aplicação, porém com sobrecarga pequena para o programador. Por outro lado, linguagens concorrentes oferecem melhor desempenho, mas 
sobrecarregam de maneira considerável o programador. Num patamar intermediário de desempenho e sobrecarga sobre o programador, situam-se as extensões paralelas.

Outro fator que deve ser considerado é a dificuldade que os programadores encontram para migrar da programação sequiencial para a programação paralela. Muitas linguagens paralelas, ainda são escritas em editores com poucos recursos (se comparadas às linguagens sequienciais), separados do compilador que, geralmente, é acionado por linhas de comandos complexas. Em adição, as linguagens sequienciais evoluíram muito, proporcionando um ambiente de desenvolvimento amigável, que facilitam a criação dos programas e a sua depuração caso seja constatado algum problema [MOR00]. A depuração e o teste de programas paralelos serão discutidos no próximo capítulo. 


\section{Teste e Depuração de Programas Paralelos}

A dificuldade na depuração de programas paralelos, o teste de software, o teste de programas paralelos, a depuração de programas paralelos, a organização dos depuradores de programas paralelos e a monitoração são os principais assuntos discutidos nesse capítulo.

\subsection{Considerações Iniciais}

"Há dois caminhos para se escrever programas livres de erros; somente o terceiro funciona."

- Perlis (Epigrams on Programming, 1982)

Os erros de programas são um fenômeno presente no mundo de software, uma vez que todo programa não trivial contém erro. $\mathrm{Na}$ maioria das vezes os erros são provocados pela falta de metodologia adequada para o desenvolvimento. Os sintomas externos de um erro são conhecidos como failure (fracasso), a manifestação física dos erros nos programas é conhecida como falha. Na depuração, essas falhas são chamadas de bug [MIL88].

A atividade de teste de software é um elemento crítico da garantia de qualidade de software e representa a última revisão de especificação, projeto e codificação [PRE95]. O principal objetivo dessa fase é de gerar casos de teste a fim de se encontrar um erro, sendo que, um bom caso de teste é aquele que encontra um erro.

A depuração é uma conseqüência de um teste bem sucedido, ou seja, quando um erro foi detectado. O processo de depuração é a parte mais imprevisível do processo de teste. Um erro pode demorar uma hora, um dia ou um mês para ser diagnosticado e corrigido.

\subsection{Dificuldade na Depuração de Programas Paralelos}

Além de erros tradicionais presentes nos programas seqüenciais, os programas paralelos apresentam os erros decorrentes da existência de diversos processos sendo executados em paralelo (erros concorrentes), que dificultam ainda mais sua depuração. Os principais tipos de erros concorrentes são [MCD89] [SCH99] [SHI96]: 
- Condição de Disputa (Race Condition): é uma falha que ocorre quando duas atividades estão progredindo em paralelo, causada por uma falta de sincronização (sistemas com passagem de mensagem) ou de exclusão mútua (sistemas com memória compartilhada). Por sincronização, uma condição de disputa ocorre se duas tarefas, uma dependendo da outra, não são devidamente sincronizadas. Por exemplo, se uma tarefa $B$ necessita do resultado de uma tarefa $A$, um mecanismo de sincronização é necessário para garantir a execução das tarefas na ordem correta. Caso contrário, $B$ pode obter um valor antigo ou um dado indefinido. Por exclusão mútua, duas ou mais tarefas entram na região crítica ao mesmo tempo, sendo que essa região deveria ser acessada por uma tarefa de cada vez [SCH99].

- Deadlock: em uma situação de deadlock, nenhuma das tarefas envolvidas é capaz de progredir, pois os recursos necessários estão sendo usados por outra tarefa.

Para ilustrar esta situação será usado o problema do "Jantar dos Filósofos", onde cinco filósofos sentados ao redor de uma mesa estão comendo, pensando ou com fome. A restrição é que existem somente cinco garfos, e cada filósofo precisa de dois garfos para comer. Consequientemente é impossível para todos comerem ao mesmo tempo. Para garantir que todos os filósofos possam comer e não morram de fome, é necessário prover um mecanismo que regule o uso dos garfos.

A Figura 3.1 ilustra a situação de deadlock, onde todos os filósofos estão com fome e apanham o garfo. Consequientemente, cada filósofo tem um garfo e aguarda pelo seu vizinho. Como todos estão em estado de espera, e nenhum libera o seu garfo, o sistema está em deadlock [SCH99].

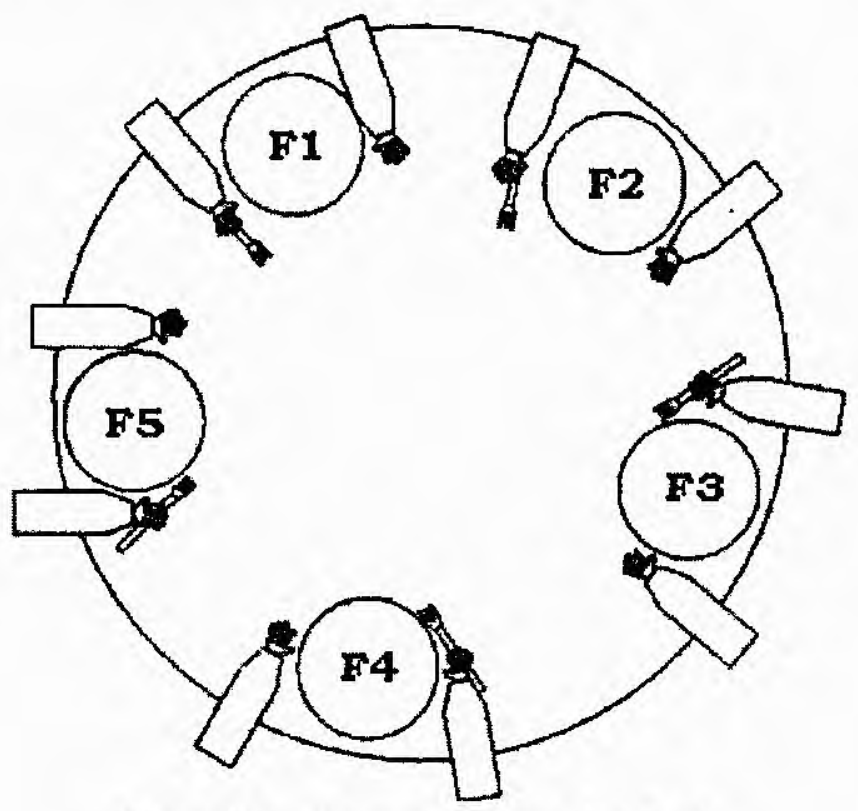

Figura 3.1 - Exemplo de um deadlock 
- Livelock: em uma situação livelock, nenhuma das tarefas envolvidas progride porque elas estão negociando umas com as outras.

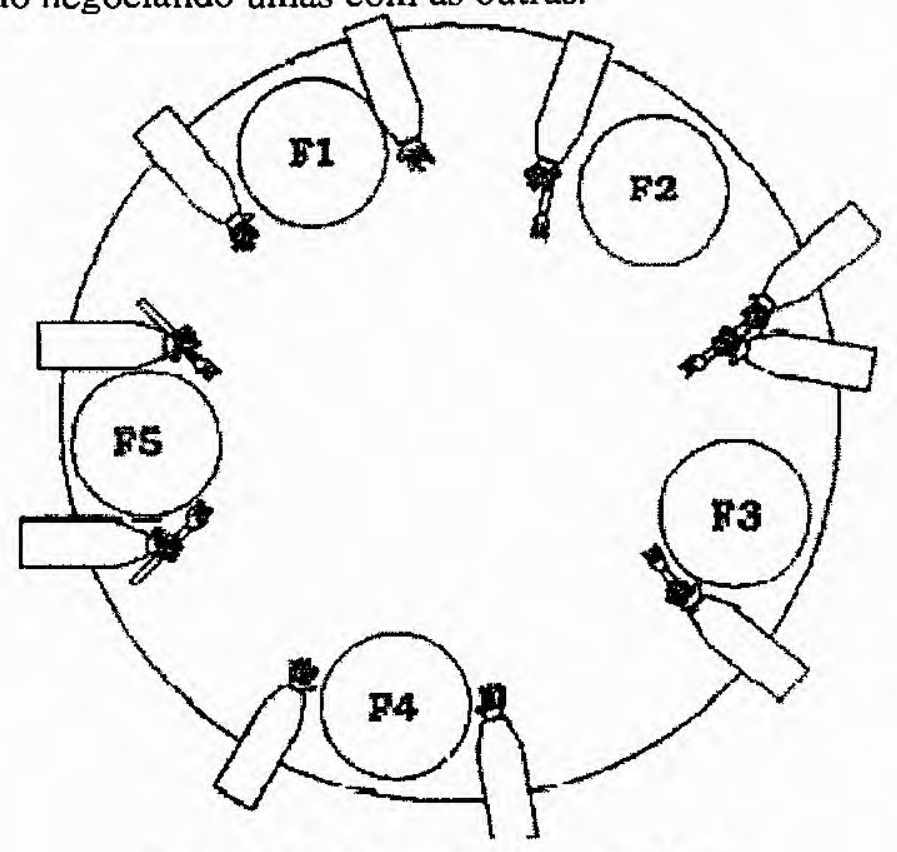

Figura 3.2 - Exemplo de um livelock

Continuando com o exemplo dos filósofos, a Figura 3.2 ilustra esse tipo de erro. Os vizinhos $F 2$ e $F 3$ estão com fome, $F 3$ tem o garfo da esquerda, e $F 2$ tem 0 garfo da direita. F3 tenta pegar o garfo da direita, mas percebe que $F 2$ esta tentando pegar o mesmo garfo. Como ele é um cavalheiro ele não pega o garfo. Mas F2 está na mesma situação e dá a $F 3$ a oportunidade de pegar o garfo. Após esta gentileza eles tentam pegar o garfo novamente, e a situação se repete infinitamente [SCH99].

- Espera Infinita: é um problema muito comum em programas paralelos, nela existe um processo esperando por uma mensagem que nunca ocorrerá, independentemente dos outros processos estarem bloqueados ou não. Como não existe um laço contendo vários processos bloqueados, não chega a caracterizar um problema de deadlock.

Além dos erros concorrentes o Não-Determinismo (Non-determinism) tende a fazer o entendimento, a escrita e a depuração de programas paralelos uma tarefa mais difícil que de programas seqüenciais [MCD89]. Programas seqüenciais são determinísticos, ou seja, dadas as mesmas entradas, os resultados são sempre os mesmos. Entretanto, programas concorrentes nem sempre reproduzem o mesmo comportamento. Esta situação é particularmente difícil, pois o programador freqüentemente tem pouco ou nenhum controle sobre isso. 
Como resultado do não determinismo em programas concorrentes, há um fenômeno chamado de Efeito de Intrusão (Probe Effect), que resulta do fato da observação de um programa concorrente poder afetar o comportamento do mesmo, ou seja, a tentativa de ganhar mais informações sobre o programa pode contribuir para que o comportamento errôneo do programa não ocorra novamente. Por exemplo, se um programa concorrente apresenta um erro de sincronismo, a simples inserção de uma linha de verificação ou a própria ação do depurador pode influenciar no comportamento do programa, sincronizando as tarefas. Esta interferência pode ser desastrosa na tentativa de diagnosticar um erro em um programa paralelo [MCD89].

A Condição de Disputa é um erro difícil de se depurar, já que ele é não determinístico, podendo ocorrer apenas uma vez em centenas de execuções. O erro é sutil, e na maioria dos casos não ocorre se o comportamento do programa é modificado utilizando uma ferramenta de depuração. Uma situação de deadlock pode, na maioria das vezes, ser detectada usando um depurador que possa se ligar a um programa em execução. Cada tarefa é examinada e o deadlock normalmente pode ser localizado rapidamente. Para depuração, a situação livelock é similar ao deadlock. Enquanto as tarefas estão negociando, vários recursos (como por exemplo, memória) vão sendo alocados até um ponto em que não se tornam mais disponíveis, e o programa trava.

Além dos erros concorrentes apresentados acima, outras características dificultam o entendimento, a construção e a depuração de programas paralelos (principalmente sobre sistemas distribuídos) [MOL84] [BAI86]. São elas:

- Tipo do processo: o fato de que o sistema tem vários pontos de controle, o toma mais difícil de entender e mais propenso a erros. As características de cada tipo de processo interferem na velocidade de processamento e não permite afirmar com precisão a ordem em que os eventos ocorrerão. Um processo pode necessitar somente da utilização da CPU ( $C P U$-bound), e o seu tempo de execução depende exclusivamente da velocidade do processador e o tempo de espera na fila. Outro tipo de processo (I/O-bound) possui a característica de realizar muito acesso aos mecanismos de armazenamento de informação, como acontece nos sistemas de gerência de banco de dados. Os processos podem ainda conter ambas as características, o que é muito comum [TAN92]. 
- Vários processadores: o tempo gasto para a execução de cada tarefa pode resultar em um comportamento diferente no sistema como um todo, pois depende da velocidade e da quantidade de processadores no ambiente paralelo. Como cada processo que compõe um programa paralelo pode rodar em diferentes processadores físicos, torna-se ainda mais difícil a descoberta do comportamento errôneo do programa e a gerência dos processos de depuração. Outro fator importante, com relação a existência de vários processadores, é que uma falha de hardware pode causar um erro na execução. E o programador pode não estar ciente que um processador está falhando e causando o comportamento errôneo no sistema.

- Tempo de comunicação: os processadores nos quais um programa paralelo roda, podem estar geograficamente dispersos. Isto pode provocar atrasos significantes na comunicação tornando algumas operações de depuração impraticáveis. O grande problema nos programas paralelos é que um erro pode se propagar bastante, até que seja detectado.

- Tamanho do Sistema: os sistemas paralelos tendem a ser grandes, possuindo um número de processos e de processadores elevados, e con muito mais recursos envolvidos. Assim, quanto maior o sistema, mais difícil é sua depuração, pois é difícil realizar testes que possam gerar todos os caminhos possíveis. Em sistemas maiores, também, mais informações devem ser manipuladas durante a depuração.

- Baixa visibilidade: a ordem de execução das instruções pertencentes a diferentes processos do programa não pode ser deduzida, principalmente rodando sobre sistemas distribuídos.

- Estado Global: o conceito de "estado global" é um problema adicional encontrado em sistemas distribuídos. Sem uma sincronização global do clock, pode ser difícil determinar a ordem precisa em que os eventos estão ocorrendo em processadores diferentes [CHE90].

\subsection{Teste de Software}

Teste é um conjunto de atividades que pode ser planejado antecipadamente e realizado sistematicamente [PRE95]. A atividade de teste é um estágio importante do desenvolvimento de software, sendo um elemento crítico da garantia de qualidade de software. Esta atividade 
corresponde a aproximadamente $50 \%$ do esforço e do custo de desenvolvimento de software, podendo seu custo ser mais elevado dependendo do tipo de software que está sendo testado.

A atividade de teste constitui uma anomalia interessante para o engenheiro de software, pois nesta fase ele cria uma série de casos de teste que têm como objetivo "demolir" o software que ele construiu. Contudo, verificando os objetivos da atividade de teste pode-se perceber que isto é bem diferente [PRE95].

A atividade de teste pode ser conduzida por três objetivos básicos [PRE95]:

1. Executar um programa com a intenção de descobrir um erro.

2. Um bom caso de teste tem uma elevada probabilidade de revelar um erro ainda não descoberto.

3. Um teste bem sucedido revela um erro ainda não descoberto.

Os objetivos acima vão contra um ponto de vista comumente defendido de que um teste bem sucedido é aquele em que nenhum erro é encontrado. Mas o objetivo é projetar testes que descubram sistematicamente diferentes classes de erros, com uma quantidade de tempo e esforço mínimos.

Há muitas taxonomias propostas para métodos de teste de software. Se um teste requer análise do controle e ou construção de dados do programa, o teste é chamado de teste estrutural (ou teste de caixa branca), e se a análise for sobre os requisitos funcionais do software tem-se o teste de caixa preta. Se o teste de programa especifica somente as entradas para o programa, ele é considerado program-based (baseado no programa), enquanto que se uma especificação formal está disponível para geração de casos de teste, o teste de software é conhecido como specification-based (baseado na especificação) [YAN96].

Como primeiro passo para estruturação de teste de software, caminhos específicos são produzidos baseados em vários critérios. Formalmente, um caminho é uma sucessão de vértices e extremidades começando de um nó inicial de um grafo de fluxo de programa até um nó final. O programa é então executado para gerar um conjunto de testes associados com esses caminhos. Se um caminho não pode ser coberto, devido à existência de um conflito gerado por algum nó no caminho, este caminho é chamado de caminho infectado. 
Para testar um programa, os testes devem ser preparados conforme algum critério de cobertura e então o programa é executado com o teste. Entre os métodos de critério de cobertura pode-se citar: todos os nós, todos os ramos e todos os caminhos [MAL91].

\subsubsection{Teste de Programas Paralelos}

Teste é uma das mais práticas e eficazes características para validação de software. Vários métodos, técnicas e ferramentas têm sido propostos para dar suporte aos usuários de teste. Porém, a maioria deles são especificamente projetados para programas seqüenciais que possuem uma execução determinística, e aplicados em programas concorrentes podem criar novos problemas [YAN92].

Quando programas paralelos são incluídos no domínio de teste, muitos algoritmos e métodos de teste para programas seqüenciais falham, principalmente devido à natureza intrínseca das linguagens paralelas e a falta de padronização de linguagens de programação em ambientes de passagem de mensagem e ambientes com memória compartilhada.

Outro fator que dificulta o teste de programas concorrentes é o não-determinismo. Embora esse assunto seja essencial para teste de programas paralelos, a motivação não é descobrir uma falha ou gerar um caso de teste. A motivação para resolver esse problema é simplesmente ser capaz de reproduzir uma execução específica usando os mesmos dados de entrada. Este é chamado de teste de reprodução (reproducible testing).

O teste de programas paralelos demanda um critério de teste adicional que enfoque $o$ teste relacionado às comunicações entre os processos. Esses testes devem incluir os testes de sincronização e comunicação, além do teste de reprodução descrito anteriormente. Para se testar programas paralelos pode-se seguir os passos do teste de software:

- Teste de tarefas: o primeiro passo da atividade de testes de software consiste em testar cada tarefa independentemente. Ou seja, testes de caixa preta e de caixa branca são projetados e executados para cada tarefa. O teste de tarefas revela erros de lógica e de função, mas não revelará necessariamente erros comportamentais ou erros de comunicação e sincronização.

- Teste comportamental: usando modelos de sistema criados com ferramentas CASE, é possível simular o comportamento de um sistema. Essas atividades de 
análise podem servir como base para o projeto de casos de teste que será realizado quando o software for construído.

- Teste intertarefas: assim que os erros em tarefas individuais e no comportamento do sistema tiverem sido isolados, a atividade de teste desvia-se para erros relacionados à sincronização e comunicação entre as tarefas. As tarefas assíncronas são testadas com diferentes taxas de dados e cargas de processamento para determinar se ocorrerão erros de sincronização intertarefas.

- Teste do sistema: o software e o hardware são integrados e uma variedade completa de testes de sistema é levada a efeito, numa tentativa de descobrir erros na interface software/hardware.

Diversas pesquisas têm sido realizadas para criação de casos de teste e análise estática de programas paralelos, bem como a redução dos custos nesta fase [BYE97] [YAN92] [YAN96].

\subsection{Depuração de Programas Paralelos}

O termo depuração pode ser definido como o processo de localização, análise e correção de uma falha suspeita. Onde a falha é definida como uma condição acidental. A depuraçāo (debugging) ocorre em conseqüência de testes bem sucedidos [PRE95], sendo um passo essencial no desenvolvimento de software, já que todos os sistemas não triviais contêm erros.

Independentemente da abordagem que se considera, a depuraçāo tem como objetivo primordial descobrir e corrigir a causa de um erro de software. O objetivo é atingido por meio da combinação de avaliação sistemática, intuição e sorte [PRE95]. Por isso, a depuração é considerada até certo ponto muito mais uma arte que uma ciência.

\subsubsection{Organização dos Depuradores de Programas Paralelos}

As técnicas de depuração paralela podem ser organizadas em quatro grupos [MCD89]:

- Técnicas de Depuração Tradicional: podem ser aplicadas com algum sucesso para programas paralelos (Seção 3.4.1.1). 
- Depuradores Baseados em Eventos: apresentam a execução de um programa paralelo como uma seqüência (ou várias sequiências paralelas) de eventos (Seção 3.4.1.2).

- Técnicas para Apresentação do Fluxo de Controle: apresentam o fluxo de controle e a distribuição dos dados associados com o programa paralelo (Seção 3.4.1.3).

- Técnicas de Análise Estática: baseada na análise do fluxo de dados dos programas paralelos, permitindo a detecção de erros sem a execução do programa (Seção 3.4.1.4).

\subsubsection{Técnicas de Depuração Tradicional}

A extensão de depuradores tradicionais para programação paralela utiliza uma coleção de depuradores seqüenciais, um para cada processo paralelo. É a técnica mais fácil de se implementar e portanto a que proporciona uma solução mais rápida.

Esta técnica de depuração não evita o probe effect, devido à necessidade de interação do programa de depuração com o sistema examinado. Outra grande desvantagem, é que em programas com muitos processos concorrentes, se torna muito difícil identificar e compreender o que realmente esta acontecendo com os processos.

A primeira diferença entre os depuradores paralelos que implementam esta técnica, está em como as saídas dos vários depuradores seqüenciais são mostradas e como os depuradores são controlados. Entre as técnicas de depuração seqüencial, utilizadas na implementação de depuradores de programas paralelos, pode-se citar [CHE90]:

- Depuração de Saída: é a técnica de depuração mais primitiva, mais fácil de se implementar, e provavelmente todo o programador já utilizou. A depuração de saída consiste na apresentação dos estados das variáveis durante a execução do programa. Vantagem: exibe somente saídas simples e os dados selecionados, simplificando a análise. Contudo, ela possui algumas desvantagens:

- As saídas devem ser observadas nos múltiplos processos ao mesmo tempo, o que é difícil em programas com um grande número de processos.

- Exige um bom conhecimento de todo o programa, para escolher o lugar apropriado em que as saídas serão inseridas.

- Requer modificações no programa provocando o probe effect. 
- Tracing: esta técnica utiliza um sinal facilmente fornecido pelo sistema operacional, compilador ou ambiente de programação para apresentar informações selecionadas e que pode ser habilitado ou desabilitado. Possui as mesmas vantagens e desvantagens da depuração de saída, e quando trabalhando sobre um sistema distribuído enfrenta os problemas da dificuldade de se ter um estado global.

- Breakpoints: é um ponto no fluxo de execução onde um processo é suspenso e algumas informações são salvas (ponto de parada). O status da execução e o valor dos dados podem ser examinados e modificados; a execução pode ser controlada e informações a serem exibidas podem ser selecionadas. Esta técnica não requer código extra no programa, o que evita alguns efeitos indesejados na depuração paralela. A principal desvantagem é a necessidade de se inserir os breakpoints em lugares apropriados do programa e examinar os dados importantes. Depuradores paralelos tradicionais, geralmente suportam algum tipo de breakpoint encontrado nos depuradores seqüenciais.

- Controle de Execução: o controle de execução permite analisar eventos concorrentes em uma ordem esperada. Alguns erros que estão ocorrendo no sistema podem desaparecer durante o controle de execução, devido à alteração do sistema.

\subsubsection{Depuradores Baseados em Eventos}

Depuradores Baseados em Eventos apresentam a execuçāo de um programa paralelo como uma seqüência (ou várias seqüências paralelas) de eventos. Os eventos podem ser divididos em duas classes: atividade de comunicação entre processos e atividade intema para um único processo.

Alguns sistemas apresentam os eventos à medida que estão ocorrendo, mas uma característica importante é a construção de um histórico de eventos contendo todos os eventos gerados pelo programa. O histórico pode ser usado pelo usuário para examinar o comportamento do programa após ele ter terminado, e se um erro for encontrado o usuário pode executar o programa utilizando o histórico como guia, permitindo a reprodução do comportamento errôneo. Finalmente, em sistemas grandes o depurador pode filtrar os dados do histórico facilitando sua consulta. 
A quantidade de informação registrada para cada evento depende de como o histórico de eventos será manipulado. Basicamente o histórico de eventos é manipulado de três maneiras:

- Consulta (Browsing): utiliza o histórico para encontrar um determinado evento, requer o mínimo de informação necessária. Frequientemente os históricos possuem um grande número de eventos, o que dificulta sua localização. Para solucionar esse problema, alguns sistemas permitem selecionar informações, e outros incluem poderosos mecanismos para examinar o histórico.

- Replay: o depurador usa o histórico de eventos para controlar uma nova execução do programa. Requer muitas informações para que os eventos de cada processo possam ser determinados.

- Simulação: o histórico de eventos pode ser usado para simular um único processo, permitindo o uso de um depurador seqüencial sem necessitar executar todo o programa. A execução de um único processo requer mais informações que a execução de todo sistema, pois o conteúdo das mensagens e os valores das variáveis compartilhadas também devem ser armazenados no histórico.

Em adição, o histórico de eventos gerado pode ser comparado com um conjunto prédefinido de atributos, e se um desses atributos é violado o depurador pode ser ativado.

\subsubsection{Técnicas para Apresentação do Fluxo de Controle}

Programas seqüenciais possuem apenas um thread ${ }^{2}$ em execução que pode ser mostrado exatamente como um texto sequiencial. Seus dados também podem ser armazenados em apenas um lugar e visualizados quando desejar. Contudo, em programas paralelos múltiplos threads de controle e dados podem estar logicamente como também fisicamente separados.

Quatro técnicas básicas para exibir informações da depuração de programas paralelos podem ser citadas:

- Representação Textual dos Dados: é o tipo mais comum para visualização, todos os sistemas fazem uso da representação simples em modo texto. Sua apresentação pode envolver cor com o objetivo de apresentar o fluxo de controle da informação.

\footnotetext{
${ }^{2}$ Um thread é um único fluxo de controle dentro de um programa.
} 
- Diagramas Processo x Tempo: é uma representação bidimensional do estado de um sistema paralelo sobre o tempo. Cada ponto na tela fornece informaçōes referentes ao estado do processo no tempo correspondente. Sua limitação está no número de processos que pode exceder o tamanho da tela, e ser resolvido através da filtragem de processos.

- Animação: a animação do programa em execução é uma alternativa para representação anterior, na qual ambas as dimensões são espaciais, mostrando imagens específicas do programa em intervalos de tempo. O estado do sistema é apresentado a cada instante em que é modificado, gerando um tipo de animação. A posição dos processos pode ser arbitrária, sob controle do usuário ou em função da estrutura do programa. Alguns sistemas permitem controlar o tempo de apresentação de cada imagem e exibir o conteúdo de mensagens trocadas entre os processos.

- Múltiplas Janelas: permite a visualização de várias imagens do programa sendo depurado, freqüentemente usando uma janela para cada processo.

Nenhuma dessas técnicas, usadas isoladamente, é suficiente para detectar todos os erros em programas paralelos. A animação permite uma boa visão dos estados do sistema em um determinado instante, e para um único instante de tempo, mais informações podem ser apresentadas simultaneamente. Já o diagrama processo $\mathrm{x}$ tempo apresenta padrões de comportamento em função do tempo, e torna-se útil para descobrir problemas relacionados a desempenho. A principal desvantagem desta abordagem é que poucas informações podem ser mostradas para cada processo em um determinado instante de tempo.

\subsubsection{Técnicas de Análise Estática}

Os depuradores baseados na técnica de análise estática não apresentam a etapa de teste, pois não necessitam da execução do programa. A análise é feita checando as falhas estruturais ao invés de se verificar as falhas funcionais permitindo a eliminação de erros antes que eles ocorram.

A técnica de análise estática é bastante utilizada em depuração paralela para detecção de certas classes de erros, principalmente quando o probe effect torna as técnicas anteriores inúteis. Basicamente a análise estática é usada para detectar duas classes de erros: problemas de sincronização e problemas nas operaçōes com dados. 
O problema de sincronização permite localizar erros como deadlock e espera infinita. Problemas nas operações com dados incluem os erros comuns aos programas sequienciais (como variáveis não inicializadas) e erros paralelos, causados pelo acesso simultâneo a uma variável compartilhada. O problema básico com a maioria dos algoritmos para a análise estática é que geralmente, no pior caso, a complexidade do algoritmo é exponencial.

\subsubsection{Combinando Análise Estática com Depuração Dinâmica}

A análise estática pode ser produtivamente combinada com a depuração dinâmica. Uma forma de combinar as duas técnicas é gerar casos de testes com análise estática para uso em conjunto com um depurador dinâmico. Com isso, as informações da monitoração dinâmica podem ser usadas para guiar uma análise estática parcial, pois a análise estática completa produz muitos estados.

Com a combinação dessas técnicas, se um trecho do programa é analisado estaticamente e nenhum erro é encontrado ele não precisa ser monitorado pela técnica dinâmica. O que deve reduzir a sobrecarga introduzida com a monitoração. Esta união pode apresentar boas soluções e diversos pesquisadores têm apresentado técnicas que combinem o uso da análise estática e dinâmica [MCD89].

\subsubsection{Monitoração}

Monitoração é o processo de reunir informações de um programa em execução. Muitos pesquisadores fazem distinção entre monitoração e depuração tradicional, mas como o objetivo da monitoração é de localizar comportamentos incorretos, ela pode ser considerada como uma ferramenta de depuração [MCD89].

Após o teste e depuração de um programa paralelo, por algum tempo, pode-se analisar o comportamento do programa em execução. A idéia básica é de prover ao programador um resumo, em tempo real, do sistema em execução. Várias informações, tais como status dos processos e nós, tráfego de informações e as transações, são úteis para observar a performance do sistema e descobrir problemas ou outros comportamentos anormais [MOL84].

As informações sobre performance do sistema podem ser coletadas pelo sistema operacional de cada computador, e incluem valores como média de tamanho das filas, utilização da CPU, e status dos processos. Os outros tipos de informações úteis para observar 
o comportamento do sistema podem obter, entre outros, o status das transações e o número de deadlocks detectados.

Examinar os registros gerados na monitoração é muito difícil e requer muita experiência, principalmente em sistemas relativamente grandes. Para reduzir a quantidade de informações a serem examinadas, um monitor pode usar a técnica de filtering, que ignora dados irrelevantes para depuração concorrente. Os dados podem ser filtrados de duas maneiras: display filtering e data filtering. Em display filtering, todos os dados são armazenados, mas somente os dados selecionados são mostrados. E em data filtering apenas os dados relevantes são armazenados. Contudo, ele pode não salvar dados suficientes para reconstruir o comportamento original [CHE90].

Quando um comportamento indesejado é observado durante a monitoração, a identificação do erro é mais difícil. Se não existir informações suficientes para refazer o comportamento de erro, o sistema terá que ser testado até que o erro ocorra novamente.

\subsection{Estudo de Caso}

Diversas ferramentas para depuração de programas concorrentes têm sido desenvolvidas nos últimos anos, uma descrição mais detalhada destas ferramentas pode ser obtida em [DEN97]. Na tentativa de definir um padrão para essas ferramentas, em março de 1997 foi criado o High Permormance Debugging Forum (HPDF). O HPDF é formado por pesquisadores e empresas da área de computação paralela e de alto desempenho, os principais objetivos da primeira versão do HPDF são [HPD98]:

- Capturar o conhecimento e a experiência dos depuradores paralelos implementados pela indústria.

- Estabelecer um conjunto bem definido de características que possam ser implementadas em todos os sistemas HPC (High-performance Computing).

- Assegurar que o depurador paralelo implementado provê um conjunto de características em um modo consistente.

Essa primeira versão descrita pelo HPDF, define um padrão de uma interface de depuração de programas paralelos baseado em comandos. Em uma próxima versão será utilizada interface gráfica. 
Nessa seção é apresentado o TotalView [DEN97], uma ferramenta de depuração para programas paralelos.

\subsubsection{TotalView}

O TotalView é um depurador para programas paralelos escrito em $\mathrm{C}, \mathrm{C}++$, Fortran, e ainda PVM e MPI. Apesar de possuir uma interface gráfica, a depuração é apresentada de maneira textual e dividida em várias janelas. As principais janelas apresentadas são:

- Root Window: lista de todos os processos sobre o controle do depurador.

- Process Window: exibe o código fonte e algumas informações de cada tarefa.

- Variable: mostra o endereço, o tipo e o valor de uma variável local, registrador ou variável global.

As características especiais apresentadas pelo TotalView para depuração de programas paralelos são:

- Configuração da aplicação e uma janela de verificação separada para cada tarefa.

- Possui a definição de grupos de processos, que são constituídos por todos os processos de um programa alvo.

- Implementa breakpoints flexíveis, permitindo que os pontos de parada sejam compartilhados entre os processos relacionados.

Para PVM e MPI existem novas janelas baseadas nas características de cada biblioteca de comunicação. Para PVM existe a PVM Task e Configuration Window, que apresenta a configuração do sistema e uma lista de tarefas em exẹcução. E para MPI, foi criada a Message State Window, que apresenta o estado de todas as comunicações existentes num processo MPI.

\subsection{Considerações Finais}

Escrever programas paralelos eficientes é uma tarefa bastante difícil, sendo possível, até mesmo, escrever um programa paralelo que seja menos eficiente que sua versāo seqüencial. Programação paralela apresenta um nível a mais de complexidade que a programação seqüencial uma vez que programas paralelos devem expressar não somente a 
computação seqüencial, mas também as interações (comunicação e sincronização) entre os processos que envolvem a aplicação [MOR00].

Além disso, para programas seqüenciais, existem diversas ferramentas que auxiliam a correçáo de erros e várias técnicas para se desenvolver um software com uma pequena quantidade de erros. Entretanto, em programas paralelos esses tipos de ferramentas e técnicas para não permitir certos tipos de erros praticamente não existem.

O que normalmente se encontra são métodos que auxiliam na elaboração de software paralelo, contudo, ferramentas que ajudam o usuário na busca e tratamento de erros não são facilmente encontradas. Para que a programação paralela possa explorar e alcançar um ganho de performance, ferramentas para depuração, teste e gerenciamento desses programas paralelos são necessárias. 


\section{Representação de Programas Paralelos}

Esse capítulo discute os benefícios que podem ser obtidos com a representação gráfica de programas paralelos e qual a melhor maneira para esta representação. Os principais tópicos apresentados são: representação de programas paralelos, programação paralela visual, e depuração em ambiente de programação paralela visual.

\subsection{Considerações Iniciais}

Representações gráficas são aspectos úteis e comuns em ambientes de programação paralela, mas geralmente elas se limitam a exibir a execução, comportamento, ou estrutura dos programas paralelos que são expressos convencionalmente como texto. O conceito de programação visual com grafo direcionado não é novo. Porém, somente nos últimos anos que um impacto significante vem sendo alcançado.

Há muitas vantagens com a utilização de grafos para representação de programas paralelos, entre elas [BRO94]:

- Grafos são uma representação mais natural para programas paralelos que uma representação textual, pois o comportamento de programas paralelos é inerentemente multidimensional.

- Uma linguagem de programação baseada em grafos pode separar a programação em dois processos distintos: criar os elementos de programação seqüencial e compor esses elementos em um programa paralelo completo.

- Grafos exibem diretamente a estrutura que os programadores devem entender para alcançar bom desempenho em seus programas.

- Ferramentas para depuração, teste, e simulação podem ser integradas nitidamente em um único ambiente visual.

Essas vantagens são discutidas nas próximas seçōes.

\subsection{Grafos}

Um grafo $G(V, A)$ é um conjunto finito não vazio de vértices $V, e$ um conjunto $A$ (arestas) de pares não ordenados de elementos distintos de $V$. Um grafo direcionado 
(dígrafo) $\mathrm{D}(\mathrm{V}, \mathrm{A}$ ) consiste de um conjunto finito não vazio de vértices $\mathrm{V}$ e um conjunto $\mathrm{A}$ (arestas) de pares ordenados de vértices distintos. Cada aresta ( $V, W$ ) possui uma única direção de $v$ para $w$, onde $(v, w)$ é divergente de $v$ e convergente a $w$ [FUR73].

Os grafos constituem uma ferramenta básica para modelar fenômenos discretos e são fundamentais para a compreensão das estruturas de dados e análise de algoritmos. A Figura 4.1 apresenta os grafos que representam as estruturas básicas de um programa [MOR00].

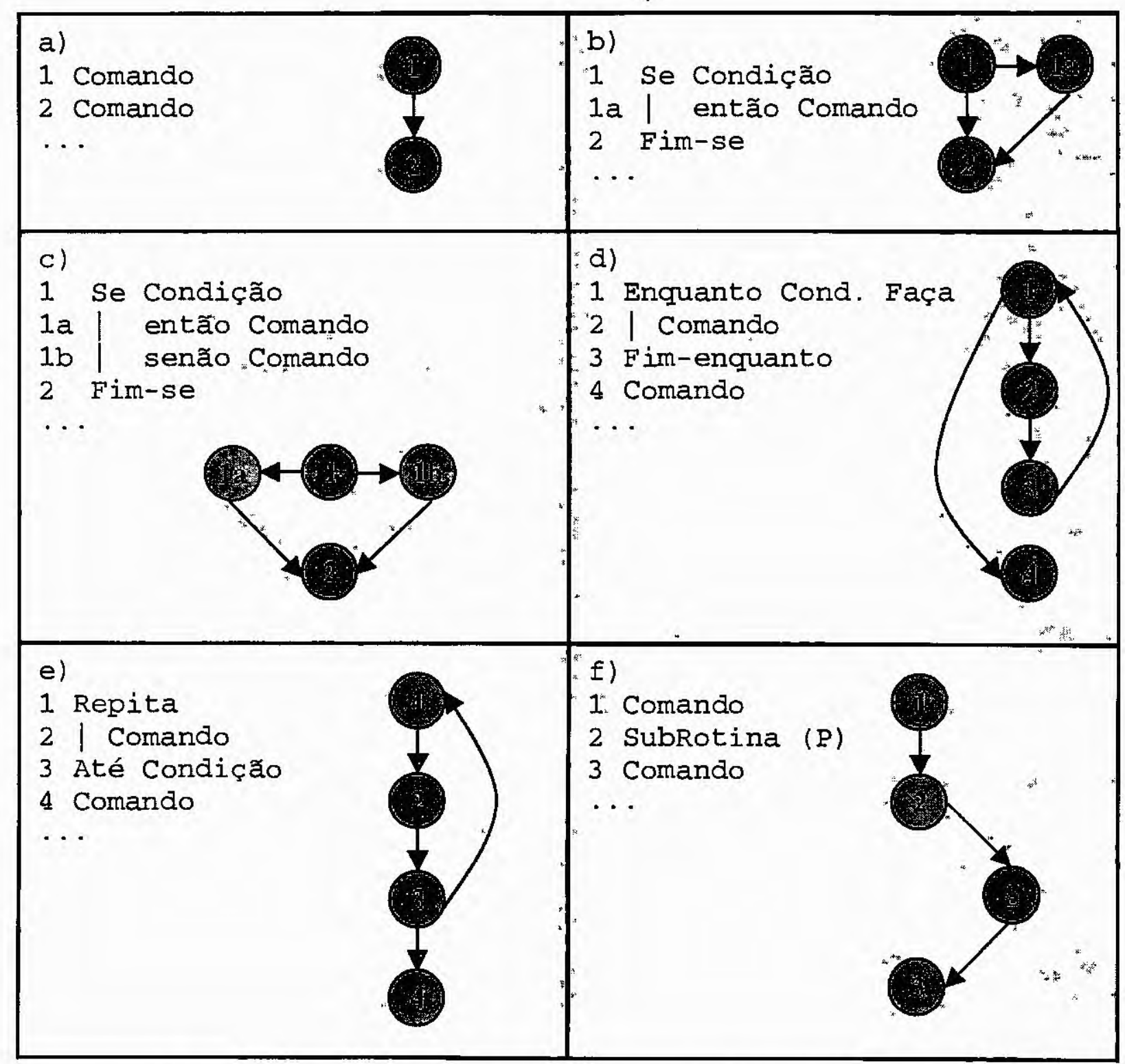

Figura 4.1 - Estrutura dos algoritmos e a representaçāo através dos Grafos 


\subsection{Programas Paralelos são Grafos}

A representação e o comportamento de programas paralelos são naturalmente multidimensionais. Essa estrutura, para o programa e suas execuções, é efetivamente representada por grafos direcionados. Grafos direcionados permitem ao programador um melhor "relacionamento" com o comportamento do programa [BRO94].

As Seçōes 4.3.1 e 4.3.2 apresentam dois exemplos que demonstram a representação de programas paralelos como grafos.

\subsubsection{Representação Direta de Paralelismo Implícito}

A Listagem 4.1 exibe um trecho de código de uma seqüência de tarefas. Em programas sequienciais as tarefas apresentam uma interpretação óbvia e implica na seguinte execução: 1-2-3-4.

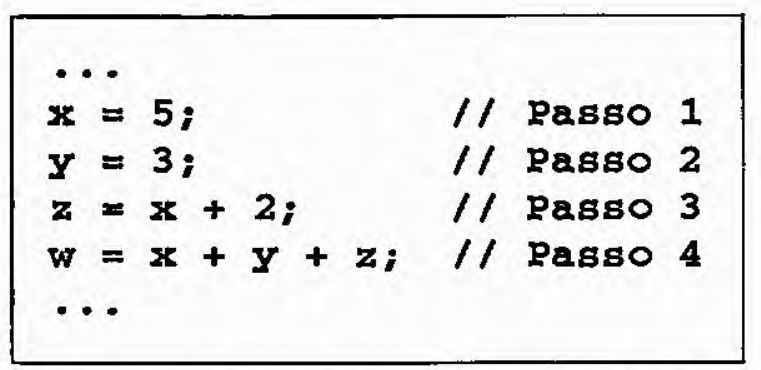

Listagem 4.1 - Programa exemplo para representação de paralelismo

Como alguns dos passos são independentes e não acessam variáveis comuns, esse programa pode ser escrito e visualizado como um programa paralelo. Por exemplo, os passos 1 e 2 podem ser executados em paralelo ou em outra ordem. Com isso, diversas sequiências de execução podem ocorrer, embora nem todas explorem paralelismo máximo. Algumas das sequiências válidas sāo: 1-2-3-4, 2-1-3-4, 1-3-2-4 e 1\|l2-3-4 (1 || 2 significa que os passos 1 e 2 são executados em paralelo).

Listar todos os caminhos possíveis é um tanto quanto incômodo para entender esse programa. Por exemplo, o passo 2 pode também rodar em paralelo como o passo 3 , desde que - passo 1 termine de executar antes. Contudo, uma representação através de grafos nitidamente resume o comportamento do programa, como pode ser observado na Figura 4.2. 


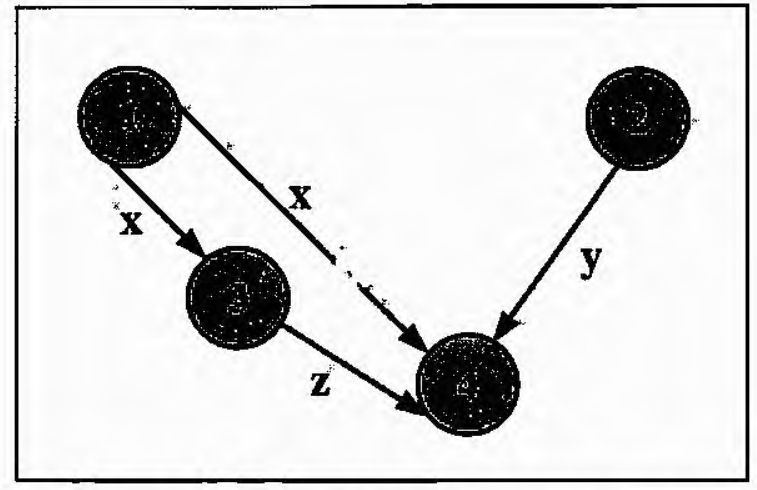

Figura 4.2 - Grafo do programa exemplo

Os nós representam os comandos e os arcos mostram o fluxo dos dados. Dois nós podem executar em paralelo se não existe um caminho entre eles.

\subsubsection{Exemplo com Passagem de Mensagem}

O exemplo da Seção 4.3.1 mostra a representação natural de paralelismo implícito em um grafo direcionado. Essa representação natural também é verdadeira para visualização de paralelismo direto.

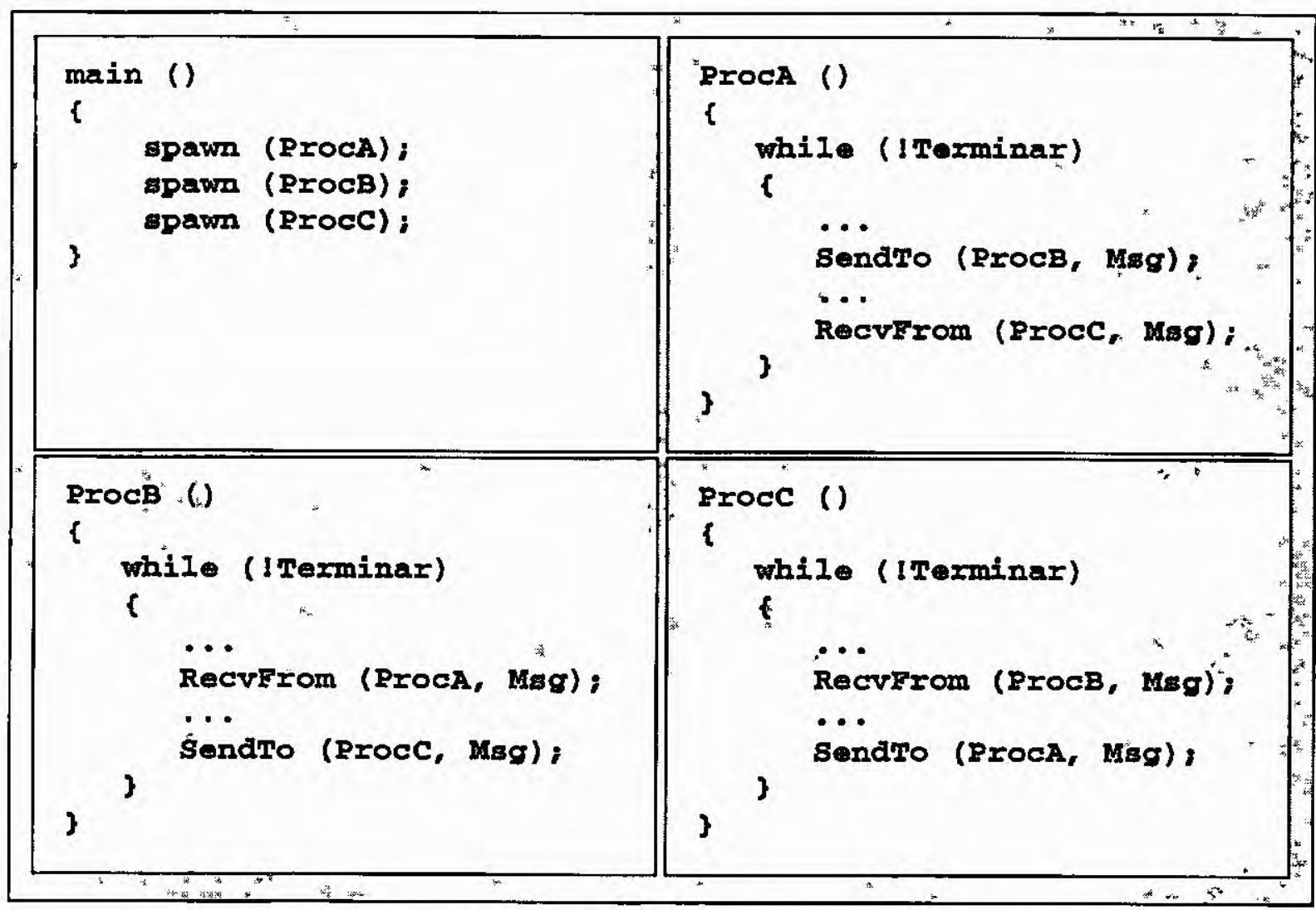

Figura 4.3 - Exemplo de um programa com Passagem de Mensagem 
Um exemplo é exibido na Figura 4.3, onde se tem um programa principal (Main) que ativa três processos paralelos (ProcA, ProcB e ProcC). Esses processos por sua vez executam por tempo indefinido efetuando a cada ciclo operações de comunicação.

As ferramentas de visualização gráfica freqüentemente representam o comportamento do programa por meio de um diagrama, que mostra as mensagens sendo enviadas de um processo para outro. A Figura 4.4(a) mostra esse diagrama, e 4.4(b) sua representação como grafo, mostrando o fluxo de instruções e as comunicações entre os processos. Os nós verdes representam um comando de envio de uma mensagem (SendTo) e os vermelhos um comando de recebimento (RecvFrom). As setas azuis indicam a comunicação.

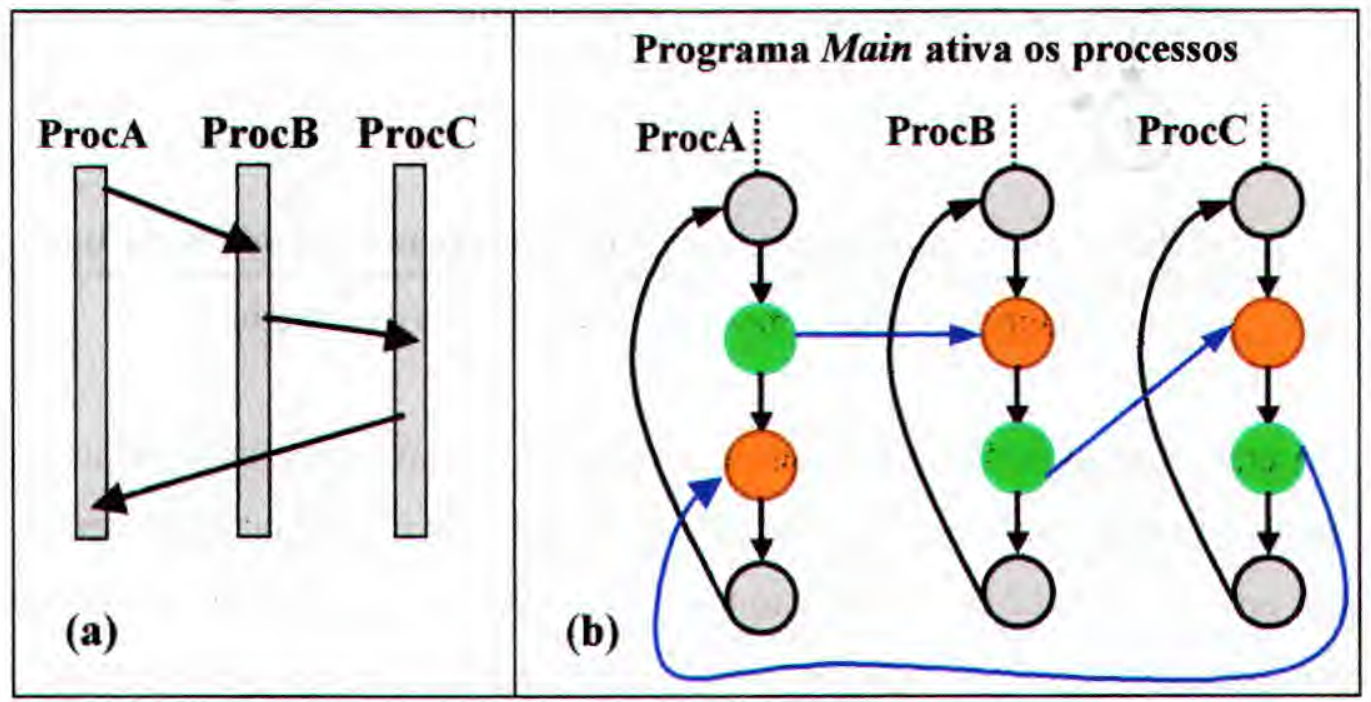

Figura 4.4 - Exemplo com Passagem de Mensagem

\subsection{Programação Paralela Visual}

Os grafos direcionados podem ser usados como base para uma linguagem de programação, reduzindo a distância entre a representação e o comportamento. Estas linguagens possuem icones específicos que representam os "tipos de computações" (por exemplo: loop, condição de parada, enquanto, repita e comunicações) de um programa [BRO94].

Os grafos podem mostrar também outras informações que são vitais para o entendimento e para o desempenho dos programas paralelos. Assuntos como balanceamento de carga inadequado ou grau de paralelismo inadequado podem ser facilmente visualizados 
nos grafos. A Figura 4.5 mostra dois exemplos, os números nos nós representam o tempo de execução.

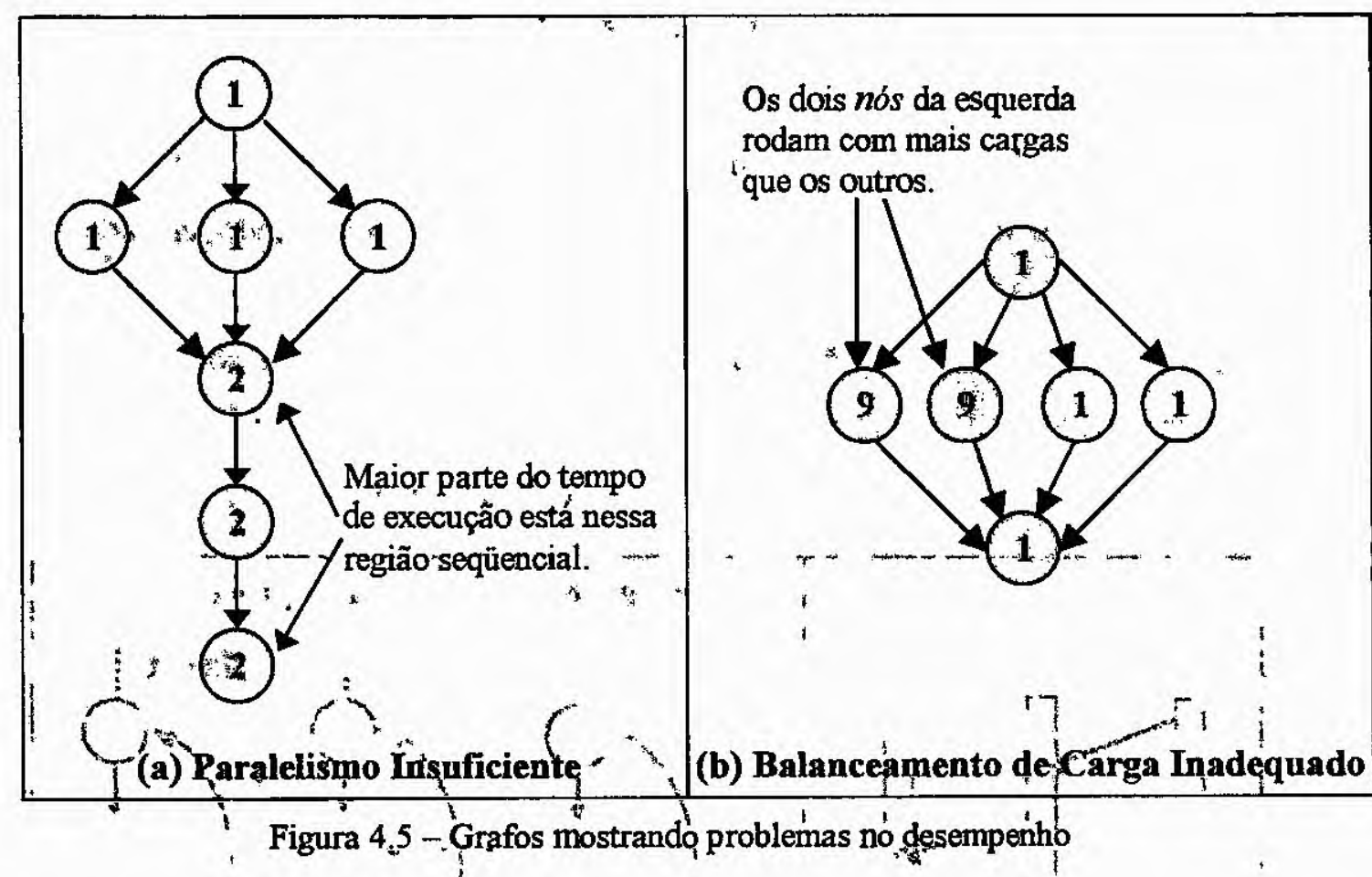

O grafo da Figura 4.5(a) representa um/ programa com paralelismo insuficiente, pois a maior parte dót tempo ele executa de maneirá seqüencial. Se não existir' dependência entre os nós, eles podém ser exécutados em parafélo. Outro problema que pode ser visualizado no grafa' da Figura 4.5(b) é um balanceamento de carga inadequado, nesse exemplo tois nós demoram nove unidades de tempo para executar, enquanto que outros dois consomem apenas uma unidade.

O modelo de grafos também traz vantag̈ens para o uso de técnicas avançadas de escalonamento, já que os componentes são freqüentemente organizados em grafos acíclicos direcionados e o tempo de execução dos componentes pode ser fixado. Além disso, características da execução de elementos são fáceis para se definir e medir já que eles são encapsulados. Esse encapsulamento pode também simplificar o escalonamento dinâmico (em tempo de execução) já que o estado dos elementos é fixad́o entre execuções. 


\subsection{Depuração em Ambiente de Programação Visual}

O suporte a depuração de programas paralelos é um dos maiores benefícios dos ambientes visuais baseados em grafos direcionados. Os principais motivos que simplificam a tarefa de depuração nesses ambientes são [BRO94]:

- Permite ao programador pensar em termos de como o programa funciona, acompanhando visualmente o comportamento do programa.

- Facilita a identificação de falhas lógicas no programa.

- Permite automatizar diversas tarefas, de maneira mais fácil, como por exemplo à tediosa tarefa de comparar o comportamento esperado com o real.

Um ambiente de programação visual provê uma representação gráfica consistente para todas as entidades diferentes usadas no processo de depuração e simplifica o projeto de depuradores concorrentes. Ele também provê um ambiente para suportar diferentes facilidades na depuração de programas concorrentes como execução e visualização de históricos e animação.

\subsection{Estudos de Caso}

Nessa seção são apresentadas duas linguagens de programação paralela visual, enfocando o funcionamento de suas representações gráficas. CODE e HeNCE são bem parecidas no propósito e na filosofia geral, mas são significativamente diferentes em detalhes [BRO94].

\subsubsection{CODE 2.0}

Para criar um programa paralelo em CODE, o programador desenha com o mouse um grafo e entra com as anotações textuais em diferentes janelas pop-up associadas com vários objetos como nó, arco, etc. Essas informações incluem itens familiares como definições de tipos e funções ou procedimentos. Quando termina as anotações a opção "Translate" do menu cria o programa paralelo, com um Makefile, pronto para ser construído e rodar na máquina paralela selecionada.

A linguagem CODE apresenta vários tipos de nós diferentes, cada um com seu próprio ícone e propósito (Figura 4.6). Muitos dos ícones são usados para definir a interface do grafo. 


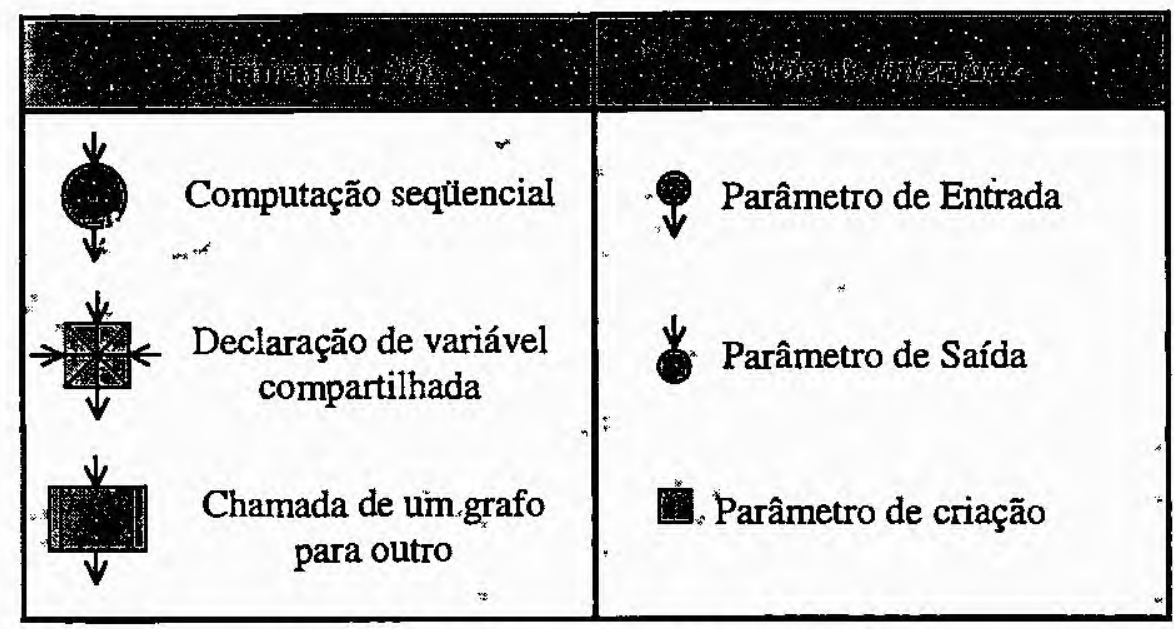

Figura 4.6 - Ícones dos nós em CODE

Em CODE um grafo pode chamar outro através do ícone de chamada, por isso existem os ícones que definem a interface dos nós, que são os parâmetros de saída, entrada e criação. O ícone de variável compartilhada é usado para declarar variáveis que podem ser compartilhadas entre um conjunto de nós. Cada nó deve especificar se o acesso a variável é somente de leitura ou leitura e escrita.

\subsubsection{HeNCE 2.0}

A linguagem HeNCE não tem facilidade para implementação hierárquica, e os grafos não podem chamar outros grafos, assim não há necessidade de nós para interface. Mas outros tipos de nós são implementados, como pode ser observado na Figura 4.7. Os arcos não requerem anotação como em CODE.

\begin{tabular}{|c|c|}
\hline & Computação Seqüencial \\
\hline & $\begin{array}{l}\text { Loop Begin e End (o subgrafo é repetido sobre um índice } \\
\text { como i=0 TO N) }\end{array}$ \\
\hline & $\begin{array}{l}\text { Condicional Bègin e End (o subgrafo é executado somente se } \\
\text { umã exprêssão é verdadeira) }\end{array}$ \\
\hline$\Delta$ & $\begin{array}{l}\text { Replication Parallel Begin e End (o subgrafo é replicado em } \\
\text { i=0 TO N, e todas as cópias executam em paralelo) }\end{array}$ \\
\hline & $\begin{array}{l}\text { Pipeline Begin e End (o subgrafo é replicado em estagios } \\
\text { indexados) }\end{array}$ \\
\hline
\end{tabular}

Figura 4.7 - Ícones dos nós em HeNCE 
Todos os ícones que controlam o fluxo funcionam em pares, um ícone inicia uma construção e outro termina. O loop funciona como na linguagem $\mathrm{C}$, no ícone de loop-begin são anotados três dados importantes: um valor inicial para variável index, uma condição para terminar o loop, e o próximo valor da variável index. O ícone de loop-end não requer nenhuma anotação. Os nós condicionais definem uma estrutura "if-then". O nó conditionalbegin deve conter uma expressão, se ela for TRUE o subgrafo é executado, caso contrário não é. HeNCE não contém uma estrutura "if-then-else".

A replicação paralela cria estruturas paralelas, replicando o subgrafo e executando em paralelo. O nó pipeline cria uma estrutura pipeline, esta estrutura é parecida com a replicação paralela, mas a diferença esta na maneira que o pipeline é organizado.

Durante a execução, a utilização dos hosts na máquina virtual é exibida, proporcionando ao usuário visualizar os hosts que estão com menos ou mais carga. HeNCE também modifica as cores e as formas dos ícones no grafo durante a execução, gerando uma animação. Grafos HeNCE são convertidos em programas que executam em PVM.

\subsection{Considerações Finais}

As ferramentas gráficas são bastante utilizadas para exibir informações sobre o comportamento de programas paralelos, mas uma linguagem de programação paralela visual baseada em grafo direcionado tem uma vantagem especial. A execução dos dados pode estar diretamente relacionada com o programa original do usuário já que ele compartilha um formato gráfico comum. Isso integra os passos de criação e depuração do programa, colaborando para um melhor desempenho e programas escritos com uma quantidade menor de erros [BRO94].

A dificuldade na programação é o maior empecilho para a ampla aceitação dos sistemas de computação paralela, principalmente MIMD. Linguagens de programação paralela baseada em grafos tem muitas propriedades atrativas que podem ajudar a diminuir esse problema. Grafos direcionados naturalmente capturam a estrutura multidimensional do comportamento de programas paralelos, auxiliando o programador entender a estrutura de seus programas. 


\section{Especificação e Projeto do ASTRAL}

Este capítulo além de apresentar a especificação e o projeto do ASTRAL,

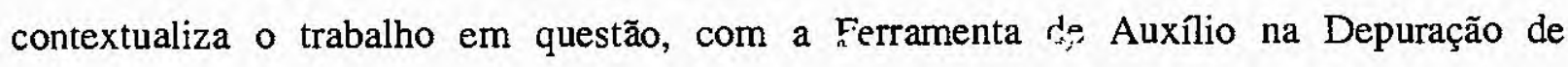
Programas Paralelos em desenvolvimento no Laboratório de Sistemas Distribuídos e Computação Paralela (LASDPC), do Instituto de Ciências Matemáticas e de Computação (ICMC) da Universidade de São Paulo (USP).

\subsection{Considerações Iniciais}

A computação paralela tem sido alvo de muitas pesquisas nos últimos anos, principalmente pela popularização dos sistemas distribuídos, que representam uma solução de custo mais acessível em relação às arquiteturas paralelas. Do ponto de vista do hardware, muito já se desenvolveu e muita experiência foi adquirida. Os detalhes de projeto variam muito de uma máquina para outra, mas a maioria adota o modelo MIMD com memória distribuída, devido a sua grande flexibilidade e facilidade de ampliação [BRO94].

Com relação ao software, diversas linguagens e várias bibliotecas estão disponíveis para a criação de programas paralelos, mas ainda existem muitas lacunas a serem preenchidas. Principalmente em relação às ferramentas para geração de testes, depuração e monitoração (desempenho e funcionalidade) dos programas paralelos. Outro motivo é que desenvolver sistemas paralelos exige conhecimentos específicos, que muitos programadores não possuem.

Com o objetivo de atacar o problema descrito no parágrafo anterior, esta em desenvolvimento no Laboratório de Sistemas Distribuídos e Programação Concorrente (LASDPC) do Instituto de Ciências Matemáticas e de Computação (ICMC) uma Ferramenta de Auxílio na Depuração de Programas Paralelos. A especificação e o projeto dessa ferramenta foram definidos por Moreira, em [MOR00], e são apresentados resumidamente na seção 5.2. A partir da seção 5.3 são apresentados a especificação e o projeto do ASTRAL, que implementa parte da ferramenta descrita na seção 5.2 . 


\subsection{Ferramenta de Auxílio na Depuração de Programas Paralelos}

A especificação e o projeto dessa ferramenta envolvem duas áreas de atuação: a depuração de programas paralelos e o seu ensino. O objetivo da ferramenta é a criação de um ambiente que integre a depuração de programes pralelos com um ambiente tutor que auxilie um usuário de programação concorrente, sem muita experiência, a identificar os erros que ocorram em programas paralelos, possibilitando o aumento do conhecimento do usuário durante a sua utilização. Desta forma, além de identificar os erros, o programador estará aprendendo como desenvolver programas paralelos e como evitar a ocorrência de erros típicos deste tipo de programação.

A arquitetura da ferramenta foi elaborada em camadas (Figura 5.1) para possibilitar maior autonomia entre as tarefas que devem ser realizadas durante sua utilização. Cada camada se comunica com a camada seguinte através de protocolos, permitindo uma maior independência na definição e implementação do projeto.

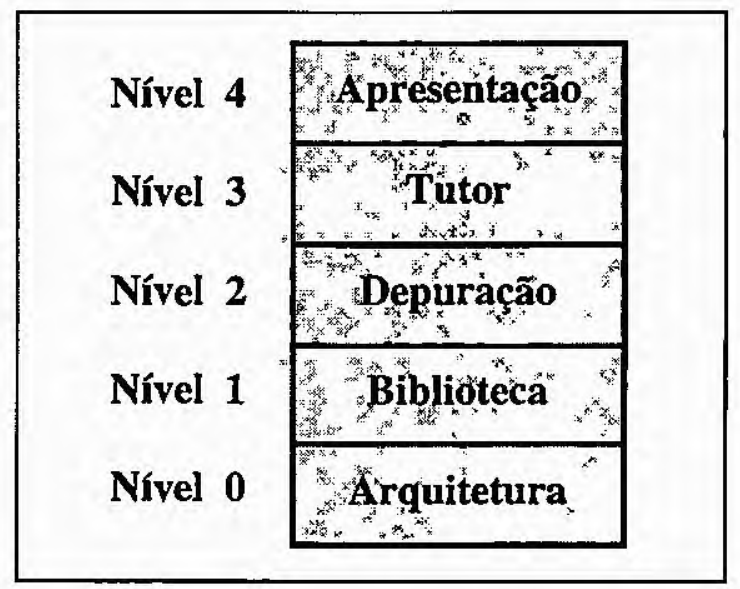

Figura 5.1 - Camadas que definem a Ferramenta

A Camada de Arquitetura (Nível 0) define o ambiente em que o programa paralelo está implementado e a sua granulosidade. Estas informações dizem respeito às características da arquitetura paralela, por exemplo, se o ambiente é fortemente acoplado ou fracamente acoplado; um sistema distribuído ou uma máquina paralela, além de outras informações relevantes como a quantidade de elementos de processamento. Enquanto a camada de arquitetura se responsabiliza pelo hardware, a Camada de Biblioteca (Nivel 1) define as linguagens e bibliotecas a serem utilizadas no desenvolvimento do programa. 
A Camada de Depuração (Nível 2), é o depurador propriamente dito. Ela está dividida em módulos funcionais, cada módulo tem o objetivo de resolver um tipo de problema específico. Existe um módulo para resolver problemas de deadlock e outro que resolve problemas de sincronização e comunicação. Além desses, existe um módulo para a busca de possíveis problemas de ordem sequiencial que podem estar afetando o programa como um todo. Por exemplo, se uma tarefa possui um loop codificado de forma incorreta gerando uma repetição "infinita", e logo em seguida a esse loop existe um comando para enviar uma mensagem para todas as outras tarefas que compōe a aplicação, ocorrerá deadlock, tendo como causa um erro na parte seqüencial do código.

Com o resultado que a camada anterior produz, é possível proporcionar ao usuário um mecanismo de ensino, facilitando o entendimento das falhas que foram realizadas durante a implementação, através de um ambiente que aumenta o aprendizado da programação paralela (Camada Tutor - Nível 3). A Camada de Apresentação (Nível 4) se confunde com a anterior, mas tem o objetivo especial de criar uma representação gráfica do programa que está sendo corrigido, permitindo a apresentação de várias janelas com imagens de cada passo da execução do programa.

\subsubsection{O Modelo da Ferramenta}

Através de um modelo de alto nível, apresentado na Figura 5.2, pode-se notar as relações dos diversos processos que envolvem a tarefa da depuração. Esse modelo apresenta uma especificação para depurar programas paralelos nas diversas linguagens e bibliotecas existentes, particularmente em sistemas distribuídos com mecanismos de troca de mensagem.

Foi elaborado um DFD (Diagrama de Fluxo de Dados) para facilitar a visualização dos processos que compõem a ferramenta e os fluxos de informações que trafegam pelas camadas. Esse diagrama representa os processos e as informações que trafegam nas cinco camadas:

- Processo 1 (Preparar Dados de Arquitetura e Biblioteca): representa as tarefas que estão contidas nas camadas 1 (arquitetura) e 2 (biblioteca), possuindo a função de atualizar as informações da arquitetura (hardware) onde a aplicação que está sendo depurada será executada, além das informações referentes às linguagens e bibliotecas utilizadas (software). 


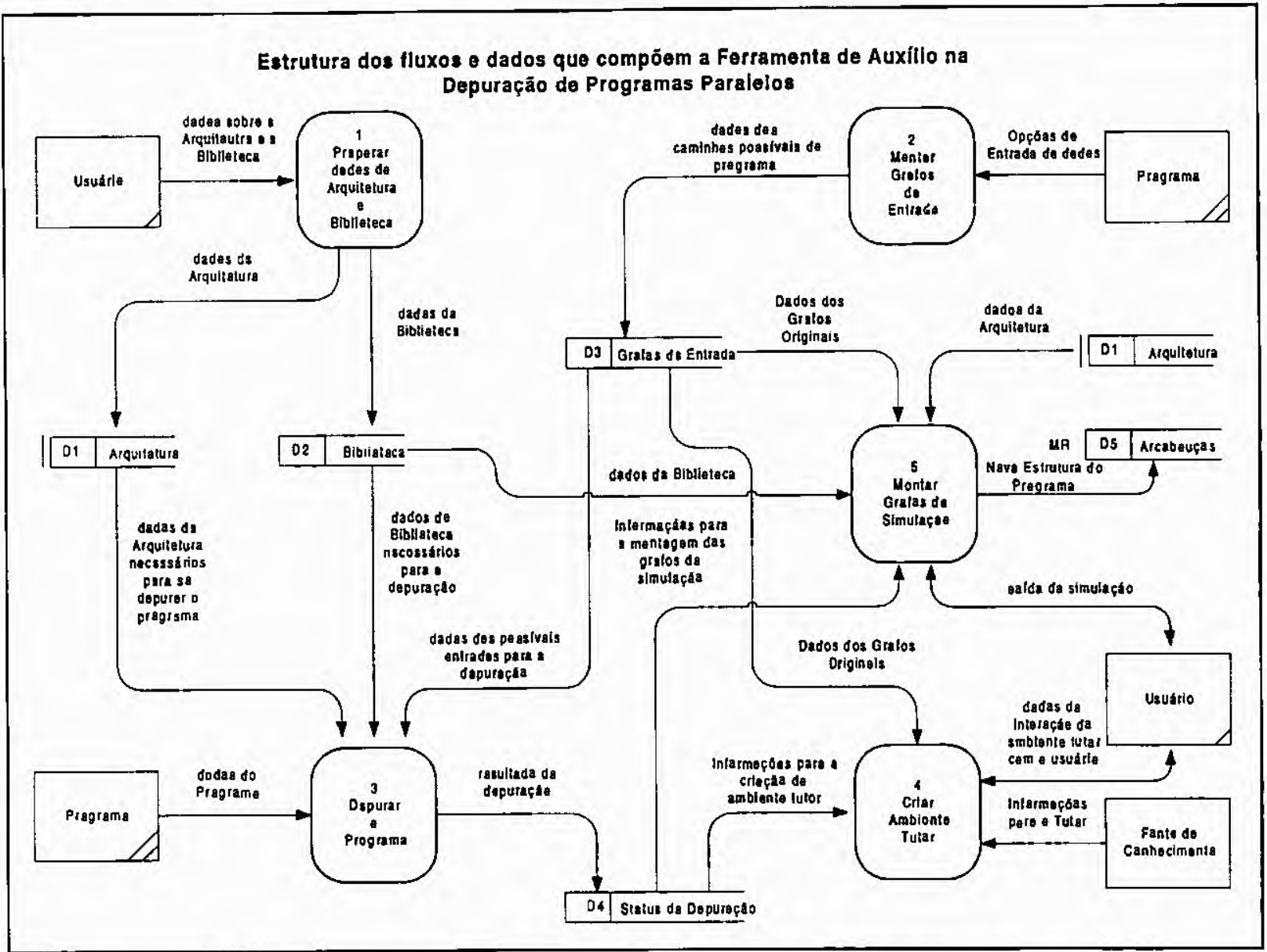

Figura 5.2 - Modelo da Ferramenta de Auxílio na Depuração de Programas Paralelos

- Processo 2 (Montar Grafos de Entrada): é responsável em criar duas classes de grafos: grafo de fluxo de instruções e grafo de comunicação. O Grafo de Fluxo de Instruções corresponde à visão sintática do comportamento funcional de um processo, onde cada comando do processo corresponde a um vértice do grafo. E o Grafo de Comunicação preserva todos os nós que representam instruções paralelas, eliminando-se do desenho os nós que não interferem na comunicação entre os processos.

- Processo 3 (Depurar o Programa): responsável pela depuração propriamente dita, se subdivide em vários outros processos, cada um resolvendo uma classe de erros em programas paralelos. Os resultados desses sub-processos são armazenados no depósito D4 - Status da Depuração, para serem utilizados pelos processos 4 e 5 . 
- Processo 4 (Criar Ambiente Tutor): representa a quarta camada da arquitetura (Camada Tutor), com base nos erros encontrados esse processo cria um ambiente de comunicação com o usuário, criando alternativas para solucionar o problema.

- Processo 5 (Montar Grafos de Simulação): representa a quinta camada da arquitetura (camada de apresentação). Esse processo permite ao usuário verificar o efeito que os erros encontrados provocam no programa, e possibilita uma visão global do sistema.

O Diagrama de Fluxo de Dados da Figura 5.2 representa a ferramenta em alto nível, a explosão dos processos e um protótipo, demonstrando a aplicabilidade da ferramenta, podem ser verificados em [MORO0].

\subsection{O ASTRAL}

O objetivo principal do ambiente (ASTRAL) desenvolvido neste trabalho é a construção e a simulação de um grafo que representa um programa paralelo. Dessa forma, o ASTRAL envolve o projeto e a implementação dos processos 2 (montar grafos) e 5 (simulação) da Ferramenta para o Auxílio na Depuração de Programas Paralelos.

A especificação do ambiente, apresentando em detalhes os objetivos do projeto, é apresentada na seção 5.3.1. Os detalhes do projeto, tais como o modelo do ambiente e a explosão dos processos, são apresentados na seção 5.3.2.

\subsubsection{Especificação do ASTRAL}

O ASTRAL é um ambiente em que um programa paralelo pode ser simulado (sem a necessidade da sua execução) através da representação de grafos direcionados (Capítulo 4), que representam as seqüências de instruções e as comunicações entre as tarefas que compõem a aplicação paralela.

Os grafos (o grafo de fluxo de instrução e o grafo de comunicação) são gerados a partir do código fonte de um programa paralelo qualquer, que pode ser aberto ou criado no próprio ambiente. Um programa paralelo é composto por dois ou mais processos que executam concorrentemente e que se comunicam. Assim, para a representação de um 
programa paralelo é gerado um grafo de fluxo de instrução para cada processo paralelo, e um grafo de comunicação representando as comunicações entre os processos paralelos. O primeiro obstáculo para construção do ambiente é justamente como construir os grafos para que possam ser visualizados pelo usuário durante a simulação. Quando forem considerados programas com milhares de linhas e dezenas de processos, é necessária a adoção de uma forma adequada de visualização.

Após a geraçāo dos grafos, o programa será simulado, permitindo ao usuário visualizar e controlar seu comportamento, percebendo a dependência que existe entre as tarefas. Um problema que deve ser considerado nesta fase é: como obter as entradas de dados para que o programa possa ser simulado.

Durante a simulação deve ser possível ao ambiente apontar alguns tipos de erros, principalmente relacionados à sincronização, como por exemplo, espera infinita. Além dos erros, no programa de simulação deve ser criada uma linha de controle (threads) para a simulação de cada grafo, possibilitando a verificação de problemas como balanceamento de carga inadequado e paralelismo insuficiente.

Baseando-se nos pontos discutidos nos parágrafos anteriores, pode-se definir as seguintes funcionalidades para o ASTRAL:

1. Montar os grafos a partir de um programa paralelo.

2. Definir quais os caminhos deste grafo deverão ser percorridos.

3. Selecionar / parametrizar os caminhos a serem percorridos

4. Simular o programa paralelo.

5. Testar o programa paralelo.

6. Apresentar os resultados da simulação para o usuário.

Essas funcionalidades são representadas na Figura 5.3, através de um modelo de alto nível proposto para o ASTRAL. Esse modelo segue a linha de especificação da Ferramenta de Auxílio na Depuração de Programas Paralelos [MOR00], utilizando a ferramenta de projeto de sistemas denominada DFD - Diagrama de Fluxo de Dados. 


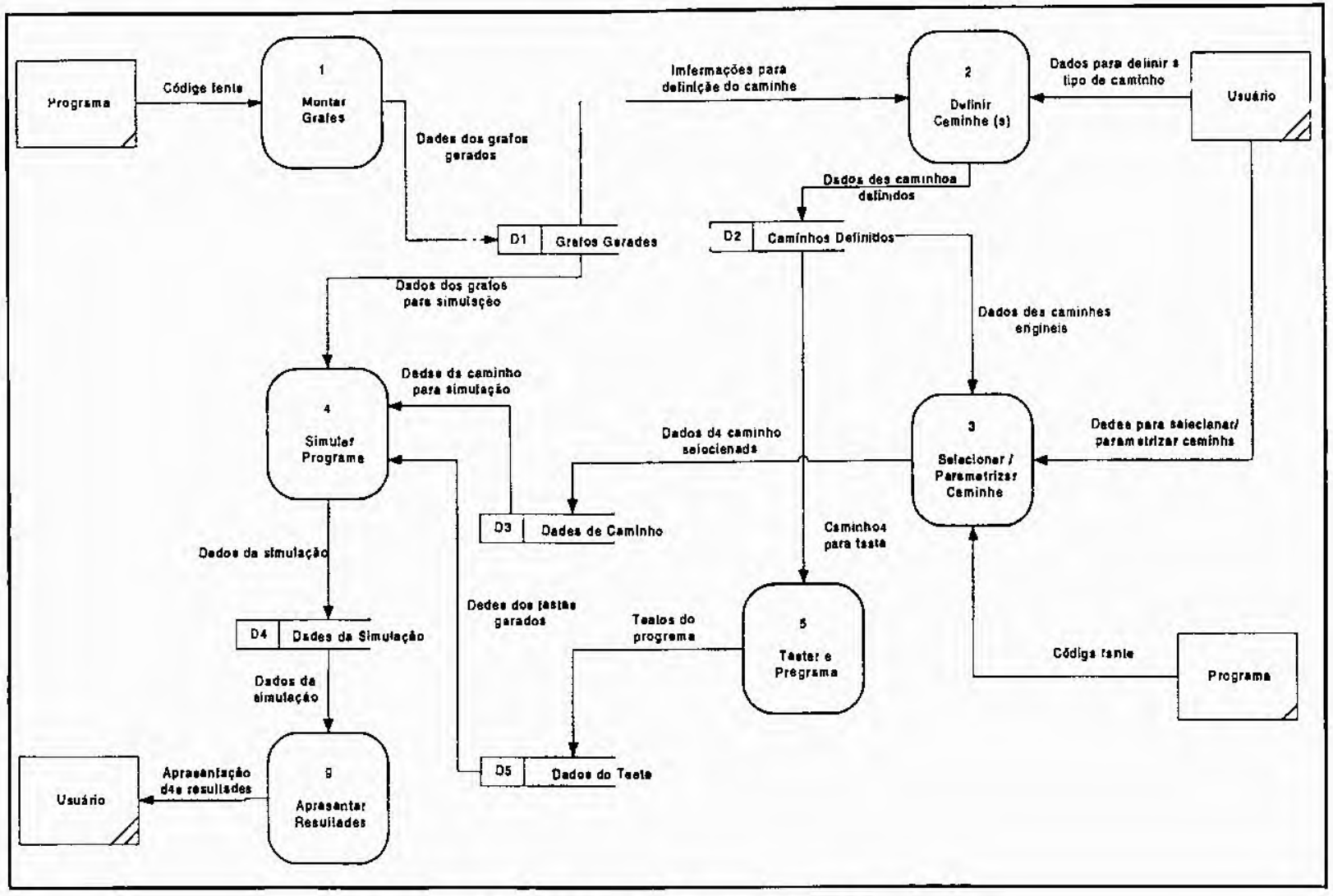

Figura 5.3 - Modelo de projeto do ASTRAL

A utilização do DFD permite a visualização e definição das tarefas que compōem o ambiente, bem como o inter-relacionamento dessas tarefas. No processo 1 - Montar Grafos os grafos de fluxo de instrução e de comunicaçāo são montados a partir do código fonte do programa. A definição detalhada desses grafos é apresentada na seção 5.3.2.1. Os dados dos grafos gerados são utilizados pelo processo 2 - Definir Caminho(s) que também obtém informações do usuário, para definir qual ou quais caminhos percorrer durante a simulação.

Após a definição dos caminhos, e de uma interação com o usuário, o processo 3 Selecionar / Parametrizar Caminho(s) permite a seleção de um caminho para que o programa seja simulado e a definição dos mecanismos que serão utilizados para auxiliar na simulação. Esses mecanismos são apresentados na seção 5.3.2.3. O processo 4 - Simular o Programa permite ao usuário verificar o efeito que os erros encontrados provocam no programa, através da simulação da execução do programa pelos grafos correspondentes.

Durante a definição dos caminhos, pode-se selecionar mecanismos para geração de diversos caminhos, que permite a utilização de critérios de testes através do processo 5 Testar o Programa. E finalmente, o processo 6 - Apresentar Resultados tem como função principal, apresentar os dados gerados na simulação e ou no teste. 


\subsubsection{Projeto do ASTRAL}

O diagrama de fluxo de dados apresentado na Figura 5.3 define os processos necessários para o projeto do ambiente de simulação e teste de programas paralelos. Esta seção apresenta uma descrição completa de cada processo que compōem o modelo.

\subsubsection{Processo 1 - Montar Grafos}

Nesse processo são geradas duas classes de grafos (a representação de programas paralelos como grafos é discutida no capitulo 4) que permitem uma melhor visualização do programa paralelo, que geralmente possui muitos processos com uma grande quantidade de dados. A explosão desse processo representa justamente estas duas classes de grafos, conforme pode ser observado na Figura 5.4.

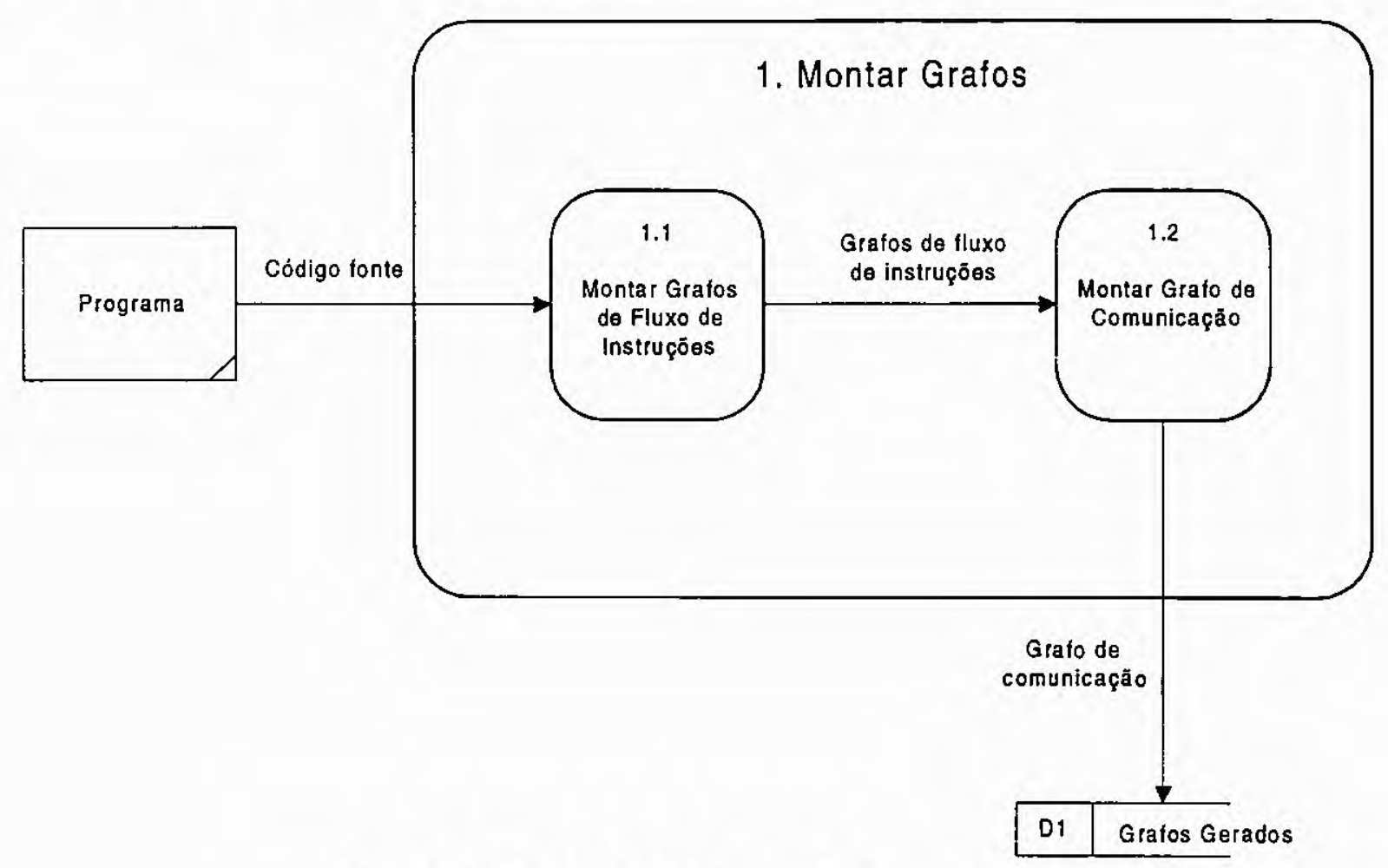

Figura 5.4 - Explosão do Processo 1 (Montar Grafos)

No ambiente, após o usuário ter aberto ou gerado um programa paralelo novo, o processo 1.1 - Montar Grafos de Fluxo de Instruções realiza uma análise semântica no programa do usuário, onde cada grafo representa a visão do comportamento funcional de um processo. Uma vez gerado os grafos de fluxo de instruções o processo 1.2 monta o grafo de comunicação. A seguir os processos 1.1 e 1.2 são detalhados. 


\section{Grafo de Fluxo de Instruções}

A representação de um programa paralelo $\mathbf{P}$, por um grafo de fluxo de instruções (ou de controle), consiste em estabelecer uma correspondência entre nós e blocos, e em indicar possíveis fluxos de controle entre blocos através dos arcos [NET95]. Ou seja, cada comando do programa que será simulado, corresponde a um vértice do grafo e os arcos indicam o fluxo do programa.

Para exemplificar o grafo de fluxo de instruções será utilizado o programa apresentado na Listagem 5.1. Esse programa possui três processos, um processo Mestre (Listagem 5.1a) que ativa os processos $A$ (Listagem 5.1b) e $B$ (Listagem 5.1c) para serem executados em paralelo. No programa, as estruturas são apresentadas através de algoritmos para não se prender a sintaxe de uma linguagem específica, mantendo a flexibilidade do projeto do ambiente. Um exemplo das estruturas básicas utilizadas para construir o grafo do programa é apresentado no Capítulo 4, Figura 4.1.

\begin{tabular}{|c|c|c|}
\hline $\begin{array}{l}\text { Processo Mestre }(2 \\
\text { inicio } \\
1 \text { comando } \\
2 \text { se condição } \\
3 \text { então comando } \\
4 \text { senão comandó } \\
5 \text { fim-se } \\
6 \text { AtivarProcessommparalelo }(\mathrm{A}, \mathrm{B}) \\
7 \text { comando } \\
8 \text { comando } \\
9 \text { comando } \\
\text { Iim }\end{array}$ & 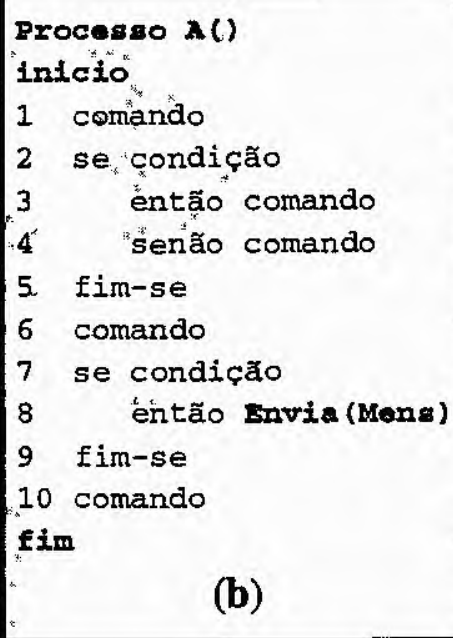 & $\begin{array}{l}\text { Processo } B() \\
\text { Inicio } \\
1 \text { comando } \\
2 \text { enquanto condição fạ̧a } \\
3 \text { comando } \\
4 \text { fim-enquanto } \\
5 \text { comando } \\
6 \text { se condição } \\
7 \text { senăo Rocebe (Hens) } \\
8 \text { fim-se } \\
9 \text { comando } \\
\text { f1m } \\
\text { (c) }\end{array}$ \\
\hline
\end{tabular}

Listagem 5.1 - Programa exemplo para geração dos grafos

A Figura 5.5 apresenta o grafo resultante gerado a partir do programa da Listagem 5.1 Nessa representação é possível notar que todos os comandos possuem um nó correspondente no grafo, e inclusive são indicados pelo número da linha no código do programa. Porém, representar todos os comandos do programa, produz um grafo de grandes dimensões. 


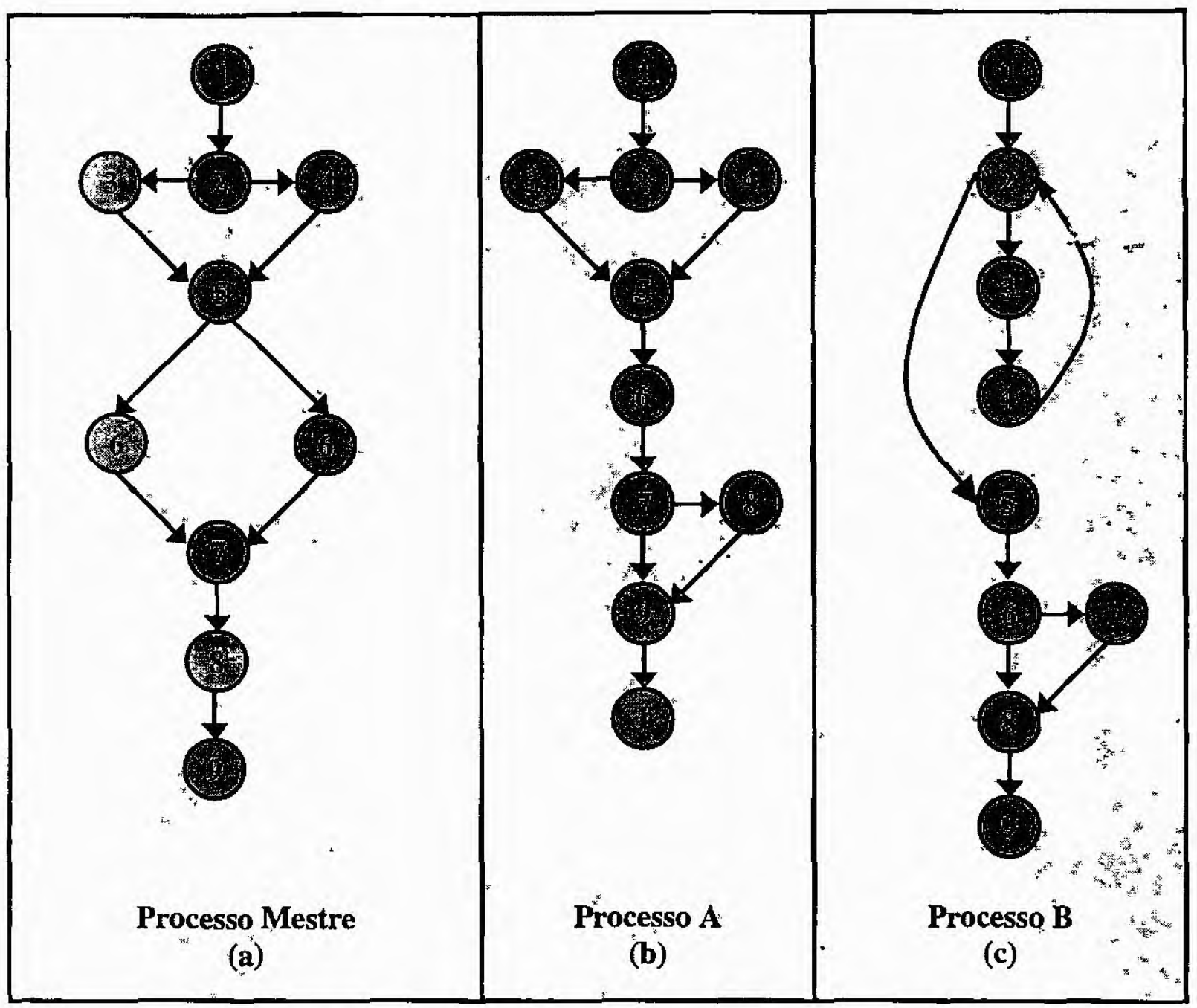

Figura 5.5 - Grafos de Fluxo de Instruçōes da Listagem 5.1

A geração de um grafo de fluxo de instrução para cada processo dificulta visualizar a comunicação e a sincronização dos processos durante a simulação. Com isso, alguns comandos, que não representam instruções paralelas, e não interferem na execução dessas instruções, podem ter seus nós excluídos do grafo. Gerando assim o processo 1.2 - Grafo de Comunicação.

\section{$\checkmark$ Grafo de Comunicação}

Para se construir o grafo de comunicação entre os processos, utilizam-se os grafos originais de fluxo de instruções de cada processo do programa. Eliminando desses grafos os nós que não representam as instruções de comunicação e sincronismo entre os processos e acrescentando os arcos de dependência entre essas instruçōes. Na Figura 5.6 pode ser visto o grafo de comunicação entre os processos A e B da Listagem 5.1. 


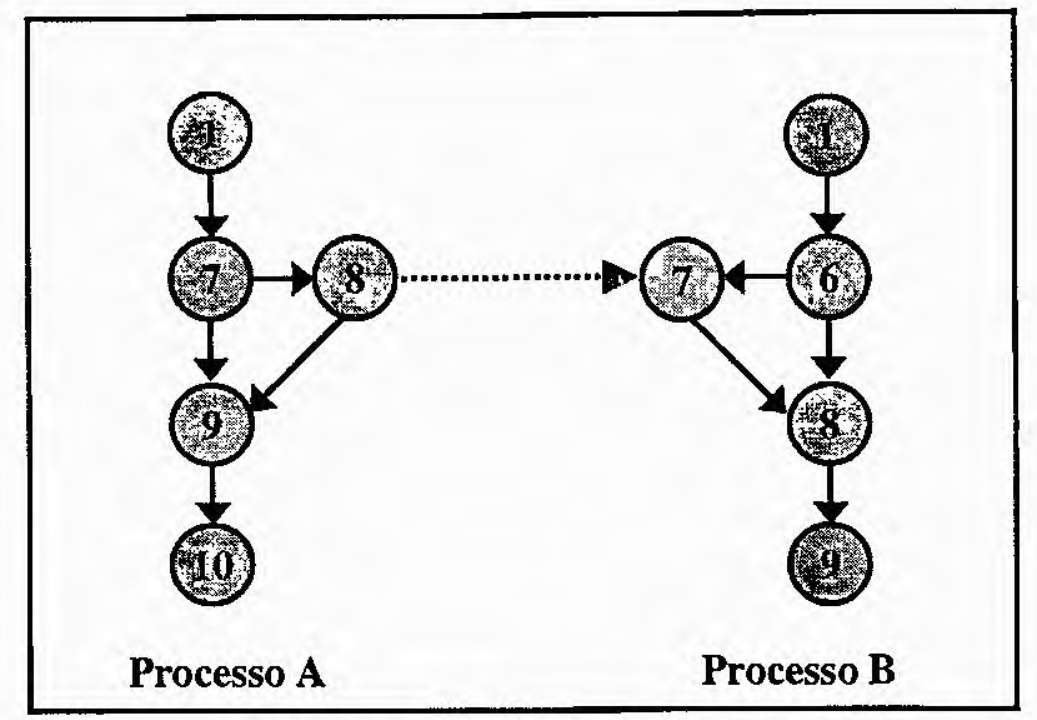

Figura 5.6 - Grafo de Comunicação da Listagem 5.1

O processo Mestre da Listagem 5.1 não é representado no grafo de comunicação, pois este não apresenta, neste caso, primitivas de comunicação. No processo $A$, os nós $2,3,4,5$ e 6 foram eliminados pois não representam um comando paralelo, e nem interferem em qualquer comando paralelo, como é o caso do nó 7. A transformação ocorrida no processo $B$ foi semelhante, os nós 2, 3, 4 e 5 não foram acrescentados no grafo de comunicação, e o processo 6 foi acrescentado pelos mesmos motivos do processo $A$.

Um fator relevante na geração do desenho do grafo é que os nós podem ter desenhos diferentes representando as diferentes estruturas de dados, conforme apresentado nos estudos de caso do Capítulo 4. Finalizando o processo 1, as informações dos grafos montados nesse processo são armazenadas para que possam ser utilizadas por outros, como por exemplo, o processo 2 que é descrito abaixo.

\subsubsection{Processo 2 - Definir Caminho(s)}

Esse processo, tem como função principal definir como o caminho será gerado para simular a execução do programa. A questão principal é como obter as entradas de dados para percorrer um caminho e simular o programa.

O detalhamento do processo 2 pode ser visto na Figura 5.7. Com as informações dos grafos gerados no processo 1 e de dados fornecidos pelo usuário, deve-se definir o tipo de caminho a ser utilizado para percorrer o programa (processo 2.1). O programa pode ser percorrido através da entrada de dados pelo próprio usuário (processo 2.2), pela execução de dados armazenados em um arquivo (processo 2.4) ou ainda através da geraçāo de vários 
caminhos possíveis (processo 2.3). Após a definição, os dados do(s) caminho(s) devem ser armazenados (processo 2.5).

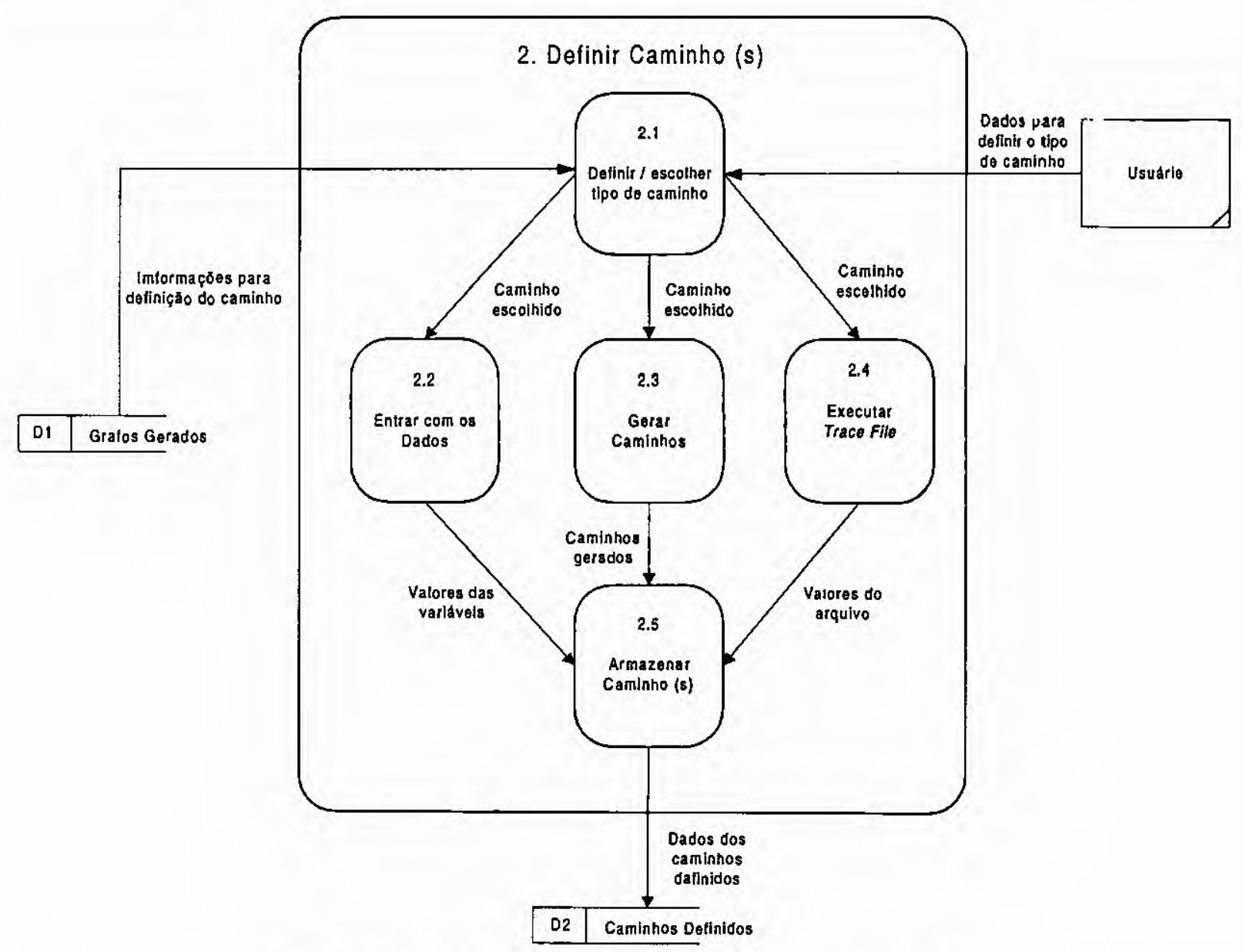

Figura 5.7 - Explosão do Processo 2 (Definir Caminhos)

Para entender melhor a necessidade da definição destes tipos de caminhos, observe os dados da Listagem 5.2, onde o envio do valor $X$ para o Processo $B$ ou $C$ depende exatamente de $X$, que é obtido através de uma entrada de dados na linha $1-\operatorname{Ler}(X)$.

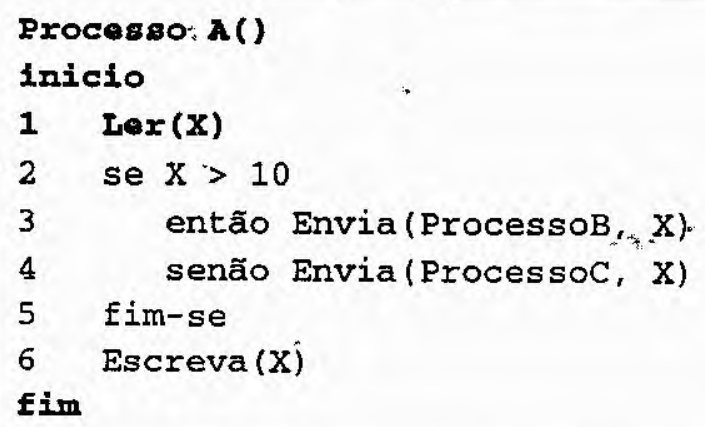

Listagem 5.2 - Programa exemplo para definição dos caminhos 
Com isso, para que um caminho no programa possa ser percorrido foram definidas, para o ASTRAL, três opções:

1. Obter os dados do usuário (processo 2.2): durante a simulação, as entradas de dados deverão ser informadas pelo usuário, como se o programa estivesse sendo executado. No exemplo da Listagem 5.2, quando o comando $\operatorname{Ler}(X)$ for simulado, uma caixa de leitura será disponibilizada para que o cliente forneça o valor de $X$. Essa opção permite ao usuário entrar com os mesmos dados que havia utilizado na execução do programa e modificar essas entradas a qualquer momento.

2. Gerar caminhos (processo 2.3): uma segunda opção é oferecer ao usuário um mecanismo para a geração de caminhos. $O$ ideal, principalmente no caso de teste, é que todos os caminhos possíveis fossem gerados, mas dependendo do tamanho do sistema isso seria totalmente inviável. $\mathrm{Na}$ Listagem 5.2 existem apenas dois caminhos que podem ser percorridos: 1-2-3-5-6 e 1-2-4-5-6. Deve-se ressaltar que para geração de caminhos faz-se necessário à utilização de algum critério de cobertura, como por exemplo o critério todos-caminhos-de-concorrência definido em [TAY92], que cobre todos os caminhos de concorrência.

3. Obter os dados de um arquivo (processo 2.4): a última opção permite percorrer o programa através de dados armazenados em um arquivo, conhecido como Trace File [HEA99]. Um inconveniente neste tipo é que o arquivo de Trace deve ser gerado durante a execução real do programa, para depois ser utilizado pelo ambiente na simulação. Para exemplificar, durante a execução do programa apresentado na Listagem 5.2, o valor de $X$ que foi fornecido pelo usuário seria armazenado em um arquivo. Quando o programa estivesse sendo simulado o valor de $X$ seria obtido deste arquivo e o caminho percorrido é o mesmo que o da execução, considerando que não houve Probe Effect (efeito de intrusão).

\subsubsection{Processo 3 - Selecionar / Parametrizar Caminho}

Após a seleção do tipo de caminho no processo 2 , o processo 3 permite ao usuário escolher o caminho (processo 3.1) que ele deseja percorrer durante a simulação. Esta escolha ocorre principalmente quando for selecionada a opção para geração de diversos caminhos. Com a definição e escolha do caminho a ser simulado, o usuário pode estabelecer alguns mecanismos para auxiliar na tarefa de simulação (processo 3.2). Os detalhes deste processo podem ser visualizados na Figura 5.8 . 


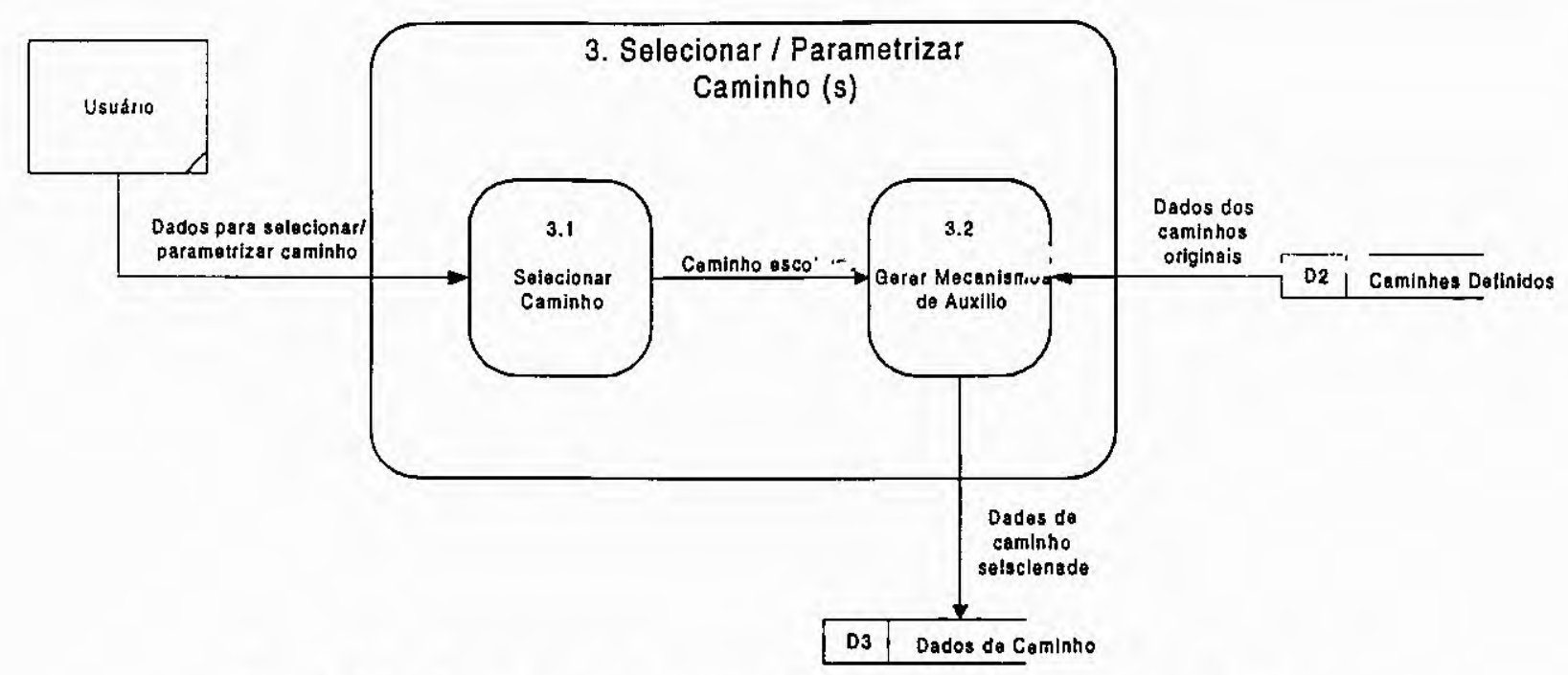

Figura 5.8 - Explosão do Processo 3 (Selecionar / Parametrizar Caminho)

O objetivo principal deste processo é estabelecer mecanismos que possam auxiliar durante a simulação, por isso ele pode ser considerado cíclico com o processo de simulação (processo 4), ou seja, mesmo durante a simulação outros mecanismos podem ser selecionados ou um mecanismo selecionado pode não ser mais utilizado.

Como o objetivo destes mecanismos é de auxiliar a simulação eles são denominados de mecanismos de auxilio. Esses mecanismos permitem uma boa flexibilidade ao ambiente, pois além dos mecanismos abaixo, outros podem ser definidos a qualquer momento:

- BreakPoints: é muito utilizado em depuradores sequienciais, produzindo pontos de parada em qualquer local do programa. Durante a simulação, quando um breakpoint é alcançado o programa é suspenso. O usuário pode então examinar o estado dos vários componentes do programa e verificar se estes estão corretos, como por exemplo o valor de variáveis [KOR97].

- Controle da Simulação: esse mecanismo permite o controle passo a passo da simulação do programa. Através de uma tecla especial, o programador pode ir verificando a simulação passo a passo, podendo observar o valor das variáveis, das mensagens e todos eventos que estão ocorrendo.

- Cortes (cuts): são um conjunto de breakpoints nos diversos processos que compõem a aplicação. Eles permitem ao usuário iniciar e parar o programa em qualquer corte. Portanto, é possível iniciar um programa não somente do ponto de entrada, mas em qualquer lugar onde se tenha um corte definido. Devido a essa característica de permitir apenas a simulação de partes do programa, o uso de 
cortes reduz consideravelmente o tempo na simulação e ou depuração de grandes aplicações [KRA96]. A maior dificuldade para geração de cortes, é justamente estabelecer cortes consistentes que não interfiram no processo de simulação. Alguns algoritmos para geração e implementação de cortes foram desenvolvidos em [GRA96].

Cada um dos mecanismos deve ainda possuir características para programação visual, como destacar os nós do grafo e o texto que já foram simulados, permitir visualizar todos os breakpoints e cortes definidos. Destacar o texto diferenciando as estruturas de computação, principalmente as estruturas relacionadas ao paralelismo. Sempre com o intuito de facilitar a visualização do comportamento do programa pelo usuário.

\subsubsection{Processo 4-Simular o Programa}

Este processo cria a simulação propriamente dita. A simulação permite ao usuário visualizar e controlar o comportamento do programa, percebendo a dependência que existe entre as tarefas. Além disso, ela permite verificar erros como processos em estado de espera infinita ou a presença de deadlock. Várias vezes, quando ocorrem esses erros durante a execução do programa, é dificil perceber qual processo está parado e em que ponto.

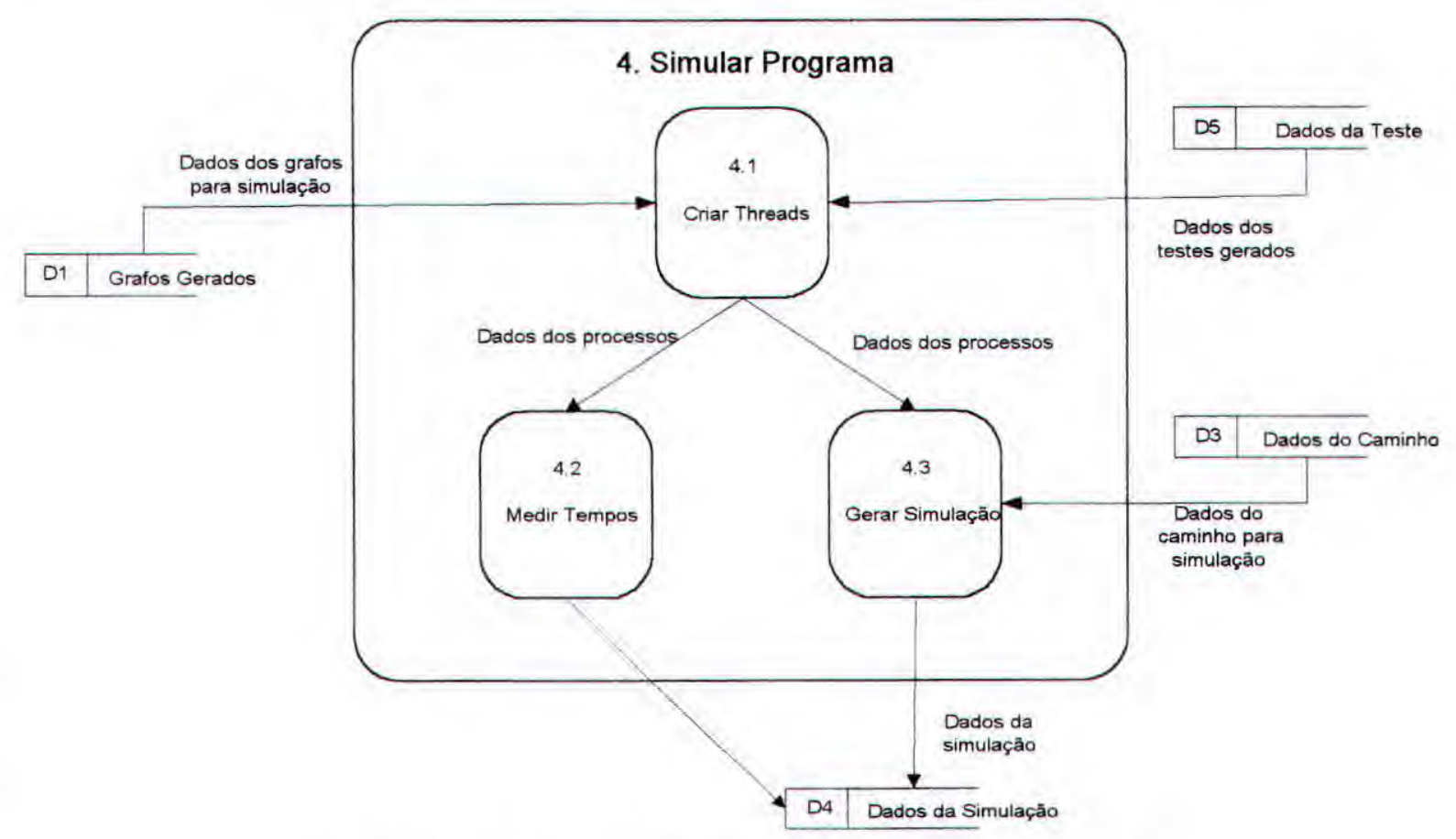

Figura 5.9 - Explosão do Processo 4 (Simular o Programa) 
Os detalhes do processo de simulação são apresentados na Figura 5.9. O processo 4.1 cria um thread para cada grafo inicializando os subprocessos que irão simular o fluxo de execução. O processo 4.2 tem a função de medir o tempo de execução de cada processo que estará sendo executado pelo processo 4.3 .

Para visualizar melhor este processo a Figura 5,10 apresenta um exemplo, onde estão sendo simulados dois processos em paralelo. Durante a simulação os nós que são simulados, bem como seus respectivos códigos vão mudando de cor, no exemplo os nós que já foram simulados são representados em marrom. O nó que está sendo simulado no momento é representado pela cor azul com exceção dos nós de comunicação, o envia é representado pela cor verde. A utilização de cores para animar a simulação melhora ainda mais o aspecto de visualização do comportamento provido pelo ambiente.

Outro fator importante que pode ser observado pelos grafos da Figura 5.10 é que o processo $A$ possui um Envia para o processo $B$, que devido ao caminho percorrido já terminou sua execução e não espera nada de $A$. Tem-se então um exemplo de erro que pode ser identificado facilmente no ambiente, a espera infinita, mas outros erros também podem ser visualizados. Além dos erros, através dos tempos medidos pelo processo 4.2 - Medir tempos de Simulação, é possível apontar problemas relacionados ao desempenho do programa.

A Listagem 5.3 descreve o código fonte dos grafos da Figura 5.10, durante a simulação o código também pode ser destacado, facilitando a visualização do usuário.

\begin{tabular}{|c|c|c|}
\hline $\begin{array}{l}\text { Processo Mestre() } \\
\text { inicio } \\
1 \text { comando } \\
2 \text { se condição } \\
3 \text { entăo comando } \\
4 \text { senão comando } \\
5 \text { fim-se } \\
6 \text { AtivarProcessosEmParalelo (A,B) } \\
7 \text { comando } \\
8 \text { comando } \\
9 \text { comando } \\
\text { fim }\end{array}$ & 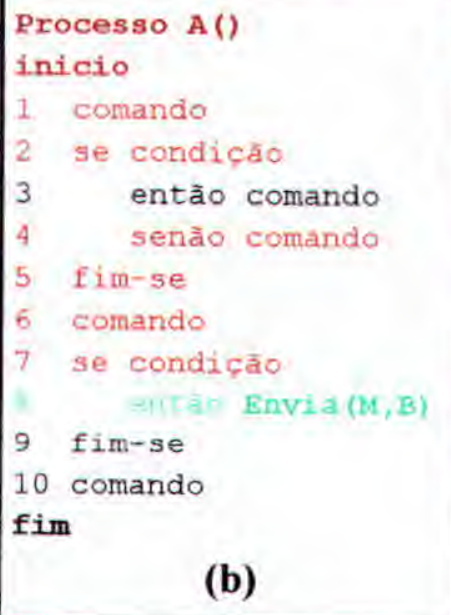 & $\begin{array}{l}\text { Processo B() } \\
\text { inicio } \\
1 \text { comando } \\
2 \text { enquanto condiçào faça } \\
3 \text { comando } \\
4 \text { fim-enquanto } \\
5 \text { comando } \\
6 \text { se condisào } \\
7 \text { senão Recebe }(\mathbf{M}, \mathbf{A}) \\
8 \text { fim- se } \\
9 \text { comando } \\
\text { fim } \\
\text { (c) }\end{array}$ \\
\hline
\end{tabular}

Listagem 5.3 - Programa exemplo para simulação 


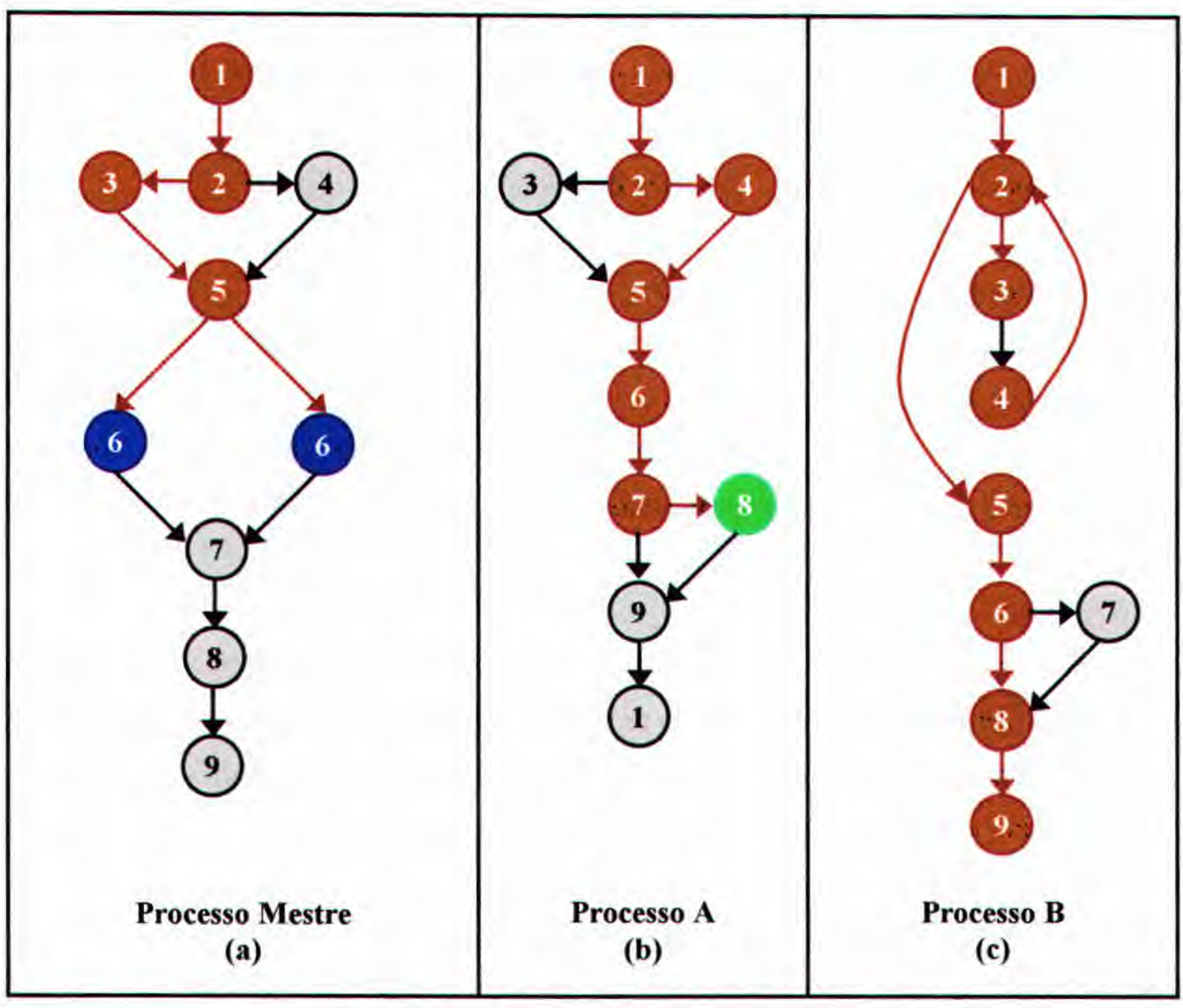

Figura 5.10 - Grafos de Fluxo de Instruções da Listagem 5.3

No exemplo da Figura 5.10(a), o processo Mestre, ativa dois processos $(A \| B)$ em paralelo. $\mathrm{O}$ tempo de simulação desses processos pode ser medido facilmente e então apontar possíveis problemas no desempenho, como:

- Paralelismo Insuficiente: considerando que os processos $A$ e $B$ que são executados em paralelo, conforme definido no grafo do processo Mestre pelo nó 6, consomem 5 unidades de tempo, e os nós 7, 8 e 9 que estão na parte seqüencial do código consomem 20 unidades de tempo. O ambiente pode apontar para o usuário que os nós da parte seqüencial estão consumindo um tempo muito maior, e se não houver dependência entre essas tarefas eles podem ser executados em paralelo.

- Balanceamento de Carga Inadequado: o ambiente pode apontar também um balanceamento de carga inadequado. Para exemplificar, se o processo $A$ consumir 30 unidades de tempo para terminar e o processo $B$ apenas 5 unidades de tempo, tem-se um caso de balanceamento de carga inadequado. 


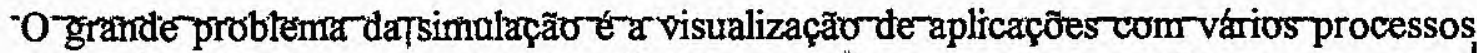
uma grande quàntidade de dádos, esse problema é tratádo pelo processo 6 que tem a funçã de apresentar ós resultados pára o usuário.' Outros detalhes da simulação ficarão mais claros

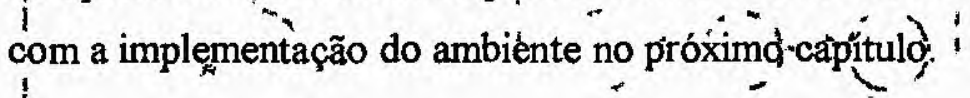

i

5.3.2.5 Processo 5 Testar $\oint$ Programa

Um doș métodos utilizado para sẹ percorrer um programa durante a. simulação do grafo pode'sèr àtravés da gẹração de camînhos (seçăo 5.3.2.2), éc a partir dòscaminhos gerados pode-se esćolher um para realizâr sua simulącão. Outra fưncionalidadé, esssa sim justificando á gẹração de diversos caminhos, é para realização de testes em bursca de un possível erro.

1 Atravéș.do teste, anteș mesmo que um erro apareça o usuário pode colocar seu sistemá to ambiente realìzando assim uma bateriá de verificações nos caminhos gerados. Permitindo à visualização dọ comportamenţo do programa para divệsas entradas de dádos, A geração dọ caminho é que deve ser levada em consideração, pois quanto maior o sistema mais caminhos Seriam gerados. O ideal para um caso de teste é que tódos os caminhos fossem percorridos, ţas a geração, e o teste de todos os caminhos é uma tarefa dificil e de certa formá impraticável-principalmente-pélo.custo.

A geração de caminhos para execução de teste deve obedecer a alguns critérios, tanto para a seleção dos casos de teste como para decidir quando parar a atividade de teste. Outra facilidade do ámbiente, para execução de teste, é que muitos dos critérios da técnica estrútural baseiam-se no grafo de fluxo de controle para estabelecer os requisitos de teste. Dentre os critérios de teste baseados nò grafo de fluxo de controle tem-se os critérios todos os nós (cada instrução do programa deve ser executada pélo menos uma vez), todos os ramos (cada transferência de controle entre blocos deve ser exercitada pelo menos uma vez) e todos os caminhos (todos os caminhos do grafo devem ser exercitados) [NET95].

A geração de critérios de teste, principalmente para programas paralelos é muito importante e por isso possui um processo (5.1) exclusivo no detalhamento do processo de teste, apresentado na Figura 5.11. O processo 5.2 - Realizar Teste obtém os dados dos critérios e gerencia a realização do teste através do processo de simulação. 


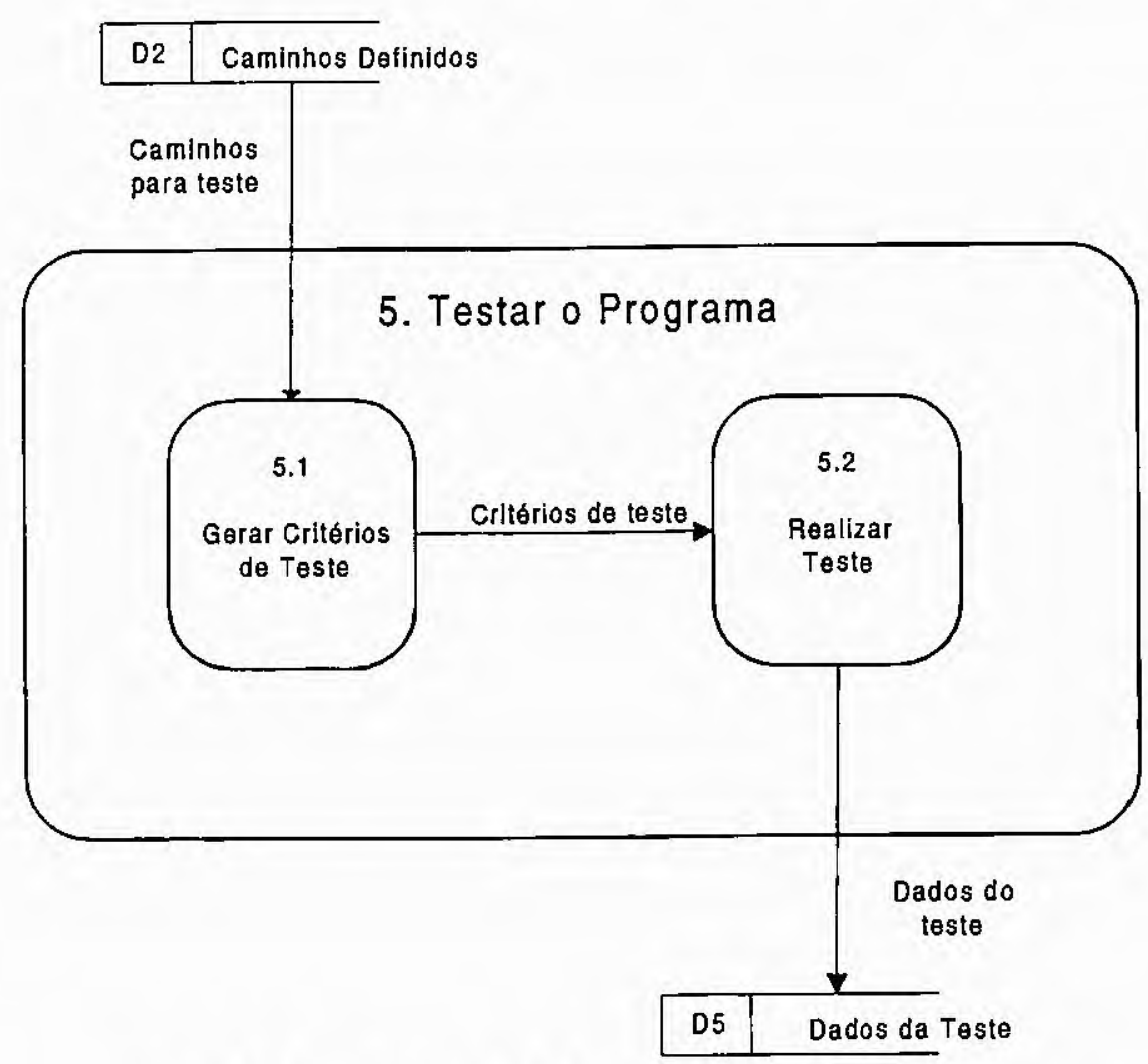

Figura 5.11 - Explosão do Processo 5 (Testar o Programa)

Critérios de teste para programas paralelos devem estar voltados para os eventos que envolvem a comunicação entre os processos, e portanto, esses critérios devem ser gerados a partir do grafo de comunicação. Taylor [TAY92] apresenta algumas definições de critérios de teste para programas concorrentes. Esses critérios são estabelecidos sobre o grafo de concorrência, que representa a estrutura de um programa concorrente. O grafo de concorrência é semelhante ao grafo de comunicação definido neste trabalho.

\subsubsection{Processo 6 - Apresentar Resultados}

Este processo tem a função de apresentar os resultados durante e após a simulação do programa. Apesar de parecer simples é um processo extremamente complexo, pois neste processo 0 ambiente trata a representação dos programas paralelos que podem possuir vários processos com uma grande quantidade de dados.

A principal desvantagem da utilização de gráficos, neste caso grafos, para representação de programas paralelos aparece quando os processos aumentam. Isto pode tornar a visualização significantemente mais complexa diminuindo o entendimento do usuário pelas informações mostradas [ERW98] [KAR96]. 
O primeiro passo para minimizar essa desvantagem é utilizar algum mecanismo para filtrar os dados e apresentá-los. Considerando que mesmo um programa com centenas de processos, as diferenças no código desses processos são pequenas, pode-se utilizar uma abstração e reduzir os dados para as partes necessárias [KAR96]. Por exemplo, se há um erro no processo Mestre, porque se preocupar com a visualização de todos os processos escravos.

Os mecanismos de abstração permitem reduzir a complexidade de visualização e conduzem o usuário diretamente ao erro. Isso proporciona ao ambiente uma boa flexibilidade, pois além dos mecanismos apresentados a seguir, outros mecanismos podem ser elaborados de acordo com a necessidade de cada arquitetura em que o ambiente for projetado.

Um resumo dos principais mecanismos de abstração é apresentado a seguir:

- Abstração de Eventos: esse tipo de abstração permite ao usuário reduzir os eventos com atributos iguais, construindo eventos concatenados.

- Abstração de Comunicação: um conjunto de comunicações entre diversos processos, pode ser representado por um único símbolo, diminuindo a complexidade de visualização. Por exemplo, uma mensagem enviada de um processo mestre para todos os outros processos em broadcast poderia ser representada por apenas um símbolo, evitando uma ligação com todos os processos.

- Esconder Processos: permite remover todos os processos que não fazem parte da análise. Os métodos para esconder os processos são:

- Visualizar um processo: modo padrão, permite a visualização de apenas um processo e todas as suas comunicações durante o processo de simulação.

- Visualizar somente eventos: o processo é visualizado mas suas comunicações não são mostradas.

- Visualizar somente as comunicações: esconde os eventos e exibe somente as comunicações.

- Esconder Processos: os processos e seus eventos são completamente escondidos.

- Agrupar Processos: pode ser útil para algoritmos que trabalham com vários grupos de processos que executam atividades similares. 
A filtragem dos dados para apresentação através dos mecanismos de abstração é a principal função desse processo, por isso não há necessidade de sua explosão.

\subsection{Consideraçôes Tinais}

Todos os caminhos definidos no ambiente devem ser simulados, o que possibilita ao usuário verificar o comportamento do programa para várias entradas de dados. Outro aspecto importante está relacionado com a construção do grafo de comunicação que pode ser bastante explorado, pois a partir desse tipo de grafo pode-se gerar apenas os caminhos de concorrência para execução de testes.

Com relação à simulação, a definição dos mecanismos de auxilio facilita esta atividade e, com isso, a busca por possíveis erros no programa. Os mecanismos de abstração, por sua vez, tendem a facilitar a visualização dos processos que estão sendo simulados no momento, e conduzir o usuário diretamente ao erro.

A visualização dos processos durante a simulação pode ser realmente reduzida com a utilização dos Mecanismos de Abstração. Mas diversos recursos que podem ser introduzidos durante a implementação também auxiliam bastante esse processo. Esses recursos foram utilizados na implementação e serão apresentados no próximo capítulo. 


\section{Implementação do ASTRAL}

Este capitulo descreve a implementação do ASTRAL, apresentando os principais passos que foram adotados com base no capítulo anterior, bem como algumas particularidades relációnàdas aos recursos de implementação.

\subsection{Considerações-Iniciais}

No capitulo anterior foram descritos a especificação e o projeto do ambiente de simulação e teste de programas paralelos. O projeto apresentado não está associado a nénhuma linguagem de programação paralela e ou biblioteca de passagem de mensagem, objetivando criar uma especificação formal que possibilite a implementação em qualquer uma dẹssas linguagens.

No entanto, a implementação do ambiente deve estar associada a uma linguagem específica. Permitindo visualizar o funcionamento dos principais dados apresentados no projeto, e alguns detalhes relacionados à linguagem escolhida. Nesta primeira versão do ambiente foi escolhida a linguagem $\mathrm{C}$, com a biblioteca de passagem de mensagens PVM (Parallel Virtual Machine).

O PVM é um conjunto integrado de bibliotecas e de ferramentas de software que complementam linguagens seriais (Fortran, $\mathrm{C}$ e $\mathrm{C}^{-}+$), para o desenvölvimento e execuçẫo de aplicações paralelas [BEG94]. Foi desenvolvido pelo Oak Ridge National Laboratory (ORNL), e seu principal objetivo 'é 'permitir que um grupo de computadores' conectados (possivelmente com diferentes arquiteturas) possa trabalhar cooperativamente formando uma máquina paralela virtual.

Para implementação do ASTRAL foi utilizado o ambiente de, desenvolvimento C++ Builder 5, que permite a criação de aplicações console WIN32 ou programas.WIN32 GUI (Graphical User Interface) de forma mais rápida e com uma maior facilidade do que as linguagens não visuais. O C ++ Builder é uma linguagem orientada a objetos, o que permite uma boa modularização do código, além de ser uma versão RAD (Rapid. Application Development - Desenvolvimento Rápido de Aplicações) da linguagem C para Windows. Mais informações sobre esse ambiente de desenvolvimento podem ser encontradas em [MAT00]. 


\subsection{O Ambiente}

A Interface do ASTRAL é dividị̦a basicamente em três partes: o Menu de opções, a Barra de Ferramentas e a Área de Trabalho. A janela principal do ambiente pode ser visualizada na Figura 6.1 abaixo.

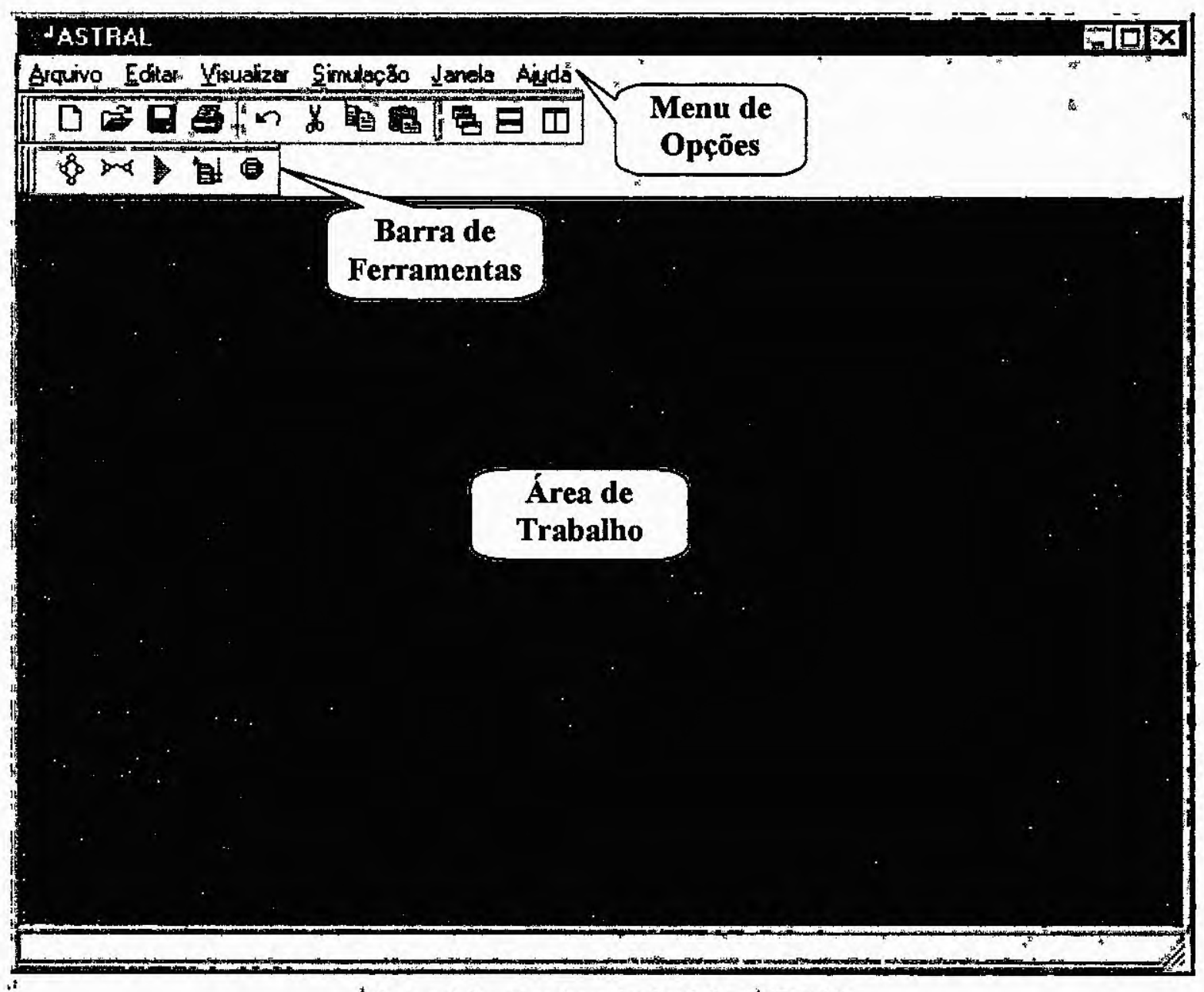

Figura 6.1 - Janela principal do ASTRAL

No Menu de.Opções está a maioria dos comandos e funções do ambiente:

- Menu Arquivo: possuí os comandos de manipulação de arquivos, como: criar um novo arquivo, abrir um arquivo existente, salvar o arquivo, e imprimir o arquivo.

- Menu Editar: possui comandos para manipulação do arquivo, como: copiar um trecho selecionado, excluir o trecho selecionado, colar o trecho em outro local, selecionar todo o arquivo, procurar por um texto, e substituir um texto.

- Menu Visualizar: neste menu estão os comandos para geração dos grafos de fluxo de instruções e de comunicação, bem como os comandos que facilitam e auxiliam na visualização dos grafos gerados (mecanismos de abstração). 
- Menu Simulação: possui os comandos para simulação do programa, como por exemplo, o controle da simulação (mecanismo de auxílio).

- Menu Janela: permite a organização (vertical, horizontal ou em cascata) de todas as janelas que estiverem abertas no programa, e também a seleção de uma janela especifica para ser visualizada em um determinado momento.

- Menu Ajuda: este último menu apresenta informações sobre o sistema (Figura 6.2).

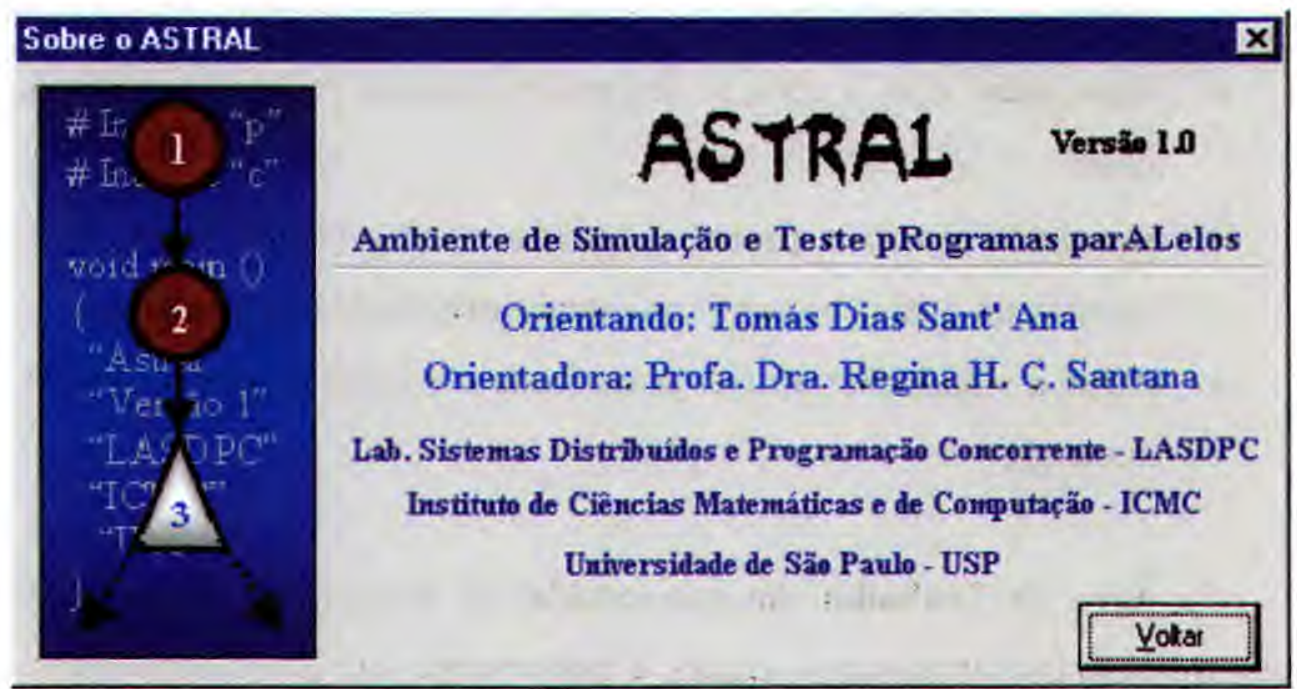

Figura 6.2 - Janela de informações sobre o ASTRAL

$\mathrm{Na}$ Barra de Ferramentas (Figura 6.3) estão disponíveis, através de ícones, os principais comandos utilizados no programa, que também estão presentes no menu.

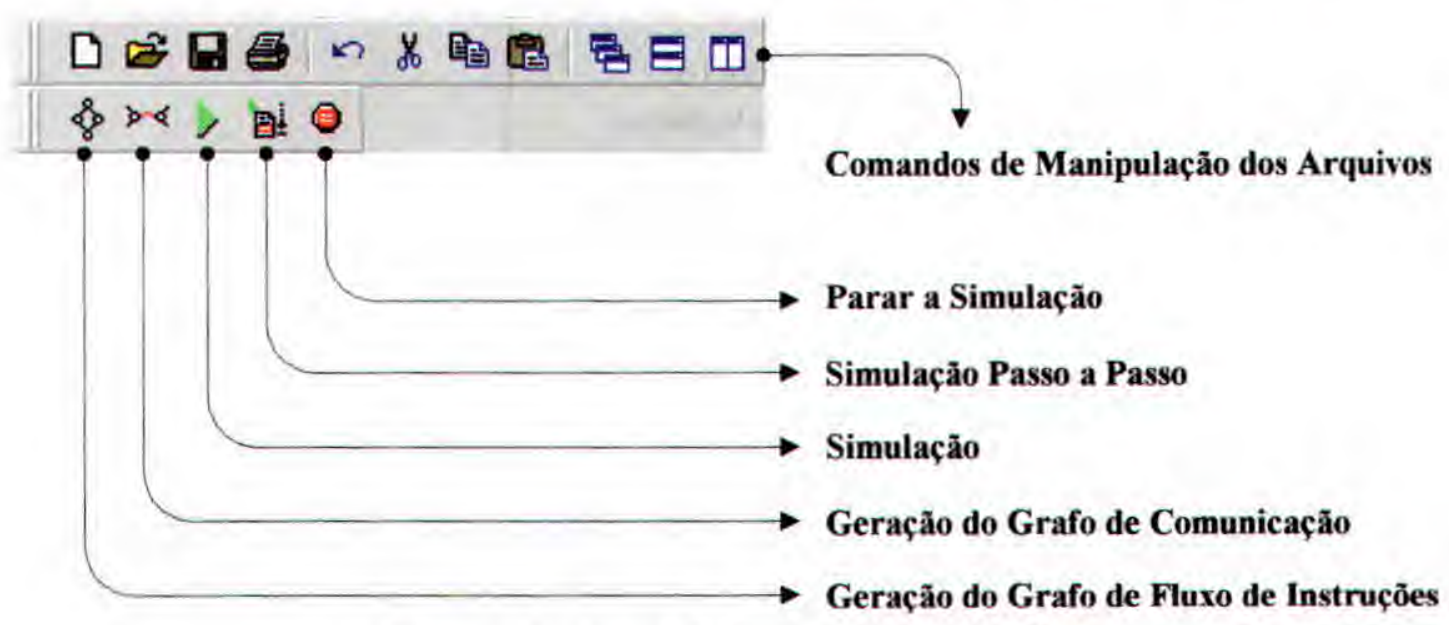

Figura 6.3 - Barra de ferramentas do ASTRAL

Cada ícone tem uma função específica:

- Comandos de manipulação de arquivos: esses ícones têm respectivamente as seguintes funções: criar um novo arquivo para editar o programa fonte, abrir um 
arquivo existente, salvar o arquivo selecionado, imprimir o arquivo selecionado, voltar o último comando realizado no texto, recortar um texto selecionado, copiar um texto selecionado, colar o texto copiado, organizar as janelas em cascata, na horizontal e na vertical.

- Geração dos grafos de fluxo de instruções: sua função é criar a.janela dos grafos de fluxo de instruções do processo selecionado.

- Geração do grafo de comunicação: esse ícone permite a geração do grafo de comunicação dos-processos envolvidos na comunicação

- Simulação: após a geracão dos grafos, pode-se rẹalizar-a simulaçãa através deste iconén.

- Simulação passo a passo: - . . ário pode controlar o processo de simulação, obseryando quạl o comando está sendo executado taquele instante.

- Parar a simulação: através deste ícone o usuário pode interromper o processo de simulação:

$\mathrm{Na}$ Área de Trabalho são apresentadas as diversaş jąnelas para simulação. Essas janelás são exibidas nas próximas secões, e basicamente são: janela do programa paralelo, dos grafos de fluxo de instruções e do grafo de comunicação. Cad’a janela possui ainda um menu local com comandos específicos (Figura 6.4).

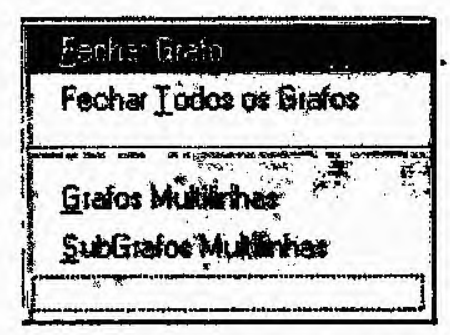

Figura 6.4 - Menu local dos grafos de fluxo de instruções

A interface do ambiente com o usuário é o mecanismo pelo qual se estabelece um diálogo entre o programa e o ser humano [PRE95], ou seja, o ambiente deve permitir uma interface amigável e de fácil utilização para o usuário. Com isso, um ambiente que permite ao usuário visualizar e controlar o comportamento de um programa paralelo, através de grafos, em busca de erros; deve prover um conjunto de funcionalidades que facilitem a sua utilização. Essas funcionalidades seguem os padrões de linguagens fortemente estabelecidas no mercado e são apresentadas no decorrer das próximas seções. 


\subsection{Criar / Editar um programa no ASTRAL}

A criação ou edição de um programa paralelo é o primeiro passo na utilização do ambiente para realizar a simulação. O usuário tem a opção de abrir um arquivo existente ou criar o arquivo no próprio ambiente, com diversos recursos de um editor de arquivo fonte comum: salvar, salvar como, fechar, fechar todos, copiar, colar, selecionar tudo, procurar, substituir, desfazer as últimas ações, entre outros.

A Figura 6.5 mostra alguns arquivos fonte abertos no ambiente. Cada arquivo possui uma página com o seu nome, e o caminho completo do arquivo selecionado é exibido como título da janela. Quando um arquivo é criado no próprio ambiente, este recebe o nome de ArquivoX.cpp, onde $X$ é número do arquivo. Como exemplo, observe na Figura 6.5 os arquivos Arquivo6.cpp e Arquivo7.cpp.

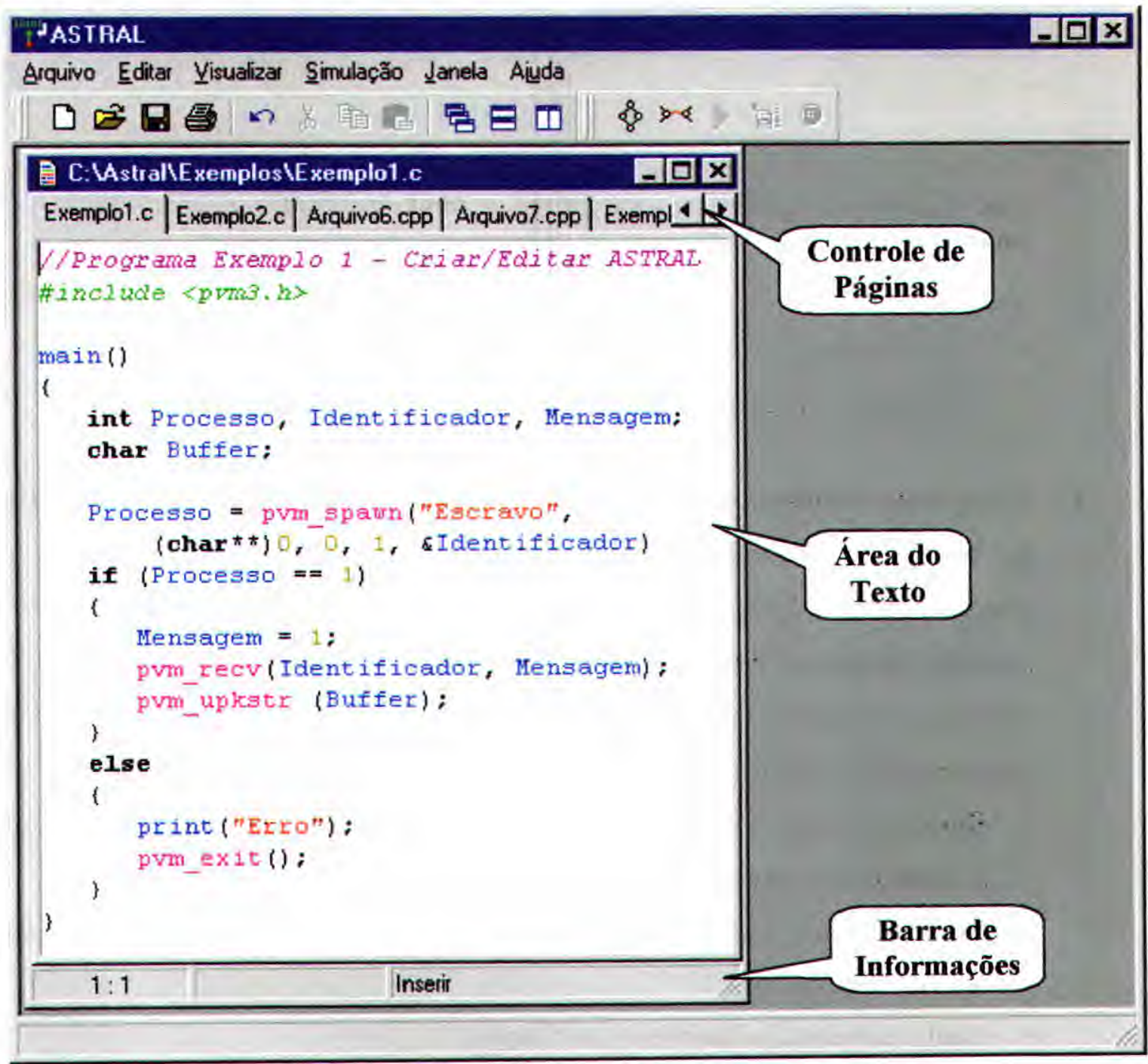

Figura 6.5 - Arquivo Exemplol.c sendo editado no ASTRAL 
Os arquivos abertos no ambiente possuem algumas peculiaridades, que podem ser visualizadas na Figura 6.5 e são descritas abaixo:

- Controle de páginas: todos os arquivos abertos estão em uma mesma janela, o que permite visualizar o nome de todos os arquivos e sem ocupar muito espaço. Essa funcionalidade é bastante interessante, principalmente em programas MPMD ${ }^{3}$ (Multiple Program Multiple Data). Os nomes dos arquivos representam sua respectiva página dentro da janela, e para mudar de um programa para outro basta clicar sobre a página onde está escrito seu nome. As páginas podem ser visualizadas em uma linha (utilizando barra de rolagem para acessar todos os nomes - Figura 6.6b) ou em múltiplas linhas (Figura 6.6a).

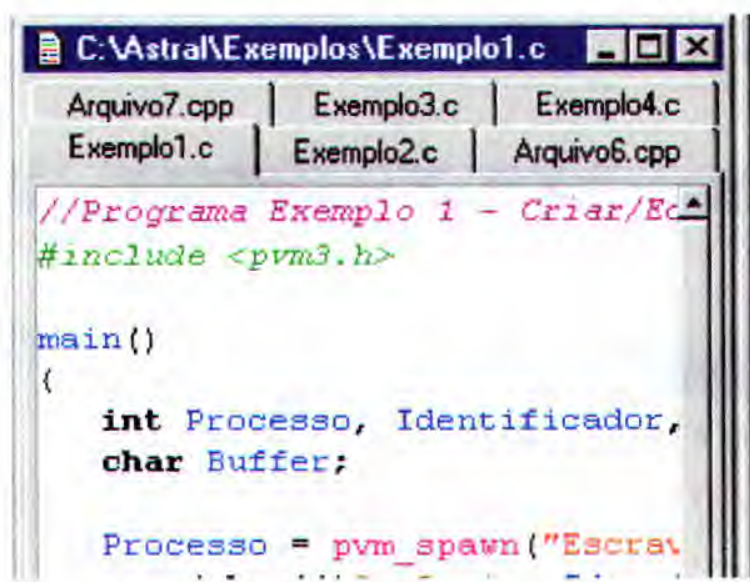

(a)

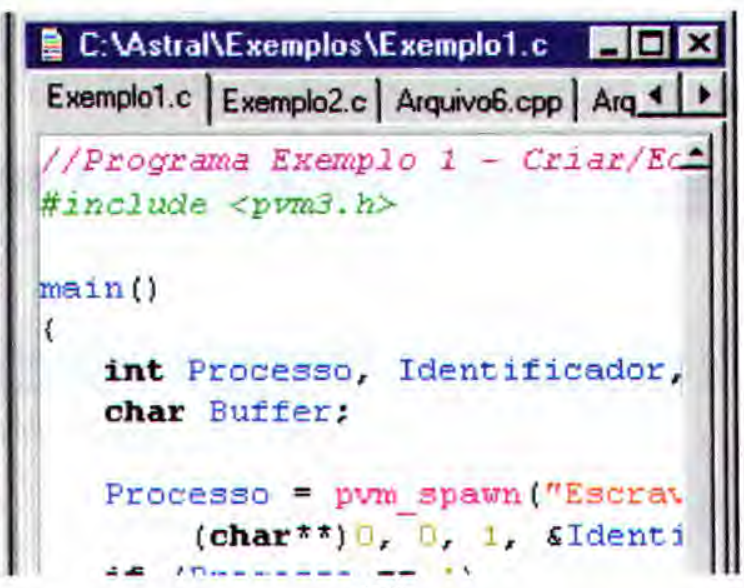

(b)

Figura 6.6 - Controle de Páginas com uma linha (b) e múltiplas linhas (a)

- Texto fonte colorido: o texto fonte do programa é representado por cores (área do texto), que permitem distinguir melhor os comandos, principalmente os comandos envolvidos na comunicação (PVM). O processo de destacar o texto é realizado quando o programa é aberto, e também durante a sua edição. Neste momento é realizada uma "pré-interpretação" para que os comandos possam ser reconhecidos. As principais cores definidas no ambiente são:

- Rosa: representa os comandos de comunicação e sincronização, neste caso os comandos e funções do PVM.

- Preto negrito: representa as palavras reservadas da linguagem C: int, char, return, entre outros.

- Azul: representa as variáveis e as funções.

\footnotetext{
${ }^{3}$ MPMD consiste em vários arquivos que formam o programa paralelo, ao contrário de um SPMD (Single Program Multiple Data) onde todos os processos do programa estão armazenados em apenas um arquivo.
} 
- Vermelho: string.

- Roxo Itálico: comentário.

- Verde Itálico: inclusão de biblioteca.

- Amarelo: número.

- Outras ,informações: na parte inferior da janela de texto (barra de informações) existem algumas informações que auxiliam a utilização dos arquivos, como: número da linha e coluna, onde está o cursor, se o programą foi ou não-modificado, e se o cursor está emr modo de inserir ou sobrescrever.

\subsection{Grafos de Fluxo de Instruções}

Após o programa aberto; $\sigma$ próximo passōé a geração dơgrafo de fluxxo de instruções.

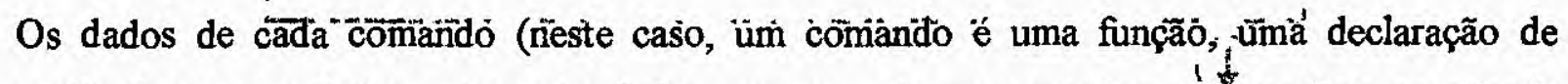
variável, uma condição, entre outros) do programa são armazenados emưma lista encadeada por alocação dinâmica de memória, esta lista é representada pela estrutura dả Listagem 6.1.

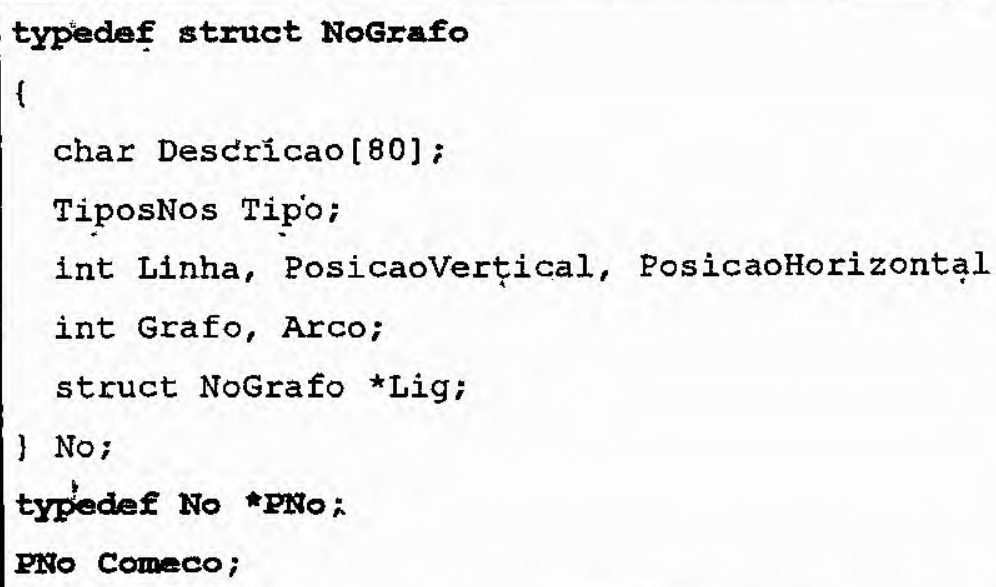

Listagem 6.1 - Estrutura de armazenamento do Grafo de Fluxo de Instruçães

Cada nó da estrutura NoGrafo (Listagem 6.1), corresponde a um comando do programa e possui as informações necessárias para que este possa ser desenhado no ambiente. A variável Comeco aponta para o nó raiz e as principais informações armazenadas por cada nó são:

- Linha: armazena o número da linha em que o comando está localizado no programa.

- Descrição: armazena a descrição do comando. 
- Posição vertical e horizontal: estes valores dependem do tipo de comando e são utilizados para desenhar o nó na posição correta.

- Grafo: para cada função do programa é gerado um grafo, portanto essa informação indica o número do grafo a que o comando pertence.

- Arco: utilizado para armażenar a posição dos comandos que necessitam de mais de um arco, por exemplo, o comando if.

- *Lig: ligação para o próximo comando do grafo.

- Tipo: é o tipo do comando, que pode sèr: if, else, função...

Os tipos de comando são representados no grafo por diferentes ícones (Tabela 6.1), que facilitam a identificação pelo usuário.

\begin{tabular}{|c|c|}
\hline leene & (x) \\
\hline & Representa o início de uma função. \\
\hline & Retorno da função (return). \\
\hline & Declaraçăo de variável. $\quad \cdots \cdots$ \\
\hline & Comando seqüencial ou função interna. \\
\hline & Chamada de função definida pelo usuário. \\
\hline & Início do comando condicional if. \\
\hline & Fim do comando condicional if. \\
\hline & Início do comando condicional if com else. \\
\hline & Fim do comando condicional if com else. \\
\hline & Iníciọ de um loop (for) ou de uma repetição (while) \\
\hline & Fim do loop (for) ou da repetição (while) \\
\hline 16? & Comando de execução em paralelo (pvm_spawn). \\
\hline & Comando de envio ( $p v m_{-}$send). \\
\hline & Comando de recebimento ( $p v m$ recv). \\
\hline
\end{tabular}

Tabela 6.1 - Relação dos ícones dò ASTRAL 


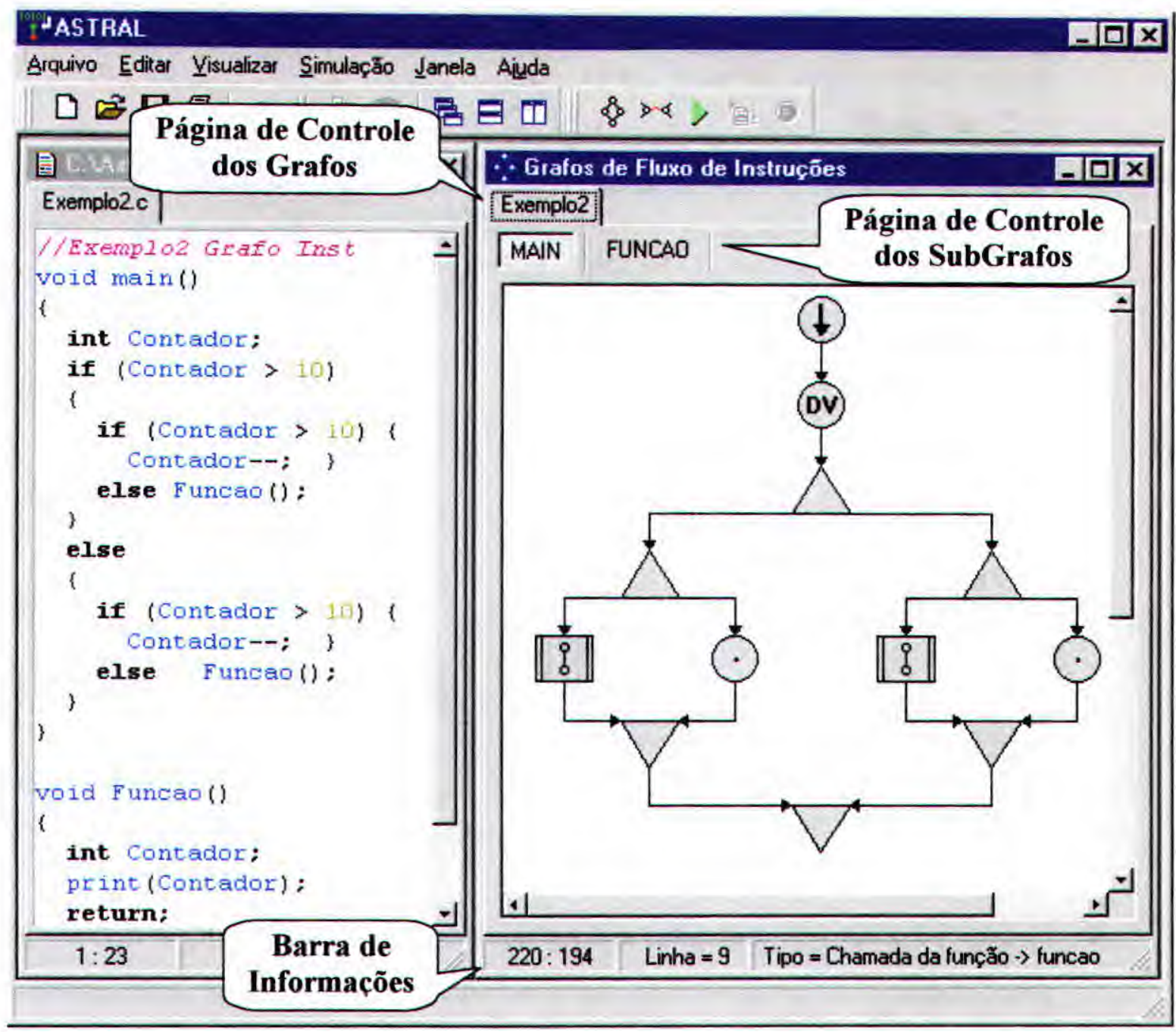

Figura 6.7 - Exemplo de um grafo de fluxo de instruções gerado no ASTRAL

A Figura 6.7 mostra o grafo de fluxo de instruções do Exemplo2.c gerado no ASTRAL. Através deste grafo pode-se observar a aplicação dos ícones apresentados na Tabela 6.1, e os recursos que o ASTRAL utiliza para reduzir as informações (mecanismos de abstração) sem prejudicar o funcionamento do programa:

- Ícones específicos: como visto anteriormente, o ambiente representa cada comando do programa por um ícone específico, descrito na Tabela $6.1 \mathrm{e}$ apresentado na Figura 6.7.

- SubGrafos para cada função: é gerado um subgrafo para cada função ou procedimento do programa. Como exemplo, observe a Figura 6.7, existe um grafo para a função principal Main (que está sendo visualizado) e outro para o procedimento Funcao. O nome da função é colocado na página de controle do SubGrafo, que pode ser acessada simplesmente clicando sobre o seu nome. A Figura 6.8 mostra o mesmo grafo, mas com a página Funcao selecionada. 


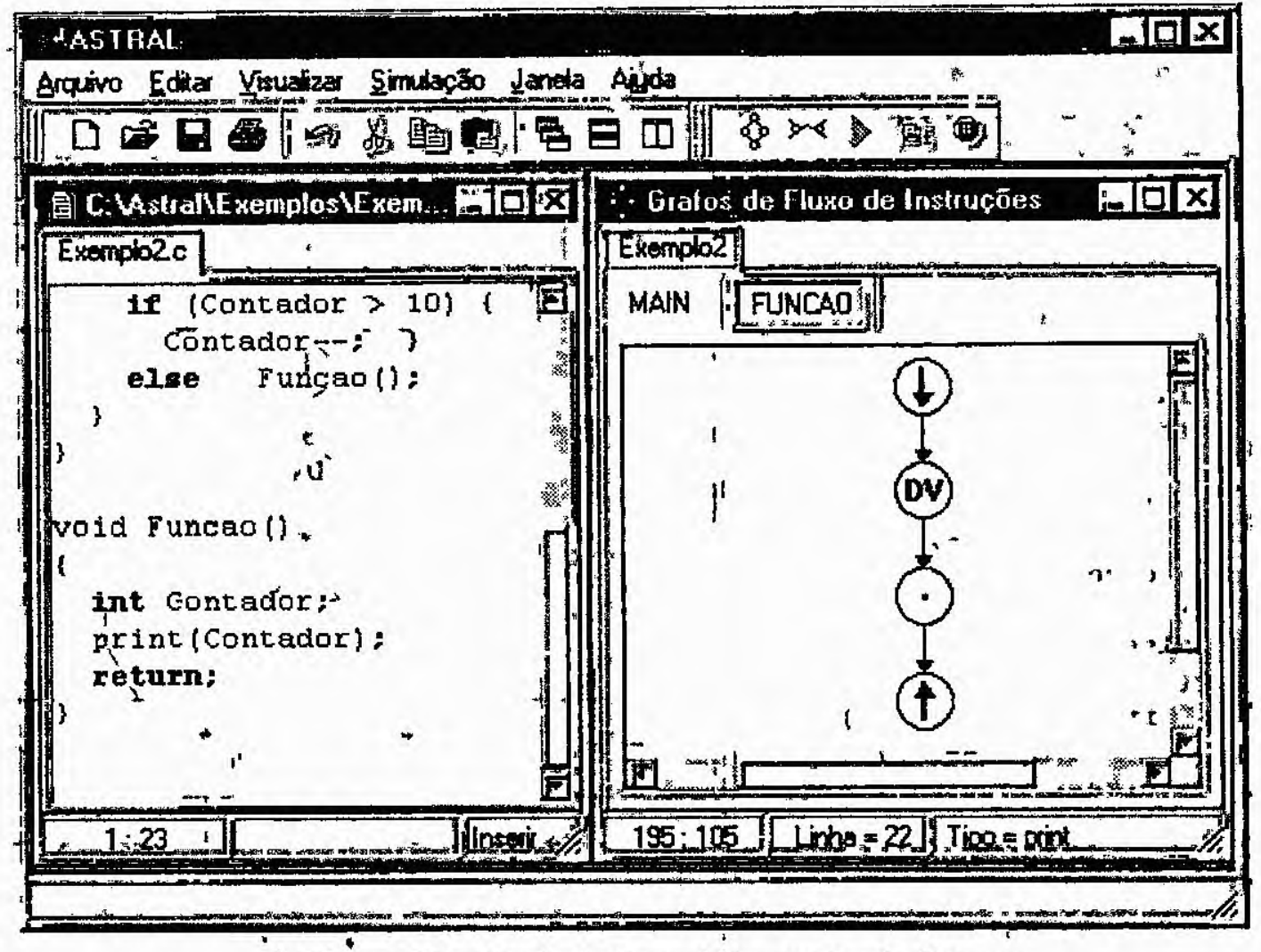

Figura 6.8 - Grafo de fluxo dé instruções de Funcao

- Grafos e-SubGrafós múltiplas linhas: quanto mäior a quantidade dé processos e funções dentro desses processos, maior o tamànho e o nưmero de grăfôs gerāđōs. Por isso, para facilitar a visualização de todos os grafos, estes pōem ser cōlocados em múltiplas linhas, como na janela de edição dos arquivos fontes.

- Número da Linha e tipo do comando: quando se move o ponteiro do mouse, sobre qualquer ícone, o número da linha 'correspondente no código,fonte e o tipo do comando são exibidos na parte inferior da janela (barra de informações) dos grafos de fluxo de instruções.

Além de exibir 'essas informações, se o usuário clicar sobre qualquer nó, automaticamente a linha onde ele está localizado será selecionada. Em adição, os comandos de chamada e ou retorno de função aceitam o duplo clique çom a função, de, r, respectivamente, visualizar’a função chamada e ou retornar para função que o chamoụ.

Em programas paralelos, cada processo é representado por um grafo,e seus respectivos subgrafos de funções. As Figuras 6.9 e 6.10 apresentam os grafos de fluxo de instruções de um programa paralelo com um processo mestre e um escravo, respectivamente. 


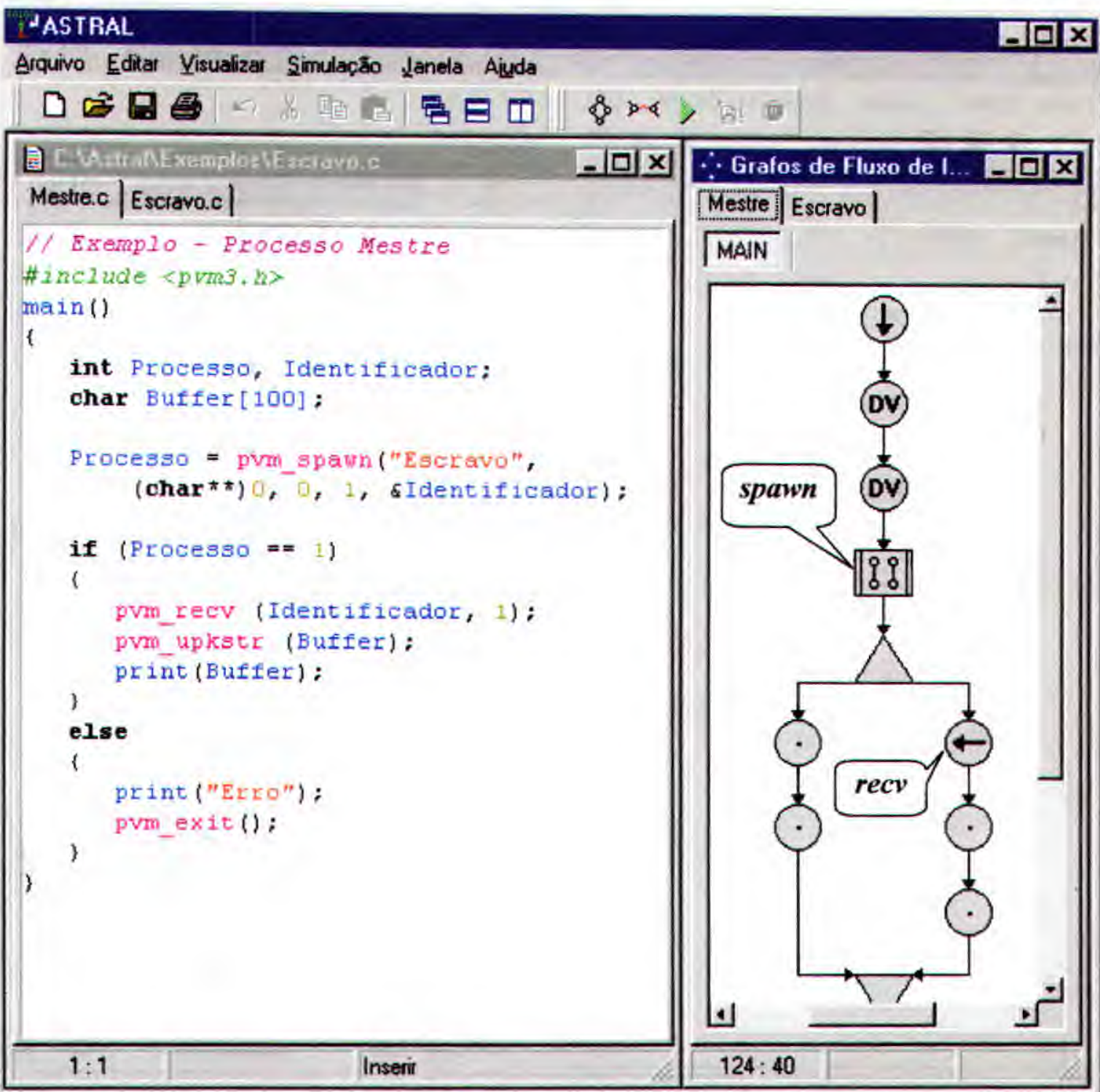

Figura 6.9 - Grafo de fluxo de instruções do processo Mestre

Ao abrir o programa Mestre.c, o usuário deve gerar o grafo de fluxo de instruções (Figura 6.9) deste processo. Observe que o grafo gerado representa todos os comandos do processo, inclusive os comandos de comunicação: o pvm_spawn (que ativa os processo em paralelo, neste caso um único processo escravo) e o pvm_recv (que aguarda uma mensagem do escravo).

Depois de gerado o grafo do programa Mestre, o usuário abre o programa Escravo.c e cria o grafo de fluxo de instruções (Figura 6.10) deste processo, O processo Escravo possui apenas um nó de comunicação pvm_send (que tem a função de enviar a mensagem para o processo Mestre), 


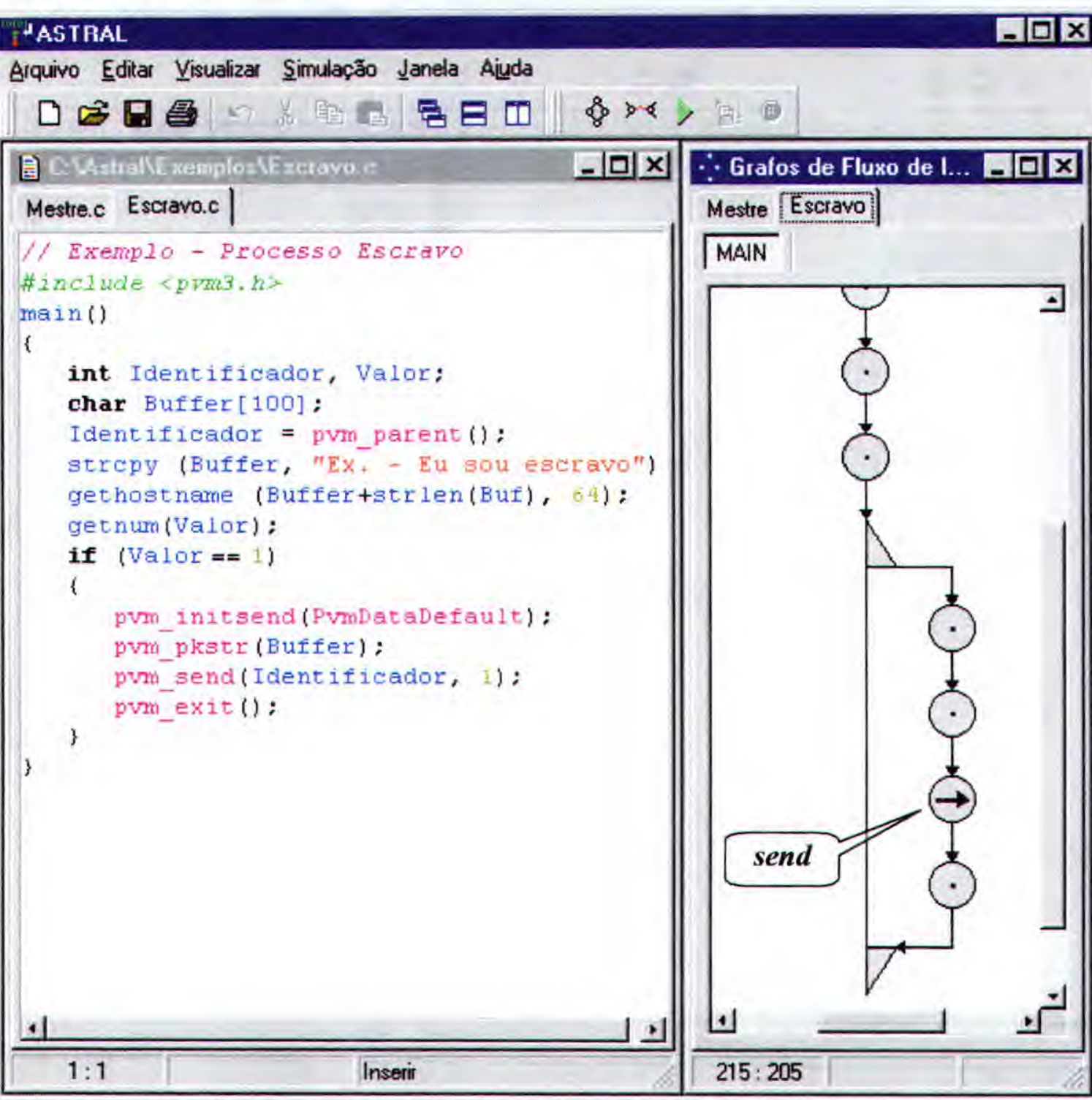

Figura 6.10 - Grafo de fluxo de instruções do processo Escravo

\subsection{Grafo de Comunicação}

Com a geração dos grafos de fluxo de instruções o ambiente permite também a criação do grafo de comunicação, que tem como função principal diminuir consideravelmente a quantidade de nós apresentados no grafo, mostrando apenas os nós envolvidos na comunicação e ou sincronização e que afetam a interação entre os processos.

No ambiente, para um programa paralelo que será simulado é gerado apenas um grafo de comunicação, ao contrário do grafo de fluxo de instruções que cria um grafo para cada processo. No grafo de fluxo de instruções cada comando é um nó do grafo e tem sua respectiva representação gráfica, o que não acontece no grafo de comunicação. 
No grafo de comunicação, as declarações de variáveis, as atribuições, as funções internas não são representadas. As funções definidas pelo usuário têm um nó de representação, mas não são gerados seus subgrafos como ocorre no grafo de fluxo de instruções. Um comando condicional ou uma repetição são representados por apenas um ícone, e são "explodidos" quando existem comandos de comunicação e ou sincronização em seu interior.

Para entender melhor o grafo de comunicação observe a Figura 6.11, neste exemplo, existe um programa Mestre que ativa um processo Escravo em paralelo. O programa utiliza o paradigma MPMD (Multiple Programa Multiple Data), onde o programa Mestre.c possuiu código do Mestre e Escravo.c o código do Escravo.

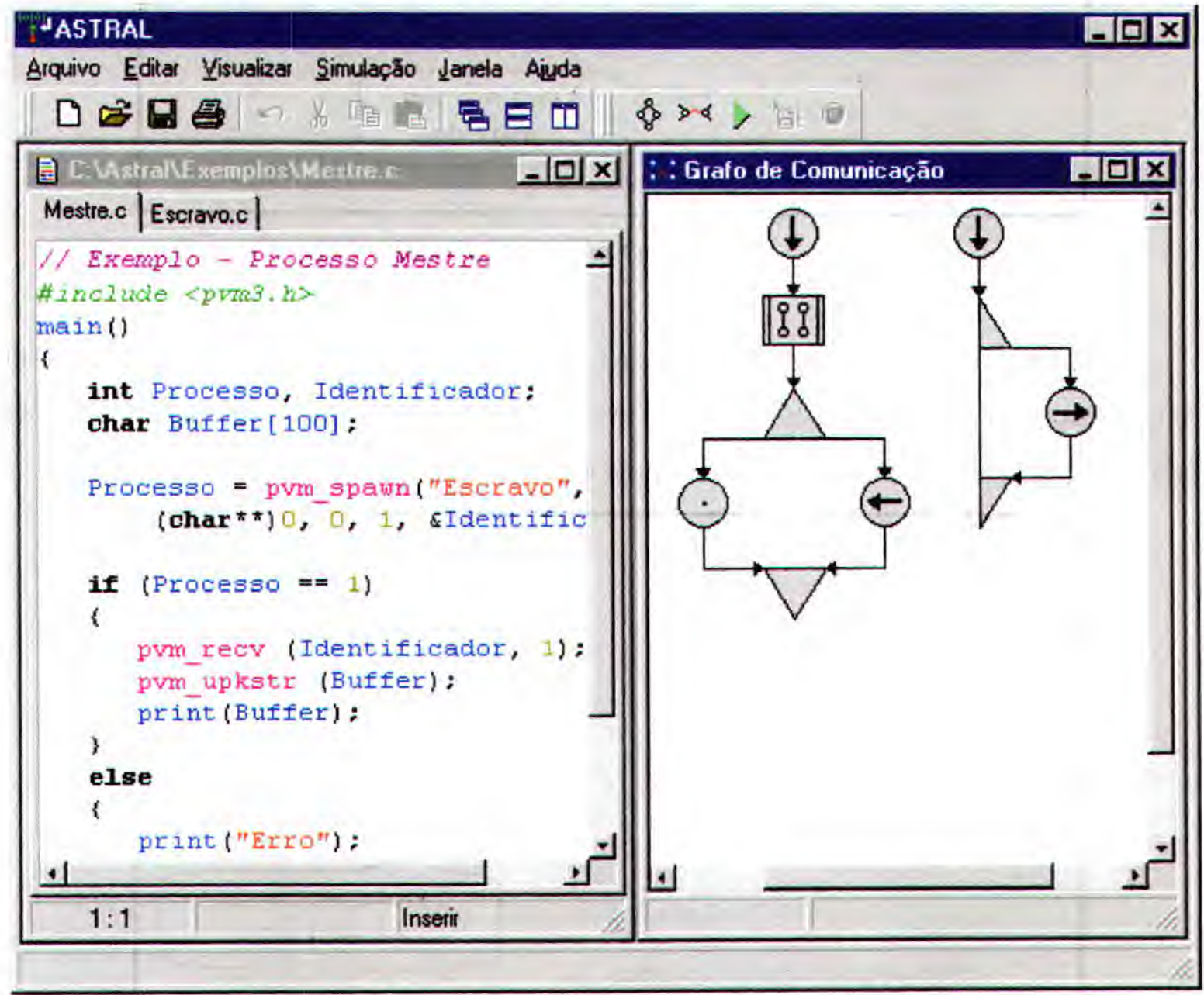

Figura 6.11 - Grafo de comunicação gerado no ASTRAL

$\mathrm{Na}$ Figura 6.11 pode-se observar o grafo de comunicação, que apresenta apenas os comandos envolvidos na comunicação. No programa Mestre.c, são representados apenas o pvm_spawn e o pvm_recv. Como o pvm_recv está dentro de um if, esse também deve ser 
apresentado, pois pode interferir na comunicação. A Listagem 6.2 exibe o código do programa Mestre.c, destacando os nós rep̉èsentados no grafo de comunicação.

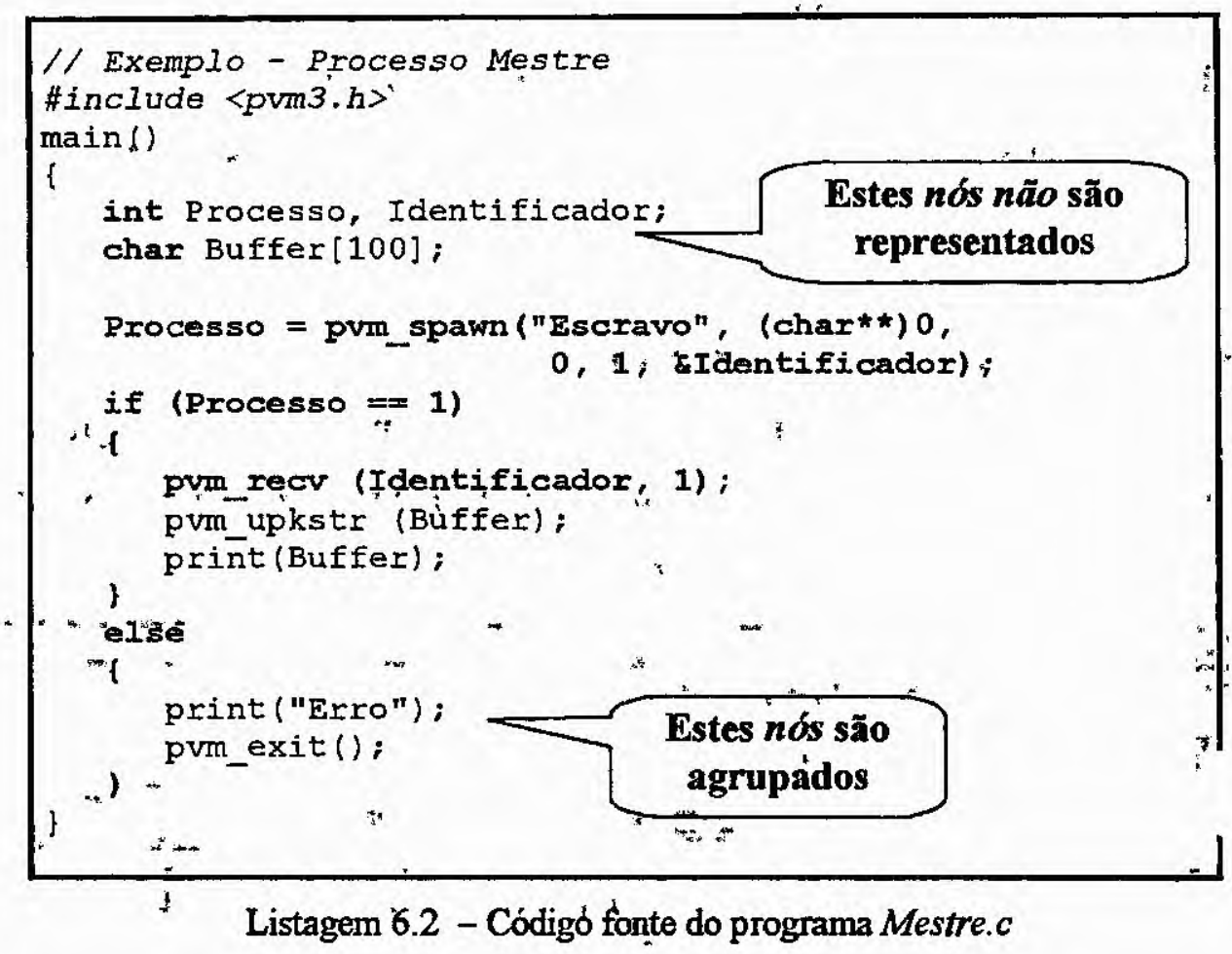

A Lis̄tagem 6.3 apresenta o programa Escravo.c, que possui apenas um comando de comunicação $\mathrm{pvm}^{\prime}$ send. Mas como ele está dentro de um if, esse também é repressentutado no grafo, pois como no caso anterior também pódé interferir na comunicação.

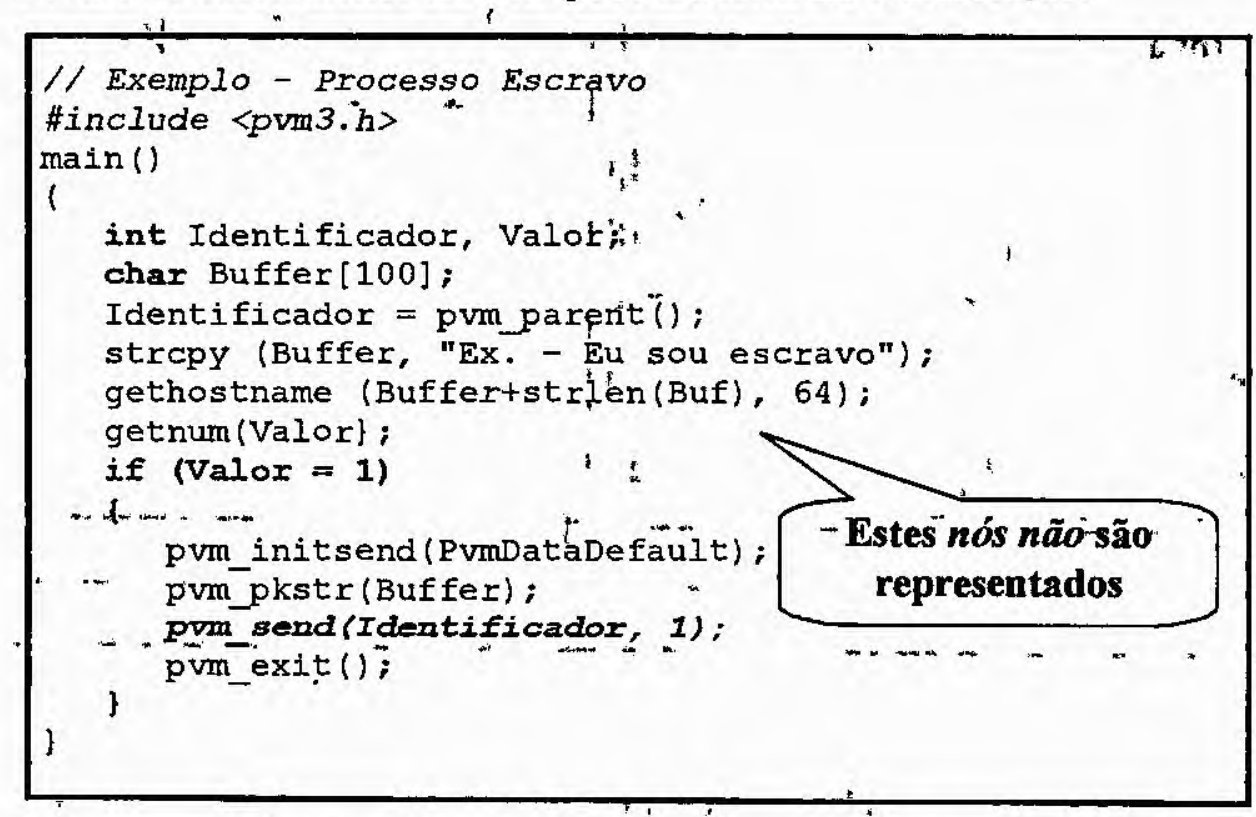

Listagem 6.3 - Código fonte do programa Escravo.c 


\subsection{Simulação}

Depois de gerados os grafos de fluxo de instruções e o grafo de comunicação o programa poderá ser simulado. Para realizar a simulação do programa, foi criado um interpretador para as principais funções da Linguagem C e de PVM (seção 6.7).

Durante a simulação quando os comandos vão sendo interpretados, seus respectivos nós são coloridos no grafo. Como pode ser observado na Figura 6.12 os nós já interpretados são coloridos de uma cor (marrom) e os nós que estão sendo interpretados no momento de outra (azul). A interpretação pode ser realizada passo a passo, permitindo ao usuário controlar a simulação do programa.

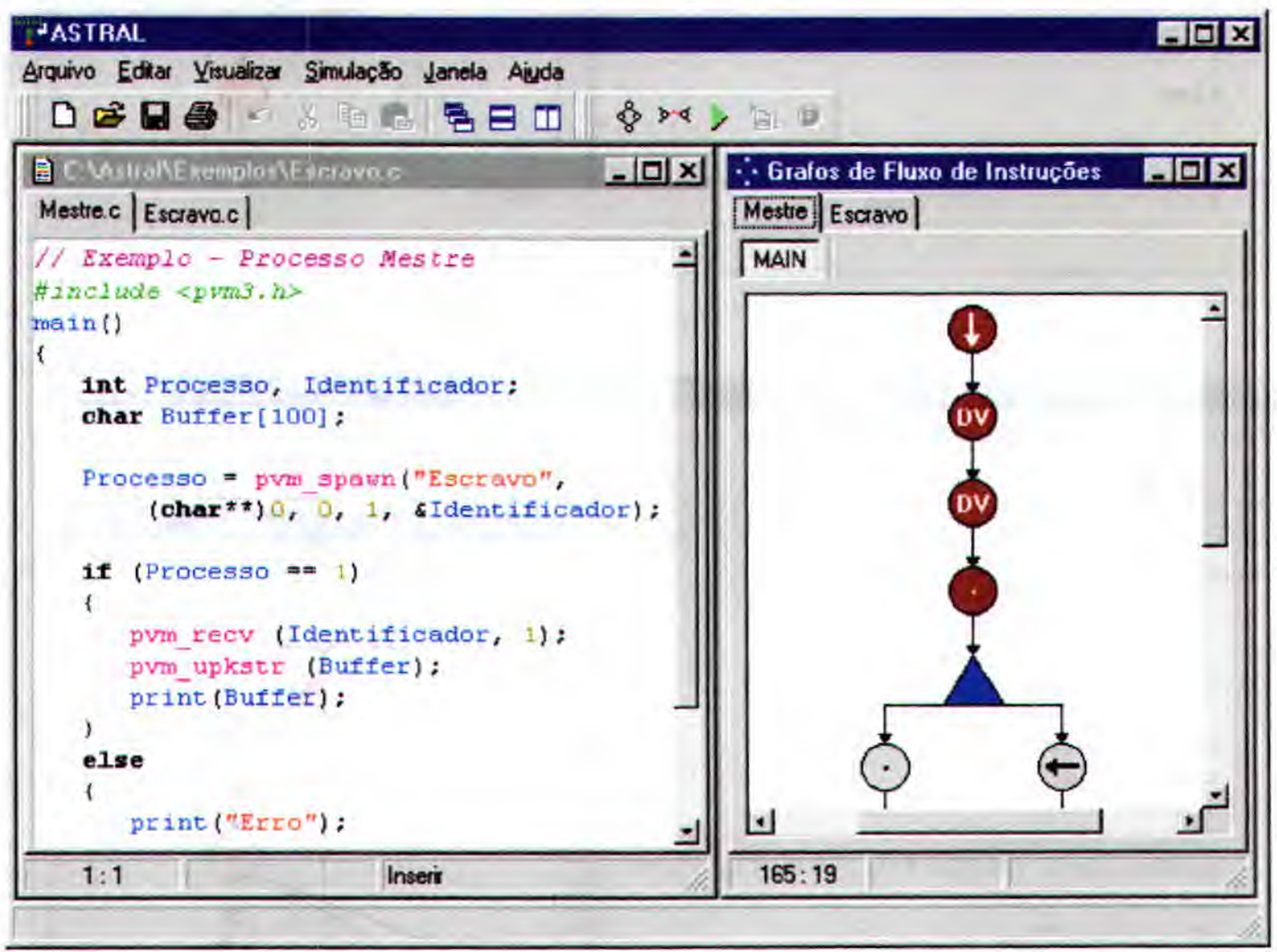

Figura 6.12 - Simulação de um programa no ASTRAL

Para realizar a simulação, é criado um thread para cada processo ativado pelo pvm_spawn. Com isso, todos os processos são simulados concorrentemente, como se estivessem rodando em paralelo. O usuário pode então observar o comportamento do programa, e os possíveis erros que possam ocorrer. A Figura 6.13 apresenta um erro simples que pode ser identificado com facilidade no ASTRAL. 
Arquivo Editar Yisualizar Simulação J̦anela Aiuda

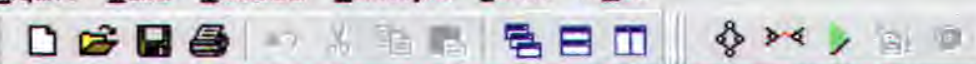

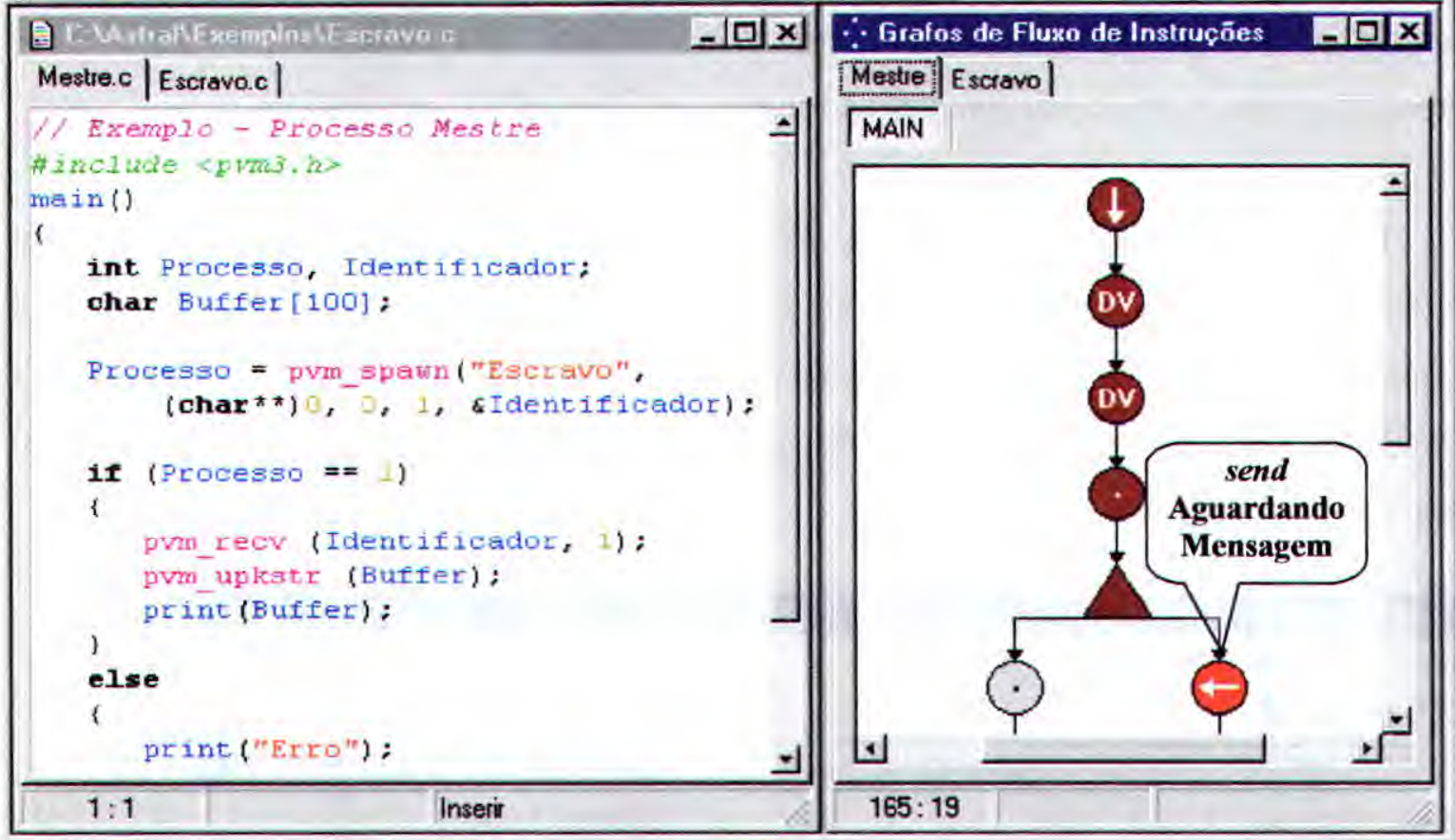

Figura 6.13 - O processo Mestre aguarda por uma mensagem do Escravo

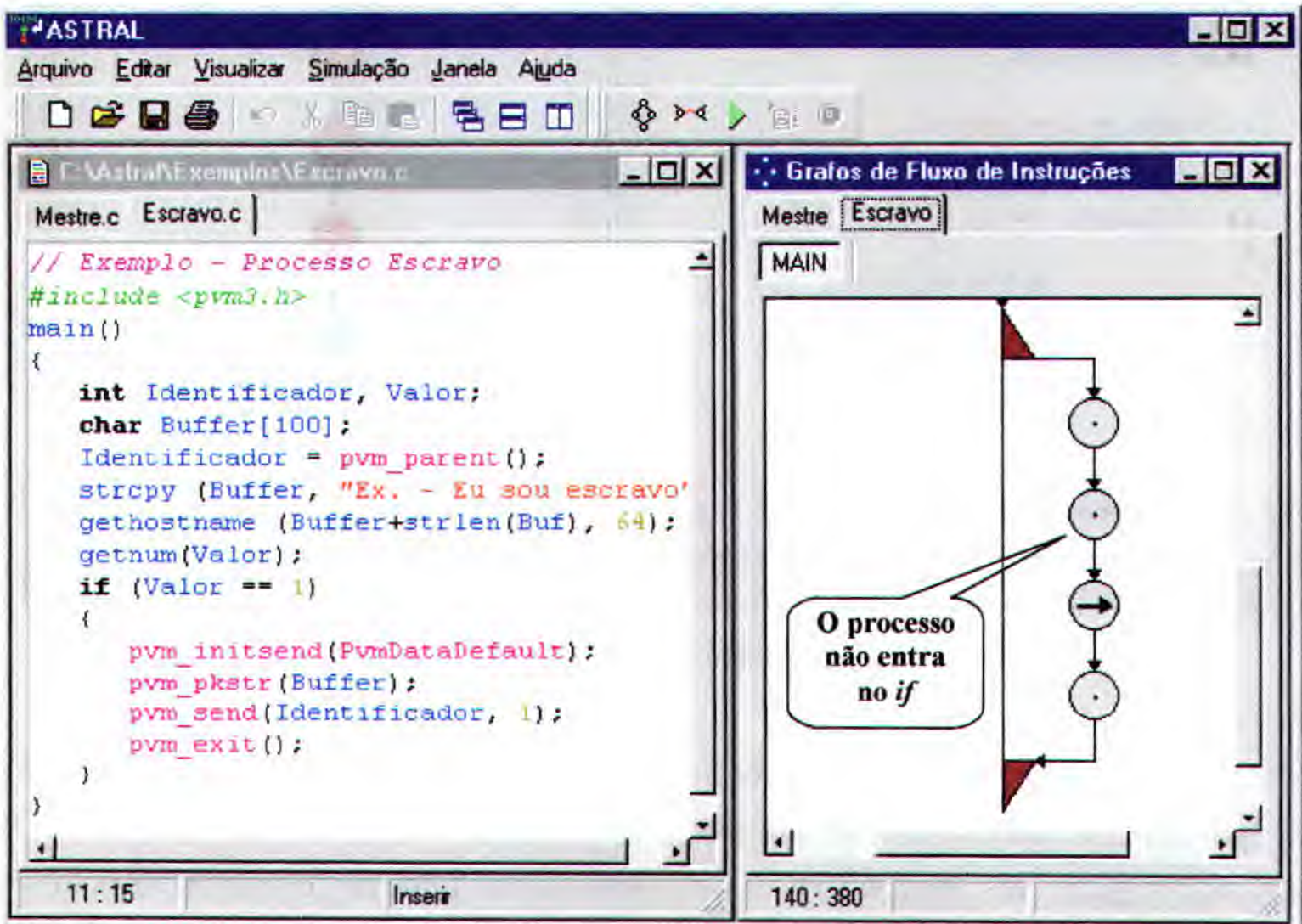

Figura 6.14 - O processo Escravo já terminou sua execução 
Na Figura 6.13 o processo Mestre aguarda por uma mensagem do Escravo, mas neste caso o escravo já terminou sua execução e não tem nada para ser enviado, como pode ser visto na Figura 6,14. Esse tipo de erro (espera infinita), considerando a primitiva pvm_recv como bloqueante (seção 2.4.3), ocorreu porque o processo Escravo não entrou no if, pois o valor da variável Valor não é igual a 1. O valor desta variável é obtido através da função getnum, que obtém o valor através da entrada de dados.

\subsubsection{Entrada de Dados}

$\mathrm{Na}$ seção 5.3.2.2 foram definidas as formas para se obter as entradas de dados para percorrer um ou mais caminhos e simular o programa. Com o objetivo de manter as principais características do ambiente, de permitir ao usuário visualizar e controlar o comportamento do programa, nesta primeira versão as entradas de dados são fornecidas pelo usuário durante a interpretação (Figura 6.15).

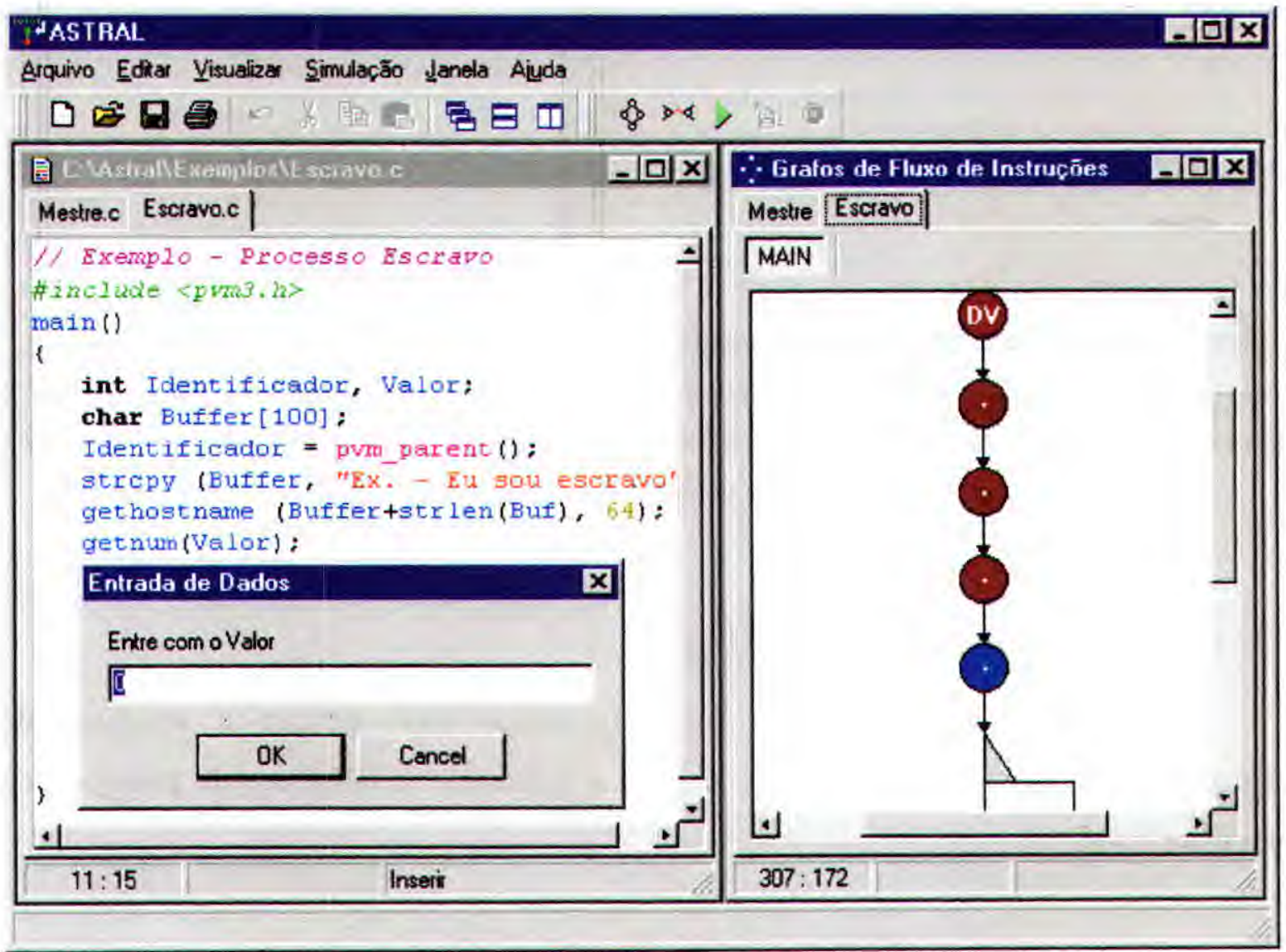

Figura 6.15 - Exemplo de uma entrada de dados durante a simulação. 


\subsubsection{Saída de Dados}

As saídas de dados dos processos também são apresentadas ao usuário, que pode visualizar os dados e avaliar a simulação. Para cada processo do programa é gerada uma página para apresentação das saídas (Figura 6.16), quando necessário. Verificando as saídas o usuário pode alterar as entradas e simular o programa com os novos dados.

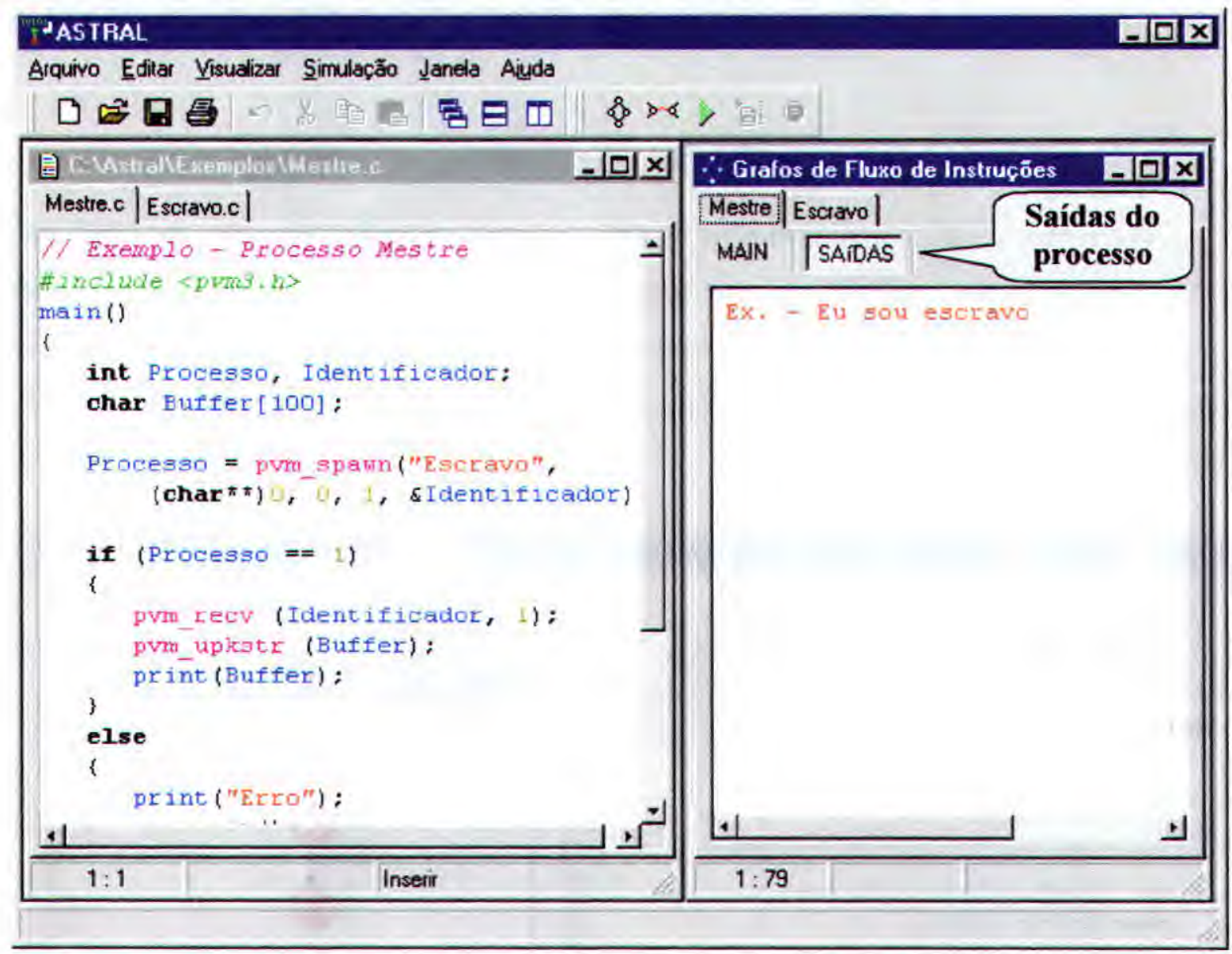

Figura 6.16 - Exemplo de uma saida de dados do processo Mestre durante a simulação.

\subsection{Estrutura interna do ASTRAL}

A implementação do ASTRAL, em sua versão atual, permite a simulação de programas desenvolvidos na Linguagem C com a utilização da biblioteca de passagem de mensagens PVM.

Para realizar a simulação foi desenvolvido um interpretador para Linguagem C [SCH96] [KEL95], nesse interpretador é considerado um subconjunto restrito da Linguagem $\mathrm{C}$ (funções parametrizadas com variáveis locais; recursividade; o comando if; os laços while e for; as variáveis inteiras e caractere; variáveis globais; constantes inteiras e caractere; o comando return; um número limitado de funções da biblioteca padrão, entre outros). 
Com relação ao PVM, também foi implementado apenas um subconjunto de funções, entre elas, funções para ativar os processos em paralelo e também funções de comunicação bloqueante e não bloqueante. É importante destacar que, com o interpretador pronto, acrescentar novas funções pode ser feito de maneira simples, principalmente com a criação de um banco de dados, para que o próprio usuário possa inserir as funções dessa e de outras bibliotecas de passagem de mensagem.

\subsection{Considerações Finais}

O ASTRAL realiza a simulação de aplicações paralelas desenvolvidas na Linguagem C, com a utilização da biblioteca de passagem de mensagens PVM. A escolha do PVM devese principalmente a sua ampla utilização pela comunidade de computação paralela, já que apresenta características interessantes como simplicidade, robustez e portabilidade; facilitando o trabalho do programador [BEG94].

Com a utilização do ASTRAL é possível visualizar a execução de um programa paralelo escrito na linguagem C e utilizando PVM. Através dessa visualização, pode-se identificar facilmente alguns tipos de erros, como: loops infinitos, processos parados em comunicações que nunca ocorrem (espera infinita), entre outros.

A possibilidade de alterar os dados do programa permite que o usuário verifique e controle o comportamento do programa para diferentes entradas. Em sua versão atual, o ambiente implementa apenas a simulação através de dados fornecidos pelo usuário. A geração de caminhos e a execução através de arquivos de trace (conforme seção 5.3.2.2), podem ser facilmente inseridas no ambiente. 


\section{Conclusões}

Nesse capítulo são apresentados os comentários finais sobre o trabalho desenvolvido, destacando as principais conclusões, as dificuldades encontradas, e os passos a serem seguidos para a sua continuidade.

\subsection{Considerações Iniciais}

Neste trabalho apresentou-se o ASTRAL, um ambiente para simulação e teste de programas paralelos. O ambiente permite ao usuário, através da representação gráfica (grafos de fluxo de instruções e grafo de comunicação), visualizar e controlar o comportamento de um programa paralelo podendo identificar erros relacionados à execução paralela e problemas de desempenho.

No início foram discutidos os aspectos relacionados à computação paralela (Capítulo 2), principal área em que o trabalho está inserido. No Capítulo 3 foram apresentados os dados sobre a depuração e o teste de programas paralelos que representam a subárea de atuação. E finalmente um estudo sobre a representação gráfica de programas paralelos (Capítulo 4).

Após a revisão bibliográfica, foram apresentados a especificação e o projeto do ASTRAL (Capítulo 5), e sua implementação (Capítulo 6). Para finalização do trabalho nas próximas seções são apresentadas as conclusões obtidas (seção 7.2), as dificuldades encontradas (seção 7.3) e os passos para continuação do trabalho (seção 7.4).

\subsection{Conclusões}

A computação paralela tem como objetivo principal a busca por um melhor desempenho, constituindo uma boa solução para usuários que necessitam de computação de alto desempenho. Com o aumento das máquinas paralelas disponíveis e principalmente com a utilização dos sistemas distribuídos para implementação de aplicações paralela, há também um aumento no número de aplicações sendo desenvolvidas para essas plataformas.

Entretanto, vários motivos dificultam a criação de software paralelo. Entre eles, destaca-se a complexidade no desenvolvimento, agravada pela falta de ferramentas que 
auxiliem a implementação e principalmente o teste e a depuração das aplicações paralelas. Em adição, a maioria das ferramentas existentes é específica e com uma interface pouco amigável.

Considerando esse contexto, foram definidos os objetivos deste trabalho que consistiram em criar um ambiente para simulação e teste de programas paralelos, que permite ao usuário observar e controlar o comportamento do programa através da representação gráfica. No ambiente, o usuário pode identificar erros relacionados ao processamento paralelo e problemas com o desempenho. Além disso, a interação com o ambiente facilita o aprendizado da programação paralela por usuários iniciantes.

Com isso este trabalho apresentou o desenvolvimento de uma ferramenta que permite a avaliação e a simulação de programas paralelos. Um aspecto importante é que a ferramenta pode ser classificada como um depurador de análise estática (Capítulo 3), pois trabalha na busca de erros no programa sem a necessidade de sua execução.

A especificação do ASTRAL é independente de plataforma, o que possibilita a implementação para simulação de qualquer linguagem e ou biblioteca paralela. A implementação do ASTRAL permite simular o código do programa sem a necessidade da plataforma em que ele foi implementado. Desta forma, as seguintes contribuições deste trabalho devem ser destacadas:

- Especificação de uma ferramenta que oferece um ambiente amigável ao usuário iniciante, com diversos recursos que permite a avaliação e simulação de programas paralelos, motivando a utilização da programação paralela.

- Instanciação desta ferramenta utilizando a linguagem C com a biblioteca de passagem de mensagens PVM.

- Criação de um interpretador para linguagem C e algumas funções de PVM.

- A definição dos mecanismos de abstração para diminuir a quantidade de informações geradas, principalmente em programas com muitos processos e uma grande quantidade de dados.

- A definição dos mecanismos de auxílio que conduzem o usuário facilitando o processo de simulação e teste em busca de possíveis erros.

- A implementação de uma ferramenta que permite ao usuário verificar graficamente o comportamento das tarefas durante a simulação, e visualizar alguns tipos de erros e problemas de desempenho em programas paralelos. 


\subsection{Dificuldades Encontradas}

Algumas dificuldades foram encontradas durante o desenvolvimento deste trabalho, entre elas, pode-se destacar:

- A instalação, para estudo de caso, das ferramentas utilizadas para visualização e depuração de programas paralelos HeNCE, CODE e PARAGRAPH. Tendo até sido necessário a realização de alterações no código fonte.

- A criação de um interpretador para Linguagem $\mathrm{C}$ e também para alguns comandos e funções de PVM.

- A representação gráfica (desenho dos grafos de fluxo de instruções e do grafo de comunicação) de cada processo na tela, mostrando as condições, as repetições e as chamadas de funções, e os outro tipos de computação existentes.

- A geração do grafo de comunicação, que merece uma especial atenção, pois permite a construção de caminhos de concorrência para realização de testes.

\subsection{Trabalhos Futuros}

Os passos sugeridos para continuidade e complementação desse trabalho são:

- Elaborar e implementar outros mecanismos de auxílio e de abstração que possam facilitar a tarefa de simulação, principalmente para programas com uma grande quantidade de dados.

- Criar uma Base de Dados que permita a inserção de todas as funções, tanto para Linguagem C e PVM, quanto para outras linguagens e ou bibliotecas de passagem de mensagem.

- Medir o tempo de execução dos processos para verificar o desempenho e apontar possíveis problemas.

- Aprimorar a geração e utilização do grafo de comunicação.

- Definir critérios para geração de caminhos e realização de testes.

- Definição e desenvolvimento de um ambiente de Monitoração, que permita monitorar o programa paralelo, gerando informações para o ambiente de simulação. 


\section{Referências Bibliográficas}

[ALM94] Almasi, G. S.; GotTlieB, A. Highly Parallel Computing. $2^{\mathrm{a}}$ ed. The Benjamin/Cummings, 1994.

[BAI86] BAiARDI, F. B.; NicoletTA, F.; VAGLINI, G. Development of a Debugger for a Concurrent Language. IEEE Transactions On Software Engineering, v. 12, n. 4, pp. 547-553, April, 1986.

[BEG94] BEguelin, A.; et al. PVM: Parallel Virtual Machine. A User's Guide and Tutorial for Networked Parallel Computing, The MrT Press, 1994.

[BEN90] BEN-ARI, M. Principles of Concurrent and Distributed Programming. New York: British Library Cataloguing in Publication Data, 1990.

[BEN93] BEN-DYKE, A. D. Architectural taxonomy, A brief review. University of Birmingham, 1993.

[BRA99] BRANCo, K. R. L. J. C. Extensão da Ferramenta de Apoio a Programação Paralela (F.A.P.P.) para Ambientes Paralelos Virtuais. São Carlos, 1999. Dissertação (Mestrado) - Instituto de Ciências Matemáticas e de Computação, Universidade de São Paulo.

[BRO94] Browne, J. C.; Hyder, S. I.; DongarRa, J.; MOORE, K.; Newton, P. Visual Programming and Debugging for Parallel Computing, Technical Report TR94229, Dept. of Computer Sciences, Univ. of Texas at Austin, 1994.

[BYE97] BYERS, D.; ENGSTRÖM, M.; KAMKAR, M. The Design of a Test Case Definition Language. AADEBUG'97. Proceedings of the Third International Workshop on Automatic Debugging: Linköping, Sweden, May, 1997.

[CHE90] Cheung, W. H.; BLACK, J. P.; MANNING, E. A Framework for Distributed Debugging, IEEE Software, Jan., 1990.

[DEN97] StRINGHINI, D.; NAVAuX, P. O. A. Um Estudo sobre Depuradores de Programas Paralelos. Trabalho Individual, CPGCC-UFRGS, Porto Alegre/RS, Dez. 1997.

[DUN90] DUncan, R. A Survey of Parallel Computer Architectures. IEEE Computer, pp. 5-16, Feb., 1990.

[ERW98] ERWIG, M. Visual Graphs. FernUniversität Hagen, Praktische Informatik IV, pp. 1-8, 1998.

[FUR73] FURTADo, A. L. Teoria dos Grafos - Algoritmos. Editora Ltda: Rio de Janeiro, 1973.

[FLY96] FLYNN, M. J.; Rudo, K. W. Parallel Architectures. ACM Computing Surveys, vol. $28, \mathrm{n}^{\mathrm{0}} 1$, pp. 67-70, 1996.

[FOS95] IAN FOSTER. Designing and Building Parallel Programs. Addison Wesley, 1995 
[GRA96] GRABNER, S. Debugging strategies for programs on distributed memory machines. PH.D. Thesis, Dept. of Graphis and Paralle Computing, Johannes Kepler University, 1996.

[HEA99] HEATH, M. T.; FInGER, J. E. Paragraph: A Performance Visualization Tool for MPI. Technical Report,University of Tennessee, Out, 1999.

[HPD98] HPDF (High PERformance DEBugging Forum). HPD Version 1 Standard: Command Interface for Parallel Debuggers. Revisão 2.1, Set, 1998.

[HWA93] HWANG, K. Advanced Computer Architecture: Parallelism, Scalability, Programmability. McGraw-Hill, 1993.

[KAR96] KRANZLMÜLLER, D.; SIEGFRIED, G.; VOLKERT, J. Event Graph Visualization for Debugging Large Applications. ACM Computing Surveys, pp. 108-117, 1996.

[KEL95] Kelley, A.; PoHL, I. A Book on C-Programming in C. $3^{\text {a }}$ ed. AddisonWesley, 1995.

[KIR91] Kirner, C. Arquiteturas de Sistemas Avançados de Computação. Anais da Jornada EPUSP/IEEE em Sistemas de Computação de Alto Desempenho, pp. 307-353, 1991.

[KOR97] KOREL, B.; RILLING J. Application of Dynamic Slicing in Program Debugging. Departament of Computer Science, Ilinois Institute of Technology, 1997.

[MAL91] Maldonado, J. C. Critérios Potenciais Usos: Uma Contribuição ao Teste Estrutural de Software. Campinas, 1991. Tese (Doutorado) - Faculdade de Engenharia Elétrica, Universidade de Campinas.'

[MAC97] MACHADO, F. M.; MAIA, L. P. Arquitetura de Sistemas Operacionais. $2^{\mathrm{a}}$ ed. LTC, 1997.

[MAT00] Mateus, C. A. $C++$ Builder 5: Guia Prático. $I^{\text {a }}$ ed. Érica, 2000.

[MCD89] MCDowell, E. C.; Helmbold, P. D. Debugging Concurrent Programs. ACM Computing Surveys, v. 21, n. 4, pp. 593-622, Dec., 1989.

[MIL88] MILLER, B. P. A Mechanism for Efficient Debugging of Parallel Programs. ACM, Proceedings of the SIGPLAN, pp. 135-144, Georgia, Jun., 1988.

[MOR00] MOREIRA, E. M. Projeto de uma Ferramenta de Auxílio na Depuração de Programas Paralelos. São Carlos, 2000. Dissertação (Mestrado) - Instituto de Ciências Matemáticas e de Computação, Universidade de São Paulo.

[MOL84] MOLINA, H. G., Junior, F. G., KoHLER, W. H. Debugging a Distributed Computing System. IEEE Transactions On Software Engineering, v. 10, n. 2, pp. 210-219, March, 1984.

[NAV89] NAVAUX, P. O. A. Introdução ao processamento paralelo. RBC: Revista Brasileira de Computação, vol. 5, n² 2, pp. 31-43, 1989.

[NET95] NeTo, J. C. da C. Teste Estrutural Baseado em Fluxo de Dados de Programas Concorrentes. São Carlos, 1995. Dissertação (Mestrado) - Instituto de Ciências Matemáticas e de Computação, Universidade de São Paulo.

[PRE95] PRESSMAN, R. S. Engenharia de Software. Makron Books, 1995. 
[QUI87] QUINN, M.J. Designing Efficient Algorithms for Parallel Computers. McGrawHill, 1987.

[SCH96] SCHIIDT, H. C Completo e Total. $3^{\mathrm{a}}$ ed. Makron Books, 1996.

[SCH99] SCHUSTER, O. Replay of Concurrent Shared-Memory Programs. Thesis of Master, University Mannheim, April, 1999.

[SOU96a] SouZA, M. A. Avaliação das Rotinas de Comunicação Ponto-a-Ponto do MPI. São Carlos, 1996. Dissertação (Mestrado) - Instituto de Ciências Matemáticas e de Computação, Universidade de São Paulo.

[SOU96b] Souza, P. S. L. Máquina Paralela Virtual em Ambiente Windows. São Carlos, 1996. Dissertação (Mestrado) - Instituto de Ciências Matemáticas e de Computação, Universidade de São Paulo.

[SHI96] Shih, J. Debugging Concurrent Programs. Thesis of Master, University of Waterloo, 1996

[TAN92] TANEnBaum, A. S. Modern Operation System. $2^{\underline{a}}$ ed. Prentice-Hall International, 1992.

[TAY92] TAYLOR, R. N.; Levine, D. L.; Kelly, C. D. Structural Testing of Concurrent Programs, IEEE Transactions Software Engineering, 18(3), pp. 206-215, Mar, 1992.

[YAN92] YANG, R. D.; ChUNG, C. G. Path analysis testing of concurrent programs. Butterworth-Heinemann, vol. 34, n. 1, pp. 43-56, Jan, 1992.

[YAN96] YANG, C. D.; Pollock, L. L. The Challenges in Automated Testing of Multithreaded Programs. University of Delaware, 1996. 